\title{
Molecular Mechanism of Heavy Metal Toxicity and Tolerance in Plants: Central Role of Glutathione in Detoxification of Reactive Oxygen Species and Methylglyoxal and in Heavy Metal Chelation
}

\author{
Mohammad Anwar Hossain, ${ }^{1,2}$ Pukclai Piyatida, ${ }^{3}$ \\ Jaime A. Teixeira da Silva, ${ }^{4}$ and Masayuki Fujita ${ }^{1}$ \\ ${ }^{1}$ Laboratory of Plant Stress Responses, Department of Applied Biological Science, Faculty of Agriculture, \\ Kagawa University, Miki-cho, Kita-gun, Kagawa 761-0795, Japan \\ ${ }^{2}$ Department of Genetics and Plant Breeding, Bangladesh Agricultural University, Mymensingh 2202, Bangladesh \\ ${ }^{3}$ Department of Applied Biological Science, Faculty of Agriculture, Kagawa University, Miki-cho, Kita-gun, Kagawa 761-0795, Japan \\ ${ }^{4}$ Laboratory of Ornamental Floriculture, Department of Bioproduction Science, Faculty of Agriculture, \\ Kagawa University, Miki-cho, Kita-gun, Kagawa 761-0795, Japan
}

Correspondence should be addressed to Masayuki Fujita, fujita@ag.kagawa-u.ac.jp

Received 16 September 2011; Revised 17 November 2011; Accepted 19 December 2011

Academic Editor: Andrea Polle

Copyright (C) 2012 Mohammad Anwar Hossain et al. This is an open access article distributed under the Creative Commons Attribution License, which permits unrestricted use, distribution, and reproduction in any medium, provided the original work is properly cited.

\begin{abstract}
Heavy metal (HM) toxicity is one of the major abiotic stresses leading to hazardous effects in plants. A common consequence of $\mathrm{HM}$ toxicity is the excessive accumulation of reactive oxygen species (ROS) and methylglyoxal (MG), both of which can cause peroxidation of lipids, oxidation of protein, inactivation of enzymes, DNA damage and/or interact with other vital constituents of plant cells. Higher plants have evolved a sophisticated antioxidant defense system and a glyoxalase system to scavenge ROS and MG. In addition, HMs that enter the cell may be sequestered by amino acids, organic acids, glutathione (GSH), or by specific metal-binding ligands. Being a central molecule of both the antioxidant defense system and the glyoxalase system, GSH is involved in both direct and indirect control of ROS and MG and their reaction products in plant cells, thus protecting the plant from HMinduced oxidative damage. Recent plant molecular studies have shown that GSH by itself and its metabolizing enzymes-notably glutathione $S$-transferase, glutathione peroxidase, dehydroascorbate reductase, glutathione reductase, glyoxalase I and glyoxalase II- act additively and coordinately for efficient protection against ROS- and MG-induced damage in addition to detoxification, complexation, chelation and compartmentation of HMs. The aim of this review is to integrate a recent understanding of physiological and biochemical mechanisms of HM-induced plant stress response and tolerance based on the findings of current plant molecular biology research.
\end{abstract}

\section{Introduction}

The molecular and physiological basis of crop plant interactions with the environment has attracted considerable interest in recent years. Being sessile organisms, plants are constantly exposed during their life cycle to adverse environmental conditions that negatively affect growth, development, or productivity. The presence of toxic compounds, such as heavy metals (HMs), is one important factor that can cause damage to plants by altering major plant physiological and metabolic processes [1-5]. In a strict sense, the term HM includes only elements with specific gravity above five but frequently biologists use this term for a vast range of metals and metalloids which are toxic to plants such as copper $(\mathrm{Cu})$, iron $(\mathrm{Fe})$, manganese $(\mathrm{Mn})$, zinc $(\mathrm{Zn})$, nickel $(\mathrm{Ni})$, cobalt (Co), cadmium (Cd), and arsenic (As) etc. Importantly, few HMs and transition metals such as sodium $(\mathrm{Na})$, potassium $(\mathrm{K})$, calcium $(\mathrm{Ca})$, magnesium $(\mathrm{Mg}), \mathrm{Fe}, \mathrm{Cu}, \mathrm{Zn}, \mathrm{Co}$, or $\mathrm{Ni}$ are, at certain concentrations, essential micronutrients that are critically involved in the functional activities of large numbers of proteins involved in sustaining growth and development of living organisms. However, at excess 
concentrations, these metal ions can become detrimental to living organisms, including plants. Although HMs are natural constituents of soils and occur naturally in the environment, nowadays, contamination of soils by toxic metals and metalloids is of major concern worldwide $[4,5]$. The problem of HM pollution is continuously worsening due to a series of human activities, leading to an intensification of research dealing with the phytotoxicity of these contaminants and with the mechanisms used by plants to counter their detrimental effects [4]. Transfer of toxic elements to the human food chain is a concrete danger that has to be faced in the near future. Therefore, a complete understanding of the molecular mechanisms and genetic basis of phytoremediation is an important aspect of developing plants as agents for phytoremediating contaminated sites.

Depending on their oxidation states, HMs can be highly reactive, resulting in toxicity of plant cells in many ways. At the cellular and molecular level, HM toxicity results in alterations of different plant physiological processes, including inactivation and denaturation of enzymes, proteins, blocking of functional groups of metabolically important molecules, displacement/substitution of essential metal ions from biomolecules and functional cellular units, conformational modifications and disruption of membrane integrity $[5,6]$, which is finally attributed to altered plant metabolism, inhibition of photosynthesis, respiration, and alerted activities of several key enzymes [2, 3, 7-13]. In addition, HMs are known to disturb redox homeostasis by stimulating the formation of free radicals and reactive oxygen species (ROS) such as singlet oxygen $\left({ }^{1} \mathrm{O}_{2}\right)$, superoxide radicals $\left(\mathrm{O}_{2}{ }^{--}\right)$, hydrogen peroxide $\left(\mathrm{H}_{2} \mathrm{O}_{2}\right)$, and hydroxyl radicals $\left({ }^{\bullet} \mathrm{OH}\right)$ $[3,8,13,14]$. Recently, methylglyoxal (MG), a cytotoxic compound, was also found to increase in response various stresses including HMs [2, 15-17]. An increase in MG level in plant cells further intensifies the production of ROS by interfering with different plant physiological and metabolic processes such as inactivation of the antioxidant defense system $[18,19]$ and interfering with vital plant physiological processes such as photosynthesis [20]. This increase in ROS and MG exposes cells to oxidative stress leading to lipid peroxidation, biological macromolecule deterioration, membrane dismantling, ion leakage, and DNA-strand cleavage and finally death of plants $[3,4,21-23]$.

Plant tolerance mechanisms require the coordination of complex physiological and biochemical processes, including changes in global gene expression [24]. Plants employ various strategies to cope with the toxic effects of metals or metalloids. Resistance to HM stress can be achieved by "avoidance" when plants are able to restrict metal uptake, or by "tolerance" when plants survive in the presence of high internal metal concentration. Avoidance involves reducing the concentration of metal entering the cell by extracellular precipitation, biosorption to cell walls, reduced uptake, or increased efflux. In a second type of situation, HMs are intracellularly chelated through the synthesis of amino acids, organic acids, GSH, or HM-binding ligands such as metallothioneins (MTs), phytochelatins (PCs), compartmentation within vacuoles, and upregulation of the antioxidant defense and glyoxalase systems to counter the deleterious effects caused by ROS and MG [2, 3, 17, 25-31]. A large number of recent studies in plants involving sensitive, tolerant, mutant, transgenic, and hyperaccumulator-adopting strategies in the fields of physiology, genomics, proteomics, and metabolomics suggest that GSH by itself and its related metabolizing enzymes, proteins, and peptides play a pivotal role in HM tolerance by controlling different plant physiological processes, including ROS and MG detoxification, HM uptake, translocation, chelation, and detoxification. The present paper represents a comprehensive understanding of physiological and biochemical mechanisms of HMinduced plant stress response and tolerance. However, special emphasis will be given to ROS and MG metabolism in HMstressed plants in relation to GSH and its related enzymes, proteins, and genes and their consequence in HM-induced ROS and MG detoxification based on the findings of current plant molecular biology research.

\section{Mode of Action of Toxic HMs in Plant Cells}

The toxicity of HMs is manifested in many ways when plant cells accumulate them at high levels. HMs can be divided into two groups: redox active $(\mathrm{Fe}, \mathrm{Cu}, \mathrm{Cr}, \mathrm{Co}$ ) and redox inactive $(\mathrm{Cd}, \mathrm{Zn}, \mathrm{Ni}, \mathrm{Al}$, etc.). The redox active $\mathrm{HMs}$ are directly involved in the redox reaction in cells and result in the formation of $\mathrm{O}_{2}{ }^{\bullet-}$ and subsequently in $\mathrm{H}_{2} \mathrm{O}_{2}$ and ${ }^{\bullet} \mathrm{OH}$ production via the Haber-Weiss and Fenton reactions [32, 33]. Exposure of plants to redox inactive HMs also results in oxidative stress through indirect mechanisms such as interaction with the antioxidant defense system, disruption of the electron transport chain, or induction of lipid peroxidation. The latter can be due to an HM-induced increase in lipoxygenase (LOX) activity. Another important mechanism of HM toxicity is the ability of HMs to bind strongly to oxygen, nitrogen, and sulphur atoms [34]. This binding affinity is related to free enthalpy of the formation of the product of the HM and ligand with low solubility of these products. Because of these features, HMs can inactivate enzymes by binding to cysteine residues. For example, Cd binding to sulfhydryl groups of structural proteins and enzymes leads to misfolding and inhibition of activity and/or interference with redox-enzymatic regulation $[1,27]$.

Many enzymes need cofactors to work properly for both $\mathrm{HM}$ ions (such as $\mathrm{Fe}^{2+}, \mathrm{Mg}^{2+}, \mathrm{Cu}^{2+}, \mathrm{Ca}^{2+}$ ) and organic molecules (such as haem, biotin, FAD, NAD, or coenzyme A). The displacement of one HM ion by another leads to the inhibition or loss of enzyme activities. Divalent cations such as $\mathrm{Co}^{2+}, \mathrm{Ni}^{2+}$, and $\mathrm{Zn}^{2+}$ displace $\mathrm{Mg}^{2+}$ in ribulose-1,5bisphosphate-carboxylase/oxygenase (RuBisCO) and result in a loss of activity $[35,36]$. Displacement of $\mathrm{Ca}^{2+}$ by $\mathrm{Cd}^{2+}$ in calmodulin, an important protein in cellular signaling, led to the inhibition of calmodulin-dependent phosphodiesterase activity in radish [37]. Additionally, HMs cause membrane damage through various mechanisms, including the oxidation of and cross-linking with protein thiols, inhibition of key membrane protein such as $\mathrm{H}^{+}$-ATPase, or causing changes in the composition and fluidity of membrane lipids [38]. Accumulation of MG, a cytotoxic compound, was found to increase in response to HM stress in plants due 


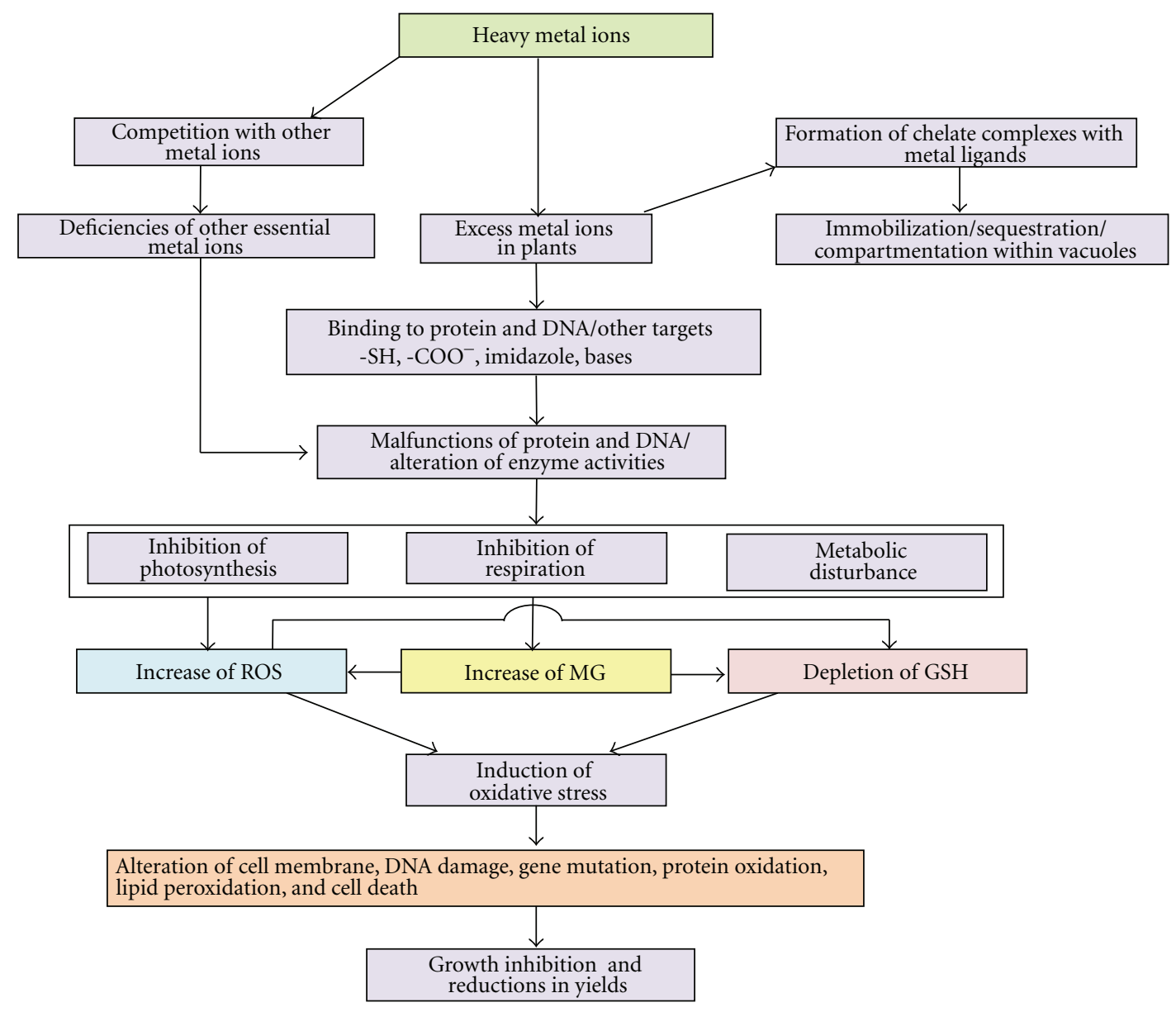

Figure 1: Possible biochemical and molecular mechanisms of heavy metal-mediated ROS induction and damage to the development of higher plants.

to impairment of the glyoxalase system that finally elicits oxidative stress by reducing the GSH content $[2,3,17,19$, 39, 40].

Based on the aforementioned, it can be concluded that HM toxicity is attributed to three mean reasons: (a) stimulation of ROS and MG production by auto-oxidation and the Fenton reaction or by modification of the antioxidant defense system and the glyoxalase system, (b) direct interaction with proteins due to their affinities for thioyl-, histidyl-, and carboxyl-groups, causing the HMs to target structural, catalytic, and transport sites of the cell, and (c) displacement of essential metal ions from specific binding sites, causing function to collapse $[8,33]$. The possible sequential events of ROS-induced damage development in sensitive plants in response to HM stress are summarized in Figure 1.

\section{Heavy Metal Stress and Plant Responses}

The exposure of plants to toxic levels of HMs triggers a wide range of physiological and metabolic alterations [5, 13]. However, as different HMs have different sites of action within the plant, the overall visual toxic response differs between HMs. The most widespread visual evidence of HM toxicity is a reduction in plant growth [7] including leaf chlorosis, necrosis, turgor loss, a decrease in the rate of seed germination, and a crippled photosynthetic apparatus, often correlated with progressing senescence processes or with plant death $[1,24,41-43]$. All these effects are related to ultrastructural, biochemical, and molecular changes in plant tissues and cells brought about by the presence of HMs [44]. Moreover, HMs influence homeostatic events, including water uptake, transport, transpiration, and nutrient metabolism $[45,46]$ and interfering with the uptake of $\mathrm{Ca}, \mathrm{Mg}, \mathrm{K}$, and P [47]. Elevated levels of HMs usually decrease photosynthesis due to their direct effect on the photosynthetic apparatus, including thylakoids. Several studies report that HMs can determine the release of proteins, lipids, and element components of thylakoid membranes, causing damage to light-harvesting complexes and Photosystem II (PS II) [48, 49]. Additionally, some $\mathrm{HMs}$ can replace $\mathrm{Mg}$ in the chlorophyll (Chl). Chl synthesis reduction, which is usually observed after HM stress, may be a consequence of enzyme inhibition involved in its synthetic pathway $[50,51]$. In addition, HM decreases carbon assimilation by inhibiting enzymes involved in $\mathrm{CO}_{2}$ fixation [52]. A timeand dose-dependent decrease in photosynthesis in maize 
(Zea mays L.) has been observed in response to $\mathrm{HMs}$ like $\mathrm{Cu}$, $\mathrm{Ni}, \mathrm{Pb}$, and $\mathrm{Zn}$ [53]. Cd-induced inhibition of respiration has also been reported in rice (Oryza sativa L.) [54]. HMs also perturb carbohydrate metabolism and their partitioning in growing plants. The activity of $\alpha$-amylase, $\beta$-amylase, and sucrose phosphate synthase decreased whereas starch phosphorylase, acid invertase, and sucrose synthase activity increased in rice (Oryza sativa L.) seedlings in response to As [55]. Additionally, nitrogen assimilation decreased in rice seedlings in response to As and $\mathrm{Al}$ due to inhibition in the activities of nitrate reductase, nitrite reductase, and glutamine synthetase $[13,55,56]$. In rice seedlings, Ni stress suppresses the hydrolysis of RNA and proteins by inhibiting the activity of ribonuclease (RNase) and protease $[13,57]$.

HMs that bind to the cell nucleus cause promutagenic damage including DNA base modification, inter- and intramolecular crosslinking of DNA and proteins, DNA strand breaks, rearrangement, and depurination [58]. HMs can also affect microtubule assembly-disassembly, thereby altering the cell cycle and cell division [59]. High mutation rate and malformed embryos have been observed in Arabidopsis plants exposed to Cd [24, 60]. The exposure of plants to stressful conditions raises the ethylene level, a gaseous hormone, which affects several plant responses, including senescence and stress [61]. In higher plants, $\mathrm{Cu}-$ induced ethylene synthesis can increase senescence [62], inhibit cell growth and increase cell wall rigidity by means of lignification [63].

HM toxicity results in the accumulation of excess ROS inside the cell (this will be described in more detail later). ROS production is dependent upon the particular HM element Heavy metal toxicity results in the accumulation of excessive ROS inside the cell; Cu can directly generate ROS, whereas $\mathrm{Cd}$ is a redox-inactive HM and can only generate ROS indirectly by enzyme inactivation and by inducing the expression of LOX in plant tissues and therefore causing oxidation of polyunsaturated fatty acids $[64,65]$. ROS action may result in cell disturbances which enhance senescence processes in cooperation with ethylene and jasmonic acid (JA), although the activation of the antioxidant machinery can help plants to overcome HM stress [44].

The plant's molecular response to HM stress is characterized by the synthesis of stress-related amino acids, protein, genes, and signaling molecules $[1,24]$. Several recent studies also showed that HMs increase the synthesis of heat shock proteins (HSPs) [13, 66, 67]. A higher proline (Pro) level was found in the Cd hyperaccumulator plant Solanum nigrum more than in the nonaccumulator plant (Solanum melongena) indicating its role in HM detoxification [68]. Phytosiderophores, nicotianamine, and organic acids are a few examples of chelating compounds that are released by roots and might influence HM uptake [24]. Different kinetics of mitogen-activated protein kinase (MAPK) cascades in response to HM stress have also been reported [69]. Alfalfa (Medicago sativa) seedlings subjected to $\mathrm{Cu}$ or $\mathrm{Cd}$ ions result in the activation of four distinct MAPKs: SIMK, MMK2, MMK3, and SAMK. Importantly, Cu stress rapidly activated SIMK, MMK2, MMK3, and SAMK while Cd showed a similar but delayed MAPK activation $[13,69]$.

\section{Molecular Mechanisms of Heavy Metal Tolerance in Plants}

Plant tolerance to a particular HM is governed by an inter-related network of physiological and molecular mechanisms and understanding of these mechanisms and their genetic basis is an important aspect to developing plants as agents of phytoremediation $[1,3,24,70]$. Different plant species may have evolved different mechanisms to tolerate excess HMs, and even within the one plant species more than one mechanism could be in operation. Plants have both constitutive and adaptive mechanisms to withstand excess HMs [71]. Physiological, biochemical, and molecular approaches continue to be employed to identify the underlying mechanisms of HM accumulation, tolerance, and adaptive mechanisms to cope with HM stress. Some adaptive mechanisms evolved by tolerant plants include immobilization, plasma membrane exclusion, restriction of uptake and transport, synthesis of specific HM transporters, chelation and sequestration of HMs by particular ligands (PCs and MTs), induction of mechanisms contrasting the effects of ROS and MG (such as upregulation of antioxidant and glyoxalase system), induction of stress proteins, the biosynthesis of Pro, polyamines, and signalling molecule such as salicylic acid and nitric oxide $[1-3,8,9,11,17,19$, $24,26,28,29,40,72,73]$.

\subsection{Restriction of Uptake and Transport of HMs}

4.1.1. Exclusion of HMs from the Plants. Uptake of HMs by plants involves root interception of HM ions, entry of HM ions into roots, and their translocation to the shoot. Once an HM is bioavailable to the plant, the entry of HM ions inside the plant, either through the symplast (intracellular) or through the apoplast (extracellular), depends on the type of HM. Most HM ions enter plant cells by an energy-dependent process via specific or generic HM-ion carriers or channels [74]. One mechanism (avoidance strategy) of preventing or lessening the toxic effects of $\mathrm{HMs}$ is by preventing excess HMs entering the plant. There are two main ways in which a plant could do this, either by precipitating or by complexing HMs in the root environment. Plants can precipitate HMs by increasing the $\mathrm{pH}$ of the rhizosphere or by excreting anions such as phosphate. Root exudation of phosphate in maize have been detected in response to $\mathrm{Al}$ stress in the Al-tolerant cultivar (South American 3) with no toxicity symptoms whereas sensitive cultivars (Tuxpeño and South American 5) showed symptoms [75]. Additionally, root exudation of malate in sorghum (Sorghum bicolor L.) and exudation of citrate in maize have also been reported in response to $\mathrm{Cd}$ stress [76]. These findings support the idea that the HM-binding capabilities of root exudates may be an important mechanism for stabilizing HMs in the vicinity of the root thus making them unavailable to the plant and lessening the experienced toxicity. Zhu et al. [73] showed that the oxalate secreted from the root apex helps to exclude $\mathrm{Cd}$ from entering tomato (Lycopersicon esculentum L.) roots, thus contributing to $\mathrm{Cd}$ resistance in the $\mathrm{Cd}$ resistant tomato cultivar (Micro-Tom). Their results suggest 
that the tolerant cultivar may have utilized exclusion of the $\mathrm{HM}$ via precipitation as an avoidance mechanism. Altolerant wheat (Triticum aestivum) genotypes have been found to produce more malic acid than sensitive genotypes upon exposure to $\mathrm{Al}[77,78]$. Additionally, iron plaque formation on the root surface (due to the release of $\mathrm{O}_{2}$ and oxidants in the rhizosphere) has been suggested as a mechanism for excluding toxic HM in plants and particularly in Oryza sativa [79, 80]. Liu et al. [80] proposed that iron plaque adsorbs and sequesters $\mathrm{Cd}$ onto the root surface and can prevent $\mathrm{Cd}$ uptake by rice plants. While excluding excess HMs from the plant holds merit, some tolerant plants and hyperaccumulator plants actually have a higher uptake of HMs when compared to sensitive plants $[4,81,82]$, so other mechanisms must also exist.

4.1.2. Cellular Exclusion of HMs. Cellular exclusion of HMs is an important adaptive strategy for HM tolerance in plants. A large fraction of HMs in plant roots are found in the apoplastic space. For example, at equal external Al concentrations, a sensitive wheat cultivar had more symplastic $\mathrm{Al}$ than the tolerant cultivar suggesting an exclusion mechanism [83]. HM transporter proteins are potentially involved in the exclusion of toxic HM ions from the symplastic to the apoplastic space.

\subsubsection{HM Complexation at the Cell Wall-Plasma Membrane} Interface. The cell wall-plasma membrane interface accumulates large portions of HMs and it is therefore believed that this could be the potential site of HM tolerance. In Italian ryegrass (Lolium multiflorum), $60 \%$ of $\mathrm{Cu}$ in the roots was bound by the cell wall and plasma membrane [84]. Plant cation exchange capacity (CEC) is largely determined by the exchange sites in cell walls [85]. Sensitive wheat cultivars have much lower cell wall CECs than tolerant cultivars [86] indicating that tolerant cultivars use a high CEC to complex HMs at the cell wall and prevent entry to the cell. However, the role of the cell wall in HM tolerance remains to be clarified.

4.1.4. Distribution of HM. Plants are able to minimize the adverse effects of excess HMs by regulating the distribution and translocation of HMs within their organs or cells. The most common forms of this are the much higher amounts of HMs found in plant roots than in shoots, except for hyperaccumulators [87-89], and reduced translocation of HM to the shoots is a widespread tolerance mechanism. Probably, this acts to exclude metals from sensitive metabolism in the shoots and, therefore, tolerant genotypes have a lower HM concentration in the shoot than sensitive genotypes. Additionally, plants also showed a resistant reaction through uniform distribution of HMs that entered a plant tissue or organ. Tolerant cowpea (Vigna unguiculata) genotypes have a relatively uniform distribution of $\mathrm{Mn}$ throughout the leaf [90]. In contrast, sensitive genotypes accumulate Mn in localized areas in the leaf which are seen as dark brown spots caused by manganese oxide precipitates [90].

\subsection{Complexation and Compartmentation of HMs within the Plant Cell}

4.2.1. Intracellular Sequestration or Compartmentation within Vacuoles. Once an HM has entered the cell, a plant uses various strategies to cope with its toxicity. One such strategy consists of transporting the HM out of the cell or sequestrating it into the vacuole, thereby removing it from the cytosol or other cellular compartments where sensitive metabolic activities takes place $[1,24,91]$. Therefore, the central vacuole seems to be a suitable storage reservoir for excessively accumulated HMs. In fact, two vacuolar proton pumps, a vacuolar proton-ATPase (V-ATPase) and vacuolar protonpyrophosphatase (V-Ppase), energize vacuolar uptake of most solutes. Grasses can actively pump $\mathrm{Zn}$ into vacuoles with the more tolerant clones being able to continue the process at higher external $\mathrm{Zn}$ levels than sensitive clones [92]. Uptake can be catalyzed by either channels or transporters. The application of powerful genetic and molecular techniques has now identified a range of gene families that are likely to be involved in transition HM ion uptake into cells, HM vacuolar sequestration, HM remobilization from the vacuole, xylem loading, and unloading of HMs (Figure 2). Some well-characterized HM transporter proteins are zinc-regulated transporter (ZRT), iron-regulated transporter (IRT) like protein ZIP family, ATP-binding cassette $(\mathrm{ABC})$ transporters, the P-type metal ATPases, the natural resistance-associated macrophage protein (NRAMP) family, multidrug resistance-associated proteins (MRP), ABC transporters of the mitochondria (ATM), cation diffusion facilitator (CDF) family of proteins, copper transporter (COPT) family proteins, pleiotropic drug resistance (PDR) transporters, yellow-stripe-like (YSL) transporter and $\mathrm{Ca}^{2+}$ : cation antiporter (CAX), and so forth [13, 93-95]. Plant cell walls are a continuous matrix, acting as a cation exchanger, holding variable quantities of metal, and providing for some HM exclusion [96]. In barley (Hordeum vulgare L.) leaves, the increase in cellular $\mathrm{Zn}$ with increasing exposure to external $\mathrm{Zn}$ was fully accounted for by an increase in vacuolar $\mathrm{Zn}$ with the cytoplasm exhibiting perfect homeostasis [97]. Vacuole isolation or compartmental flux analysis, although less frequently used in the study of HM accumulation, may also provide valuable information. In order to determine the localization of $\mathrm{Cd}$ and the potential Cd-binding peptides, protoplasts and vacuoles were isolated from leaves of Cdexposed tobacco (Nicotiana rustica var Pavonii) seedlings [98]. Purified vacuoles contained virtually all of the Cdbinding peptides and $\mathrm{Cd}$ found in protoplasts. Computer simulation studies with $\mathrm{Zn} \mathrm{[99]} \mathrm{and} \mathrm{Cd} \mathrm{[100]} \mathrm{showed}$ that the vacuole is the probable site of HM sequestration and detoxification in Nicotiana tabacum. Evidence for plant vacuoles as the site of HM sequestration appears to be quite conclusive. However, many plant HM transporters remain to be identified at the molecular level and the transport function, specificity, and molecular location of most of these proteins in plants remain unknown.

4.2.2. Formation of Metal Complex by Phytochelatins. Chelation of HMs in the cytosol by high affinity ligands is 


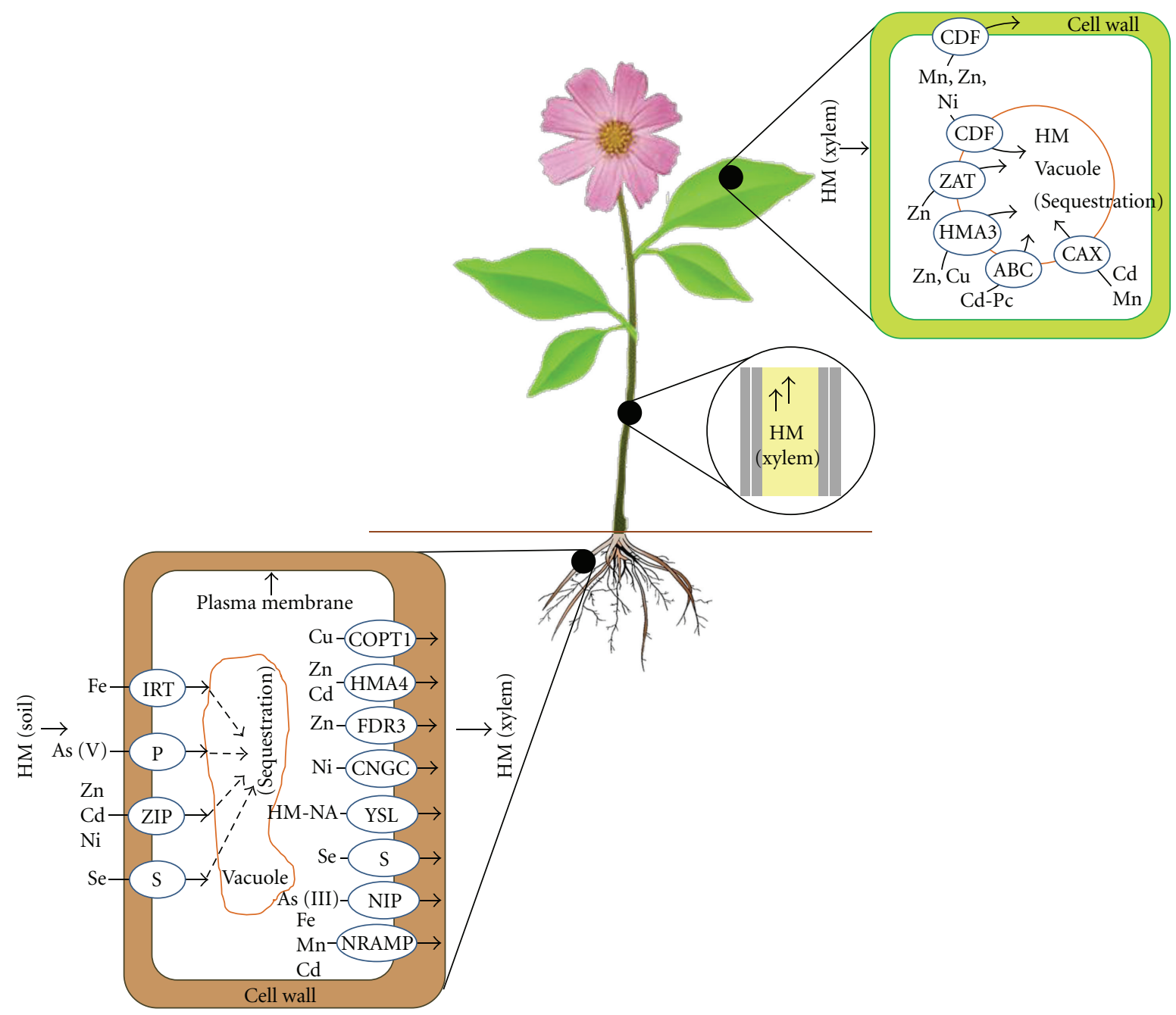

FIGURE 2: Diagrammatic representation of uptake and transport of heavy metals in plants through metal transporters(modified from) [4, 70].

potentially a very important mechanism of HM detoxification and tolerance in plants under HM stress. Plants make two types of peptide metal binding ligands: phytochelatins (PCs) and metallothioneins (MTs). Recent advances in the understanding of different aspects of biosynthesis and function of PCs are derived predominantly from molecular genetic approaches using model organisms. PCs are a family of Cys-rich polypeptides with the general structure ( $\gamma$-GluCys) $)_{n}-\mathrm{X}$, in which $\mathrm{X}$ is Gly, $\gamma$-Ala, Ser, Gln, or Glu and $n=2-11$ depending on the organism, although the most common forms have 2-4 peptides [28]. PCs are synthesized from GSH; the metal binds to the constitutively expressed enzyme $\gamma$-glutamylcysteinyl dipeptidyl transpeptidase (PC synthase), thereby activating it to catalyze the conversion of GSH to phytochelatin [101]. The biosynthesis of PCs is induced by many $\mathrm{HMs}$, including $\mathrm{Cd}, \mathrm{Hg}, \mathrm{Ag}, \mathrm{Cu}, \mathrm{Ni}, \mathrm{Au}$, $\mathrm{Pb}, \mathrm{As}$, and $\mathrm{Zn}$; however, $\mathrm{Cd}$ is by far the strongest inducer $[102,103]$. PCs complex Cd ions through the thiolic group $(-\mathrm{SH})$ of Cys and the PC-Cd complexes are accumulated in the vacuole through the activity of $\mathrm{ABC}$ transporters, thus limiting the circulation of free $\mathrm{Cd}^{2+}$ inside the cytosol
[72]. Additionally, plants are not able to metabolize or eliminate Cd. Rather, they adopt the strategy of making Cd-GSH and Cd-PCs complexes to sequester Cd within vacuoles efficiently $[1,72]$ and also to transport $\mathrm{Cd}$ over a long distance through xylem and phloem vessels [104]. Further confirmation of the induction of PCs under HM stress was provided by the fact that PC production was found to be positively correlated with HM accumulation in both above-ground and below-ground tissues. In our study, with water hyacinth (Eichhornia crassipes) and Cd stress, we found that $\mathrm{Cd}^{2+}$ taken up by water hyacinth roots was present as Cd-binding complexes whereas, in the absence of $\mathrm{Cd}^{2+}$, no such complexes were observed [105]. This indicates that these $\mathrm{Cd}^{2+}$-binding complexes are formed in response to $\mathrm{Cd}^{2+}$ and play an important role in the accumulation of $\mathrm{Cd}$ in water hyacinth. Next, we characterized that the latter Cd-binding complex with a molecular weight of 4000 was composed of two cadystins A, $(\gamma \text {-Glu-Cys })_{3}$-Gly, two cadystins B, ( $\gamma$-Glu-Cys) $)_{2}$-Gly, and inorganic sulfur, which is identical to the fission yeast Cd-BPI [106]. Iglesia-Turiño et al. [107] studied $\mathrm{Hg}$ accumulation in rape (Brassica 
napus) plants grown under an $\mathrm{Hg}$ concentration gradient $(0-1,000 \mu \mathrm{M})$ and found that $\mathrm{Hg}$ accumulation was strongly correlated with PC2 concentration. PCs are also involved in the homeostasis of $\mathrm{Zn}^{2+}$ and $\mathrm{Cu}^{+} / \mathrm{Cu}^{2+}$ by providing a transient storage form for the ions $[108,109]$. The induction of PCs by the anion arsenate has been observed in a survey for peptide-inducing metal ions [102] and suggests a unique mode of PC synthase activation. Nouairi et al. [110] observed that $\mathrm{Cd}$ treatment registered a consistent increase in PC synthesis up to $50 \mu \mathrm{M}\left(94.66 \mu \mathrm{mol} \mathrm{g}^{-1} \mathrm{FW}\right)$ in Brassica juncea leaves with respect to the control $\left(10.57 \mu \mathrm{mol} \mathrm{g}^{-1} \mathrm{FW}\right)$. However, after a 15-day exposure, the PC content in B. napus leaves was not significantly different to the control at any concentration of $\mathrm{Cd}$. In addition, phytochelatin synthase (PCS) gene expression studies in garlic (Allium sativum L.) plants exposed to HMs [111] and an in vitro analysis in the marine alga Dunaliela tertiolecta [112] also suggested a role of PCs in the detoxification of HMs and in the mitigation of oxidative stress. Both HM-resistant and HM-sensitive plants produce PCs; however, several reports have concluded that PCs are not primary responsible for the hyperaccumulation of $\mathrm{Zn}, \mathrm{Ni}$, or $\mathrm{Pb}$ [113-115]. The HM-detoxification process is not limited to the chelation of HM ions. After the activation of PC synthase by the HM ions and HM chelation by the PCs synthesized, the HM ion complex is transported to the vacuole and stabilized there by forming a complex with sulfides or organic acid [96]. It has also been shown that PCs have a role in HM transport [116], so that their detoxifying capabilities may actually be secondary or part of a more complex mechanism. Although it is clearly demonstrated that PCs can have an important role in HM detoxification and accumulation in higher plants, formation of HM complexes provides insufficient explanation for either the HM specificity or species specificity of hyperaccumulation [117]. Therefore, it remains to be determined what exact role PCs play in the HM-tolerance mechanism at the cellular level and this requires more thorough research.

4.2.3. Complexing by Metallothioneins. MTs are low molecular weight (4-8 kDa), Cys-rich, HM-binding, gene-encoded polypeptides that can bind HMs via the thiol groups of their Cys residues [118]. Although the precise physiological function of MTs has not yet been fully elucidated, proposed roles include (a) participation in maintaining the homeostasis of essential transition HMs, (b) sequestration of toxic HMs, and (c) protection against intracellular oxidative damage [119]. Plant MTs are extremely diverse and have been subdivided into three classes based on the arrangement of the Cys residue [120]. The Cys-Cys, Cys-X-Cys, and Cys-X-X-Cys motifs (in which $\mathrm{X}$ denotes any amino acid) are characteristic and invariant for MTs. The organization or distribution of cysteine residues confers different MT isoforms and their ability to bind and sequester different HM ions for detoxification and homeostasis. The biosynthesis of MTs is regulated at the transcriptional level and is induced by several factors, including hormones, cytotoxic agents, and HMs, such as $\mathrm{Cd}, \mathrm{Zn}, \mathrm{Hg}, \mathrm{Cu}, \mathrm{Au}, \mathrm{Ag}, \mathrm{Co}, \mathrm{Ni}$, and $\mathrm{Bi}[28$, 121]. Gene expression studies were performed to quantify mRNA levels in different tissues, at different developmental stages and under stress conditions such as HM exposure. MT genes appear to be differentially regulated in a tissuespecific manner and in relation to the developmental stage and also in response to a number of stimuli, including HMs [122]. Ahn et al. [123] showed that three Brassica rapa MT genes (BrMT1, BrMT2, and BrMT3) are differentially regulated under various HM stresses. In Fe-treated seedlings, $B r M T 1$ and BrMT2 were not appreciably induced, while elevated expression of BrMT3 was apparent at 6 and $24 \mathrm{~h}$. In $\mathrm{Cu}$-treated seedlings, BrMT1 expression was increased at $3 \mathrm{~h}$ and it remained at the increased level thereafter, while BrMT2 expression was downregulated and BrMT3 remained unchanged. Similarly, in Zn-treated seedlings, BrMT1 increased slightly while BrMT2 was downregulated and BrMT3 remained unchanged. In Mn-treated seedlings, $B r M T 1$ and BrMT3 genes showed increase expression until $12 \mathrm{~h}$ and then were downregulated. BrMT2 expression did not change until $12 \mathrm{~h}$ and then was gradually downregulated. Several data demonstrated the role of MTs in HM detoxification and homeostasis, but metal-inducibility of plant MTs has not always been demonstrated. Further information regarding the structures and properties of MTs could clarify their mechanism(s) of action and functions. The use of a model system and a model hyperaccumulator like Arabidopsis halleri and some Thlaspi species is likely to further elucidate the molecular mechanisms of HM transport, trafficking, tolerance, and homeostasis in plants [124].

4.2.4. Metal Chelation by Organic Acids, Amino Acids, and Phosphate Derivatives. Mechanism of HM tolerance and detoxification in plants can be divided into two categories: external exclusion and internal tolerance. In the external detoxification process, organic acids excreted from plant roots may form stable HM-ligand complexes with HM ions and change their mobility and bioavailability, thus preventing the $\mathrm{HM}$ ions from entering plants or avoiding their accumulation in the sensitive sites of roots. In internal HM detoxification, organic acids may chelate with HM in the cytosol, where the ions can be transformed into a nontoxic or less toxic form $[27,28,91]$. Plants produce a range of ligands for $\mathrm{Al}, \mathrm{Cd}, \mathrm{Cu}, \mathrm{Ni}, \mathrm{Co}$, and $\mathrm{Zn}$. Carboxylic and amino acids, such as citrate, malate, and oxalate, histidine (His) and nicotianamine (NA), and phosphate derivatives (phytate) are potential ligands for HMs and are found to play a role in tolerance and detoxification $[8,27,28,91,96,119,125]$.

Citrate has a high capacity to chelate HM ions and has been well documented in the case of $\mathrm{Fe}$ [91]. However, other HMs such as $\mathrm{Cd}, \mathrm{Ni}, \mathrm{Co}$, and $\mathrm{Zn}$ also have a strong affinity for citrate. Long before the discovery of PCs in plants, research on several Ni hyperaccumulators had shown that $\mathrm{Ni}$ is predominantly bound to citrate and that the amount of citrate produced is strongly correlated with the accumulated $\mathrm{Ni}[126,127]$. Since then, there have been a large number of studies in which carboxylic acids have been found to be associated with HMs. A correlation between citric acid exudation and $\mathrm{Al}$ tolerance was detected by Miyasaka et al. [128] in snapbean (Phaseolus vulgaris L.). Citric acid has been considered to be a major ligand at low 
Cd concentrations [129] and also found to contribute to $\mathrm{Zn}$ accumulation and tolerance [130]. Exposure of cells of the Co hyperaccumulator Crotalaria cobalticola and nonaccumulators Raufolia serpentina and Silene cucubalus to Co ions resulted in an increase of citrate, further denoting its involvement in the complexation of HM ions [131].

Root secretion of oxalate and detoxification of HMs like $\mathrm{Al}$ have also been reported [132]. Buckwheat (Fagopyrum esculentum Moench.) secretes oxalic acid from the roots in response to $\mathrm{Al}$ stress and accumulates nontoxic-Al-oxalate in the leaves [133]; thus detoxification occurs both externally and internally. Zheng et al. [134] found that buckwheat had higher resistance to $\mathrm{Al}$ compared with an Al-tolerant cultivar of wheat, Atlas 66. In wheat and maize, there is evidence that such secretion from the roots is mediated by $\mathrm{Al}$-activated anion channels in the plasma membrane [132]. Similarly, malate was proposed to cytosolic $\mathrm{Zn}$ chelators in $\mathrm{Zn}$ tolerant plants [135]. Removal of $\mathrm{Al}$ from the roots results in a rapid decline in malate secretion to the non-Al level, indicating responsive $\mathrm{Al}$ and malate-secreting mechanisms. The differences in the degree of tolerance to $\mathrm{Al}$ depend on the transport of malate out of the apical root cells via an Al-activated malate-permeable channel [136]. Salazar et al. [137] observed that Al-tolerant genotypes secreted about 10 fold higher malate and about 3-5-fold higher succinate than Al-sensitive seedlings over $24 \mathrm{~h}$ exposure to $50 \mu \mathrm{M}$ Al. Li et al. [138] found that alteration in the metabolism of organic acid was involved in the $\mathrm{Al}$-induced secretion of organic acids in rye (Secale cereale L.) but only activation of an anion channel seems to be responsible for the rapid secretion of malate in wheat.

Histidine and NA also play roles in the chelation of HM ions both within plant cells and in the xylem sap [139]. Salt at al. [140] identified putative Zn-His complexes in the roots of the closely related $\mathrm{Zn}$ hyperaccumulator Thlaspi caerulescens. Additionally, free His in the xylem exudates of a Ni hyperaccumulator (Alyssum lesbiacum) was found to increase 36-fold in response to $\mathrm{Ni}$ stress [141]. Transgenic plants overexpressing the Salmonella typhimurium ATP phosphoribosyl transferase gene (StHisG) accumulated about 2-fold higher histidine levels than wild type plants and showed more than 10 -fold increased biomass production in the presence of toxic $\mathrm{Ni}$ in the growth medium [142], convincingly demonstrating a mechanistic link between His and moderate Ni tolerance.

The plant HM chelator NA is a free nonproteinogenic amino acid. NA is mobile in the plant and has been detected in root and leaf cells as well as in phloem sap. It can bind $\mathrm{HM}$ ions like $\mathrm{Fe}, \mathrm{Zn}, \mathrm{Cu}$, and $\mathrm{Ni}$. NA is synthesized by a one-step condensation reaction of three molecules of Sadenosyl-Met (SAM) by the enzyme NA Synthase [143]. In Solanaceous plants, NA was shown to act in Fe homeostasis [144]. In addition to its role in long-distance HM transport, $\mathrm{NA}$ is proposed to be involved in the regulation of HM transfer within plant cells $[145,146]$. Weber et al. [147] used Arabidopsis Gene Chips to identify those genes that are more active in roots of $A$. halerii than $A$. thaliana under controlled conditions. Two genes showing highest levels of expression in A. halerii roots code for an NA Synthase and a putative $\mathrm{Zn}^{2+}$ uptake system. In addition, roots of A. halerii also showed higher levels of both NA Synthase and NA. Taken together, these observations suggest active roles of NA in plant $\mathrm{Zn}$ homeostasis and NA Synthase in hyperaccumulation of $\mathrm{Zn}$ in A. halerii.

Phytate has been suggested as a possible complexing agent for HMs. Phytate tends to be associated with HM deposits in plants, including in Al-tolerant Zea mays vacuoles [148]. Zinc-phytate globules appeared to be quantitatively more frequent in tolerant ecotypes of Deschampsia caespitosa roots than in sensitive ecotypes [149]. However, it is unclear if $\mathrm{HM}$ phytate complexes cause a tolerance or stress response.

Based on the aforesaid, it could be stated that organic acids, amino acids, and phosphate are derivatives of HM detoxification. However, further research is needed to quantify the organic acids being produced as a toxicity versus tolerance response over a range of plant species by using various HMs.

4.3. Hyperaccumulating Mechanisms. HM-tolerant plants are often excluders, limiting the entry of root-to-shoot translocation, or retain the uptaken HM into the root cells or detoxifying them by their chelation in the cytoplasm or storing them in vacuoles. However, a class of rare plants called hyperaccumulators rapidly and efficiently translocate the HMs to the shoot via the xylem (Figure 2). Translocation in the xylem is probably transpiration driven [150]. They hyperaccumulate HMs even from low external HM concentrations, and most of the HM is translocated to the shoot [151]. At the root membrane level, HM uptake is unusually high in hyperaccumulators. This may be due to constitutive high expression of an HM transporter in the plasma membrane, as was found for the $\mathrm{Zn}$ and $\mathrm{Cd}$ hyperaccumulator Thlaspi caerulescens $[152,153]$. T. caerulescens shows reduced HM accumulation in root vacuoles, enhanced root-shoot translocation, enhanced uptake into leaf cells, and higher HM tolerance [154]. The high HM tolerance may in part be due to highly efficient intracellular compartmentalization and chelation [155]. Different chelators may be involved in translocation of HM cations through the xylem (Figure 2), such as organic acid chelators $[150,156]$, or nicotianamine [156]. Uptake of HM ions from the xylem apoplast into the shoot symplast is mediated by HM transporters in the shoot cell membrane.

4.4. Heat Shock Proteins (HSPs). Heat shock proteins (HSPs) act as molecular chaperones in normal protein folding and assembly but may also function in the protection and repair of protein under stress conditions. Induction of HSPs by several transition $\mathrm{HMs}(\mathrm{Zn}, \mathrm{Cu}, \mathrm{Cd}, \mathrm{Hg}, \mathrm{Al}, \mathrm{Cr}$ ) has been reported [13, 157-161]. Increased accumulation of a large HSP (HSP70) was reported in response to Cd stress $[157,159]$. Ireland et al. [161] also reported the increased accumulation of HSP70 protein in response to Cd stress in marine macro algae and fresh water plant species. In addition, expression of a small HSP (sHSP) was also found in the roots of Armeria maritima plants grown in $\mathrm{Cu}-$ rich soil [158]. Similarly, accumulation of HSP25 increased in response to $\mathrm{Al}$ stress in soybean (Glycine $\max (\mathrm{L}$.) 
Merr) [160]. A short burst of heat stress given prior to $\mathrm{HM}$ stress induces $\mathrm{Cd}$ tolerance. The molecular chaperones induced during HM stress could prevent irreversible protein denaturation resulting from the oxidative stress linked to HM exposure or help to channel their proteolytic degradation. However, the putative role of HSPs in HM tolerance is largely unknown.

4.5. Chemical Modification. Metal-modifying enzymes may be involved in the assimilation of HMs into organic molecules (e.g., selenate is metabolized to dimethylselenide [162]), or in changing the oxidation state of metals (e.g., toxic $\mathrm{Cr}(\mathrm{VI})$ is reduced to nontoxic $\mathrm{Cr}(\mathrm{III})$ ). Lytle et al. [163] showed that Eichhornia crassipes (water hyacinth), supplied with $\mathrm{Cr}(\mathrm{VI})$ in nutrient culture, accumulated nontoxic $\mathrm{Cr}(\mathrm{III})$ in root and shoot tissues. This suggests that $E$. crassipes detoxified $\mathrm{Cr}(\mathrm{VI})$ upon root uptake and transported a portion of the detoxified $\mathrm{Cr}$ to leaf tissues. In dicots, $\mathrm{Fe}$ (and possibly also $\mathrm{Cu}$ ) is reduced by a reductase at the root cell membrane before uptake $[155,164]$. Reduction of HMs in situ by plants may be a useful detoxification mechanism for phytoremediation.

4.6. Modulation of Transcription Factor (TF). Metal response element binding transcription factor 1 , also called metalresponsive transcription factor 1 (MTF-1), plays an important role in the cellular response and tolerance to HM stress by triggering the activation of genes responsible for HM uptake, transport, and detoxification. TFs involved in HM stress response and tolerance have already been identified in different plant species $[165,166]$. Importantly, Cd-responsive TFs share the same signal transduction pathway with other stress-related TFs [167]. TFs belonging to different families, such as WRKY, basic leucine zipper (bZIP), ethylene-responsive factor (ERF), and myeloblastosis protein (MYB), play a significant role in controlling the expression of specific stress-related genes in response to Cd stress [28].

4.7. Induction of Antioxidant Defense and Glyoxalase System. $\mathrm{HM}$ stress invariably induces oxidative stress and antioxidative defense systems, composed of free radical scavenging molecules such as AsA and GSH, and the enzymes involved in their biosynthesis and reduction $[3,8,13,168]$. Additionally, MG, a cytotoxic compound, was found to increase in response to various abiotic stresses, including HM stress $[2,17,169]$, which is mainly detoxified by the glyoxalase system in plants and enhanced oxidative stress tolerance (discussed in more detail later in the next section).

4.8. Synthesis of Salicylic Acid and HM Tolerance. Salicylic acid (SA) is a natural signal molecule which plays an important role in regulating a number of physiological and biochemical process making plants resistant to biotic and abiotic stresses [170, 171]. Freeman et al. [172] showed that constitutively elevated SA signals GSH-mediated Ni tolerance in Thlaspi, a Ni hyperaccumulator. SA pretreatment induces enhanced accumulation of GSH and protection against Ni toxicity, since GSH is known to protect against Ni-induced lipid peroxidation in Arabidopsis and Thlaspi hyperaccumulators [172]. A wealth of research has shown that exogenous SA application significantly enhanced HM tolerance in plants $[170,171,173]$. However, the protective function of SA mainly includes the regulation of ROS and antioxidants, induction of gene expression, and adsorption and distribution of elements [170, 171, 173, 174].

4.9. Synthesis of Proline. Accumulation of Pro in response to HM stress has also been widely reported $[8,175-177]$. Siripornadulsil et al. [178] demonstrated that increased Pro levels provide enhanced protection against $\mathrm{Cd}$ in microalgae. Moreover, many HM-tolerant plants have also been reported to possess substantially elevated constitutive Pro levels in the absence of excess HM ions when compared with their nontolerant relatives [8]. Importantly, Pro reduces Cd stress not by sequestering $\mathrm{Cd}$ but by reducing $\mathrm{Cd}$-induced free radical damage and maintaining a stringent reducing environment (higher GSH levels) within the cell. In seeking additional supporting evidence for this, we recently showed in mung bean (Vigna radiata L.) [3] that exogenous Pro induces HM (Cd) tolerance by maintaining a higher GSH level and GSH metabolizing enzymes. However, further research towards integration of the growth inhibiting and protecting properties of Pro is needed. Huang et al. [179] studied the physiological and biochemical responses in the leaves of two mangrove plant seedlings (Kandelia candel and Bruguiera gymnorrhiza) exposed to multiple $\mathrm{HMs}\left(\mathrm{Cd}^{2+}\right.$, $\mathrm{Pb}^{2+}$ and $\mathrm{Hg}^{2+}$ ) and concluded that Pro, GSH and PCs-SH in $K$. candel may play a more important role in ameliorating the effect of HM toxicity than in B. gymnorrhiza.

4.10. Polyamines. Polyamines (PAs) are low molecular weight organic cations and are ubiquitous in all living organisms. The common PAs in plants are spermidine (Spd), spermine $(\mathrm{Spm})$, and their diamine precursor, putrescine (Put). They influence a variety of growth, and development processes in plants and have been suggested to be a class of plant growth regulators and to act as second messengers (for a recent comprehensive reviews see Hussain et al. [180]). PAs are essential for normal growth and development through transcriptional and translational regulations [181], although their physiological significance derives from their involvement in various kinds of biotic and abiotic stress responses including HM stress in plants [182]. They have the capacity for scavenging free radicals and ROS [183], thus exerting a strong antioxidant function during various types of stress [184]. PAs and Pro are part of the "general adaptation syndrome" (GAS) response to environmental adversities, such as low temperature, HMs, or nutrient deficiency [184188]. Several genes coding for the enzymes involved in PA metabolism have been characterized and cloned from different plant species. Engineered plants, overexpressing PAs biosynthetic genes, confer increased tolerance to multiple environmental stresses [189, 190], including HMs [191].

4.11. Synthesis of Nitric Oxide and HM Tolerance. Nitric oxide (NO), a ubiquitous bioactive signaling molecule, plays an important role in a broad spectrum of multiple 
physiological processes in plants by regulating the level and toxicity of ROS and hormones [192, 193] and by inducing transcriptional changes that permit the identification of genes involved in different functional processes such as signal transduction, defense and cell death, transport, basic metabolism, and ROS production and degradation [194]. NO protects plants from oxidation damage by regulating general mechanisms for cellular redox homeostasis and promoting the transformation of $\mathrm{O}_{2}{ }^{--}$to $\mathrm{H}_{2} \mathrm{O}_{2}$ and $\mathrm{O}_{2}$ and also by enhancing $\mathrm{H}_{2} \mathrm{O}_{2}$-scavenging enzyme activities [192, 195197], although the NO molecule itself possesses antioxidant properties [198]. In addition to a direct ROS scavenging activity and to the modulation of lipid peroxidation by LOX inhibition, NO may also protect cells against oxidative processes by stimulating GSH synthesis. Solanum nigrum, a Cd hyperaccumulator, has received extensive attention in recent years. Xu et al. [199] reported that NO levels rapidly increased in S. nigrum roots under Cd stress and Cd-induced NO can both maintain intracellular antioxidative capacity and reduce oxidative damage. These results suggest that $\mathrm{Cd}$ induced NO accumulation is advantageous for protecting against Cd stress in plants. Application of exogenous NO also modulated ROS-scavenging enzymes, induced the activity of $\mathrm{H}^{+}$-ATPase and $\mathrm{H}^{+}$-PPase in the plasma membrane or tonoplast, and also significantly alleviated the growth inhibition induced by $\mathrm{CuCl}_{2}$ in tomato plants. These results indicate that exogenous NO could effectively induce tomato seedlings to adjust physiological and biochemical mechanisms against $\mathrm{Cu}$ toxicity and maintain fundamentally metabolic capacity and normal growth under HM stress [200]. Exogenous NO also improves $\mathrm{Cd}$ tolerance by increasing the production of Pro and total GSH and reducing oxidative damage in the roots of Madicago truncatula seedlings [201]. Laspina et al. [202] reported that NO, when applied before Cd exposure, significantly attenuates $\mathrm{Cd}$-induced oxidative damage in sunflower (Helianthus annuus L.) leaves. This result was mainly attributed to the prevention of growth inhibition and Chl degradation, the recovery of CAT activity and GSH levels, and the enhancement of AsA content and APX activity. These components of the antioxidant machinery allow the plant to cope better with HM stress. Based on the previous discussion it is therefore concluded that $\mathrm{NO}$ induces HM tolerance by regulating different physiological and biochemical mechanisms.

The previous discussions clearly demonstrate that plant HM tolerance is highly a complex and involves interrelated physiological, biochemical, and metabolic plant processes.

\section{Reactive Oxygen Species Production in Plant Cells}

Higher plants produce ROS during different metabolic processes in cellular organelles. However, during HM stress, their rate of production is dramatically elevated. Organelles with a highly oxidizing metabolic activity or with an intense rate of electron flow, such as Chl, mitochondria, and peroxisomes, are the predominant sources of ROS production in plant cells $[19,203-205]$. The Chl is the prime source of ROS having the capacity to produce high amounts of superoxide $\left(\mathrm{O}_{2}{ }^{\bullet-}\right)$ through the Mehler reaction and $\mathrm{H}_{2} \mathrm{O}_{2}$, essentially during the reduced rate of photosynthetic carbon fixation, a typical situation during abiotic stresses [206]. It is generally accepted that the water oxidizing system of PS II is affected by $\mathrm{HM}(\mathrm{Cd})$ by replacing the $\mathrm{Ca}^{2+}$ and $\mathrm{Mn}^{2+}$ ions in the PS II reaction centre; thereby inhibiting the reaction of PS II leads to the uncoupling of the electron transport in the Chl [207-211]. Cd was also found to inhibit the electron flow on the reducing side of PS I [212]. The negative effects of HM can also be observed in the carboxylating phase of photosynthesis. The main targets of the influence of $\mathrm{HM}$ are two key enzymes of $\mathrm{CO}_{2}$ fixation, ribulose 1,5-bisphosphate carboxylase ( $\mathrm{RuBisCO}$ ) and phosphoenol pyruvate carboxylase (PEPC). $\mathrm{Cd}^{2+}$ ions lower the activity of RuBPC and damage its structure by substituting for $\mathrm{Mg}^{2+}$ ions, which are important cofactors of carboxylation reactions, and may also shift RubisCO activity towards oxygenation reactions [211-213], and the glycolate that is produced moves from the $\mathrm{Chl}$ to peroxisomes, where it is oxidized by glycolate oxidase (GO) forming $\mathrm{H}_{2} \mathrm{O}_{2}$ [206]. The peroxisomal activities of xanthine oxidase $(\mathrm{XO})$ generate $\mathrm{O}_{2}{ }^{--}$and glycolate oxidase, flavin oxidase, and $\beta$-oxidation yield $\mathrm{H}_{2} \mathrm{O}_{2}[205,214,215]$. HM stress enhanced peroxisomal mobility correlated with an increase in $\operatorname{ROS}[8,31,216]$. There is a rapid induction of $\mathrm{H}_{2} \mathrm{O}_{2}$ in leaf peroxisomes in response to $\mathrm{Cd}$ stress [217]. Plant mitochondria are suggested to be an important source of abiotic stress-induced ROS generation. The mitochondrial electron transport chain consists of several dehydrogenase complexes which reduce a common pool of ubiquinone (Q). ROS production is likely to occur mainly in complex I and the Q zone [218]. Susceptibly of mitochondrial respiratory chain pathways and HM-induced loss of functions have also been reported [12, 219]. The presence of free HM cations, redox active or inactive, in mitochondria may significantly contribute to the initiation and perpetuation of oxidative stress [217, 220]. Plasma membrane-bound NADPH oxidases as well as cellwall associated peroxidases are the main sources of $\mathrm{O}_{2}{ }^{--}$ and $\mathrm{H}_{2} \mathrm{O}_{2}$ producing apoplastic enzymes [205]. NADPH oxidase-dependent ROS induction has been reported in wheat in response to Ni stress [221], in pea (Pisum sativum) in response to Cd stress [222], in Vicia faba in response to $\mathrm{Pb}$ stress [223], and in Arabidopsis in response to $\mathrm{Cd}$ and $\mathrm{Cu}$ [224]. In addition to these metabolic ROS resources, in the presence of redox-active $\mathrm{HMs}(\mathrm{Fe}, \mathrm{Cu}, \mathrm{Cr}, \mathrm{V}$, and $\mathrm{Co}$ ), - $\mathrm{OH}$ can be formed from $\mathrm{H}_{2} \mathrm{O}_{2}$ through the Fenton reaction or from $\mathrm{H}_{2} \mathrm{O}_{2}$ and $\mathrm{O}_{2}{ }^{--}$through the Haber-Weiss reaction [225]. The extremely reactive ${ }^{\bullet} \mathrm{OH}$ in the cell causes extensive oxidative damage of membranes and other macromolecules, including photosynthetic pigments, protein, DNA, and lipids $[19,226,227]$. ROS are normally scavenged immediately at their sites of production by locally present antioxidants. However, when this local antioxidant capacity cannot cope with ROS production, $\mathrm{H}_{2} \mathrm{O}_{2}$ can leak in the cytosol and diffuse to other compartments. Importantly, beyond their harmful effects on cells, ROS (especially $\mathrm{H}_{2} \mathrm{O}_{2}$ ) have been proposed to act as signals (Figure 3 ) in stress response and modulate the activation of stress responsive pathways, 


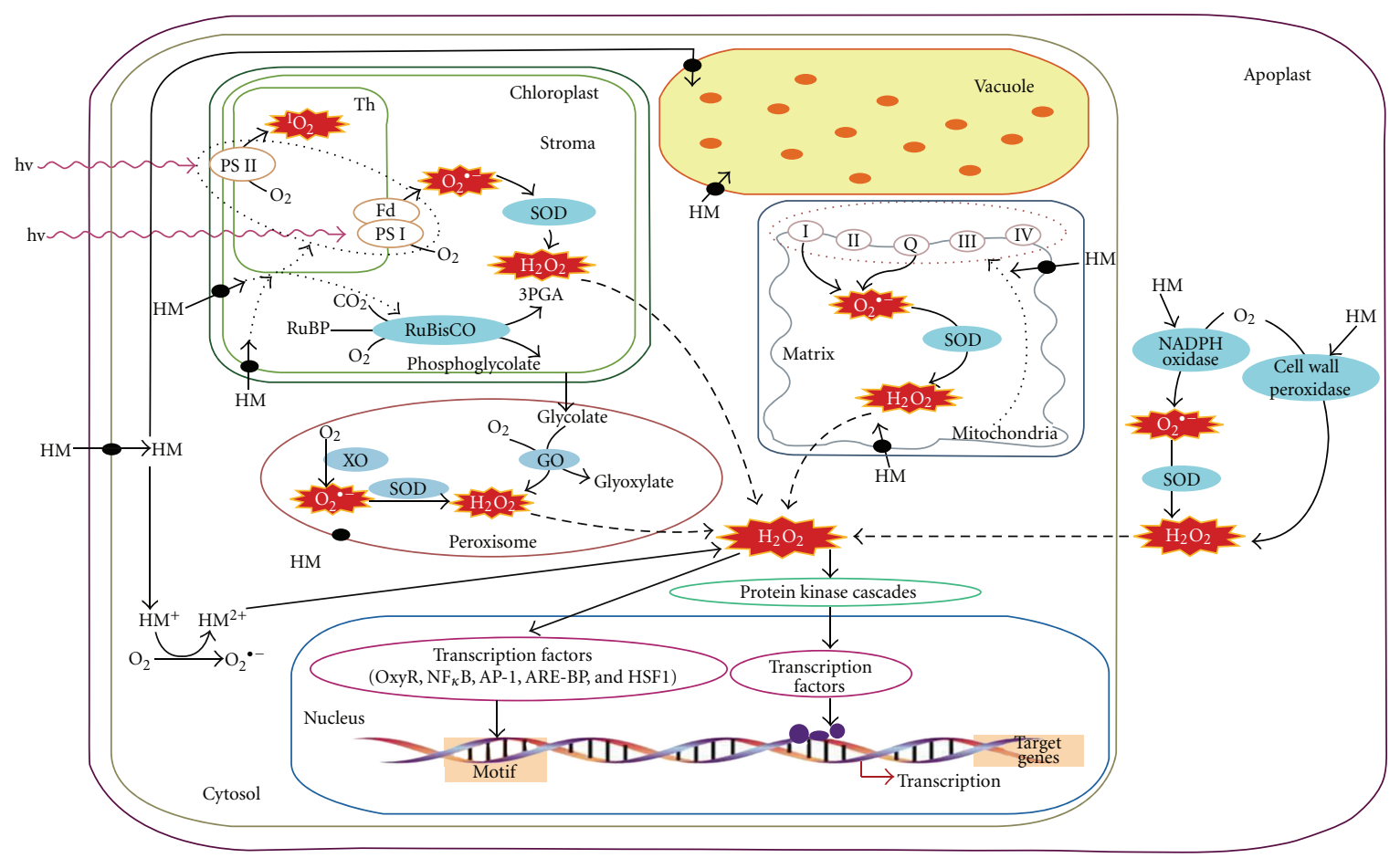

FIGURE 3: Heavy metal-induced ROS production in different organelles of plant cells and ROS-induced signaling in defense gene expression (modified from Hossain et al. [19]; Sharma and Dietz [8]). Yellow circles in the vacuole designate the deposit of HMs.

proteins, and genes $[8,11,19,204]$. $\mathrm{As}_{2} \mathrm{H}_{2}$ is immediately produced under HM stress, it is probably a key molecule triggering signal transduction and HM tolerance in plants [31].

\section{Methylglyoxal Production in Higher Plants in Response to Stress and Its Negative Consequence on Cellular Systems}

MG is a highly reactive $\alpha \beta$-dicarbonyl aldehyde. Extensive research has been carried out on mammalian and animal systems, and different pathways have been proposed for endogenous MG formation from metabolic intermediates of carbohydrates, protein, and lipid metabolism. However, very little work has been done in plant systems regarding the endogenous production of MG. MG is formed spontaneously in plants by nonenzymatic mechanisms under physiological conditions from glycolysis and from photosynthesis intermediates, glyceraldehyde-3-phosphate (G3P), and dihydroxyacetone phosphate (DHAP) [15, 228]. Under stress conditions, the rate of glycolysis increases, leading to an imbalance (in the initial and latter five reactions) in the pathway. Triosephosphates are very unstable metabolites, and removal of the phosphoryl group by $\beta$-elimination from 1,2 -enediolate of these trioses leads to the formation of MG $[229,230]$. Therefore, spontaneous production of MG is an unavoidable consequence of the glycolysis pathway during stress. MG can also be formed enzymatically from G3P and DHAP. Triosephosphate isomerase hydrolyzes G3P and DHAP and removes phosphate to yield MG [231]. Many studies in plants have demonstrated the rapid induction of MG levels in response to various stresses in plants, including HM stress [2, 15-17, 232-234]. Singla-Pareek et al. [17] reported a significant increase (1.7-fold) of MG level in tobacco in response to $\mathrm{HM}$ stress $\left(5 \mathrm{mM} \mathrm{ZnCl}_{2}, 24 \mathrm{~h}\right)$. In our report, we also found a significant increase (1.5-fold) in MG level in pumpkin (Cucurbita maxima Duch.) seedlings subjected to $\mathrm{HM}$ stress $(1 \mathrm{mM} \mathrm{CdCl} 2,24 \mathrm{~h})$. Importantly, we also observed a rapid increase in MG levels in response to salinity, drought, high temperature, and low temperature stresses [2]. The rapid increase in the level of MG in plants due to different stresses (including HM stresses) clearly suggests that it is a general stress response. There is a possibility that MG could therefore act as a signal for plants to respond to stress [19].

MG is both a mutagen and a genotoxic agent. At high cellular concentrations, it inhibits cell proliferation [235] and results in a number of adverse effects such as increasing the degradation of proteins and inactivating the antioxidant defense system $[18,19,236]$. Additionally, MG causes increased sister chromatic exchange and endoreduplication [237]. It also induces DNA strand breaks and increases point mutations [237]. MG can also cause oxidative stress indirectly through the formation of advanced glycation end products (AGEs), the irreversible chemical modifications, and cross-links in proteins $[199,238]$. Very recently, Saito et al. [20] showed that unless MG is detoxified immediately after its production in the chloroplast, it will act as an intrinsic mediator that catalyses the photoreduction of $\mathrm{O}_{2}$ 


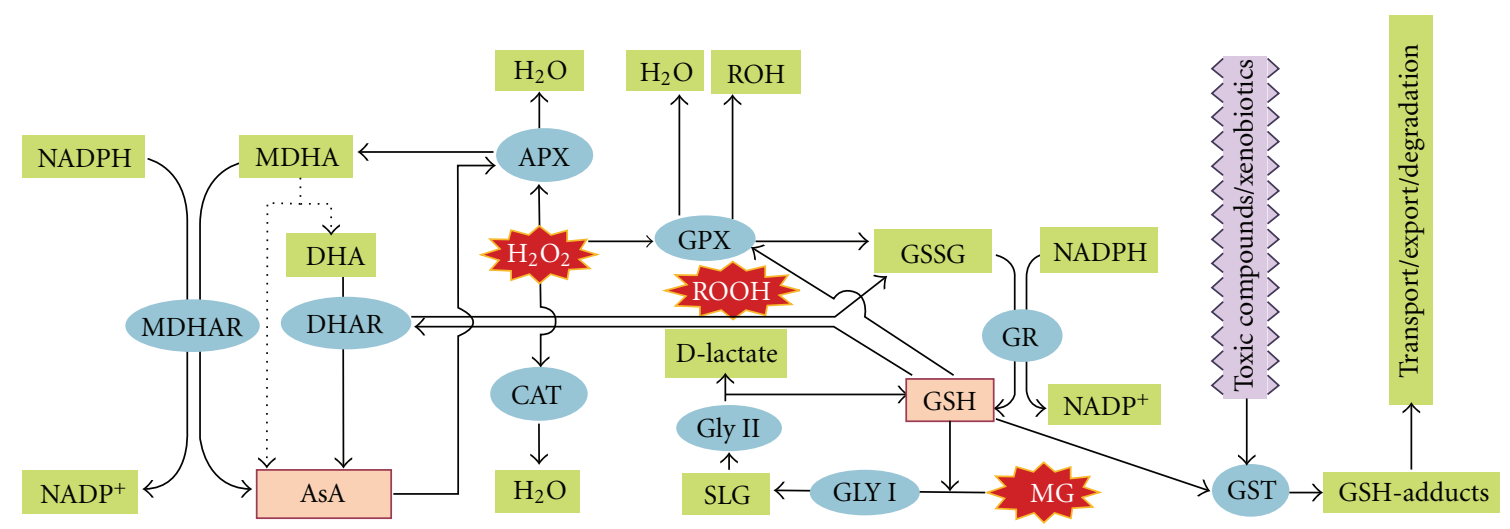

FIgURE 4: Schematic illustration of possible metabolic interaction of AsA- and GSH-based antioxidant system and GSH-based glyoxalase system in plant cells (modified from Hossain et al. [19]). Dotted lines indicate nonenzymatic reactions. For further discussion, see text.

at PS I, leading to the production of $\mathrm{O}_{2}{ }^{\bullet-}$. Therefore, efficient detoxification of MG overproduced during normal physiological processes or various abiotic stresses is one of the most important adaptive strategies of plant stress tolerance $[15,16,19]$.

\section{ROS and MG Scavenging and Detoxification Systems in Plants}

Plants use an intrinsic mechanism known as the plant antioxidant system as a defense mechanism to regulate ROS levels according to the cellular needs at a particular time. These antioxidants include the enzymes superoxide dismutase (SOD; EC 1.15.1.1), ascorbate peroxidase (APX; EC 1.11.1.11), monodehydroascorbate reductase (MDHAR; EC 1.6.5.4), dehydroascorbate reductase (DHAR; EC 1.8.5.1), glutathione reductase (GR; EC 1.6.4.2), catalase (CAT; EC 1.11.1.6), glutathione peroxidase (GPX; EC 1.11.1.9), glutathione $S$-transferase (GST; EC 2.5.1.18), and water-soluble compounds such as AsA and GSH [11, 19, 40, 203]. Although AsA and GSH function as cofactors of enzymes of the antioxidant and glyoxalase pathways, both can also directly quench ROS and regulate gene expression associated with biotic and abiotic stress responses to optimize defense and survival. Importantly, sustaining the ROS concentration (especially $\mathrm{H}_{2} \mathrm{O}_{2}$ ) at an appropriate level can promote plant development and reinforce resistance to environmental stressors by modulating the expression of genes and redox signaling pathways [239]. Similarly, the glyoxalase system is an integral component and major pathway of cellular metabolism of MG in living systems present in the cytosol of cells and cellular organelles, particularly mitochondria. The function of the glyoxalase pathway in abiotic stress tolerance has widely been reported (for a recent review see Hossain et al. [19]). The ubiquitous glyoxalase pathway consists of two enzymes: glyoxalase I (Gly I; lactoylglutathione lyase; EC 4.4.1.5) and glyoxalase II (Gly II; hydroxyacylglutathione hydrolase; EC 3.1.2.6). These enzymes act coordinately to convert MG and other 2-oxoaldehydes to their 2-hydroxyacids using GSH as a cofactor in a two-step reaction [240]. The spontaneous reaction between GSH and MG forms hemithioacetal, which is then converted to S-D-lactoylglutathione (SLG) by Gly I. The second reaction is the hydrolysis of SLG to D-lactate catalyzed by Gly II and GSH is recycled back into the system (Figure 4). MG detoxification is therefore strongly dependent on the availability of cellular GSH. Deficiency of GSH limits the production of hemithioacetal, leading to the accumulation of MG. The reactions catalyzed by the glyoxalase system are irreversible. The existence and widespread distribution of this shunt pathway document its fundamental importance in biological systems. Recent investigations in plants have brought new developments in the involvement of the glyoxalase system in stress tolerance and its involvement with oxidative defense systems (Figure 4). Further insights into the biological function of the glyoxalase system came from the molecular cloning of their respective genes that provides a potential framework for interpreting the physiological roles of the glyoxalase system in higher plants against various abiotic stresses, including HMs [2, 3, $11,15,16,19,40,169,232,241]$.

\section{Plant Metal Tolerance and Involvement of Antioxidative and Glyoxalase Systems}

Plenty of research has been conducted by using HM accumulator, hyperaccumulator, HM-tolerant, and HM-sensitive genotypes and also involving transgenic approaches, to specify the constitutive and induced higher levels of key nonenzymatic and enzymatic antioxidants which could be correlated with HM sensitivity and HM tolerance [8, 13]. Encouraging observations have been made showing a strong relationship between HM tolerance and antioxidative and glyoxalase systems (Table 1), whereas plants with low antioxidant capacity show sensitivity of HM toxicity. A large number of HM-hyperaccumulating and HM-tolerant plants reflected that higher GSH biosynthesis and GSH utilizing and regenerating enzymes can have a significant impact on HM tolerance [172, 173, 242-248]. However, an increase of at least GSH biosynthesis was found to play a central role in $\mathrm{Ni}$ tolerance in $\mathrm{Ni}$ hyperaccumulators (Thlaspi spp.) [172]. Additionally, the potential role of nonprotein thiols (NPTs) such as GSH and PCs in $\mathrm{Cd}$ 
TABLE 1: Heavy metal tolerant plant species and traits associated with GSH and their metabolizing enzymes in ROS and MG metabolism.

\begin{tabular}{|c|c|c|c|}
\hline Plants & Phenotype/genotype & $\begin{array}{l}\text { Components of defense } \\
\text { system related to GSH }\end{array}$ & References \\
\hline Arabis paniculata & $\begin{array}{l}\mathrm{Zn} / \mathrm{Cd} \\
\text { hyperaccumulator }\end{array}$ & High GSH level & {$[247]$} \\
\hline Phragmites australis & Cd accumulator & $\begin{array}{l}\text { High GR, GST, GPX } \\
\text { activities and AsA and } \\
\text { GSH level }\end{array}$ & {$[242]$} \\
\hline Sedum alfredii & Zn hyperaccumulator & High GSH level & [249] \\
\hline Thlaspi caerulescens & $\begin{array}{l}\text { Cd tolerant } \\
\text { Cd accumulator }\end{array}$ & High GSH level & {$[243]$} \\
\hline Pisum sativum & Cd tolerant & High GSH level & {$[173]$} \\
\hline Arabidopsis thaliana & Ni tolerant & High GSH level & {$[172]$} \\
\hline Thlaspi goesingense & $\begin{array}{l}\mathrm{Ni} \text { tolerant} / \mathrm{Ni} \\
\text { accumulator }\end{array}$ & High GSH level & {$[172]$} \\
\hline Triticum aestivum & $\mathrm{Al}$ tolerant & High GST activity & {$[244]$} \\
\hline Pteris vittata & As hyperaccumulator & High GSH level & {$[245]$} \\
\hline Sedum alfredii & $\begin{array}{l}\mathrm{Cd} / \mathrm{Zn} \\
\text { hyperaccumulator }\end{array}$ & $\begin{array}{l}\text { High GSH level and high } \\
\text { DHAR and GR activities }\end{array}$ & {$[246]$} \\
\hline Nicotiana tabacum & $\begin{array}{l}\text { Zinc tolerant Gly I and } \\
\text { Gly II inserted } \\
\text { transgenic plants }\end{array}$ & $\begin{array}{l}\text { High Gly I and Gly II } \\
\text { activities and high GSH } \\
\text { level }\end{array}$ & {$[17]$} \\
\hline Sedum alfredii & $\mathrm{Pb}$ accumulator & High GSH level & {$[248]$} \\
\hline
\end{tabular}

uptake and complexation in the $\mathrm{Zn} / \mathrm{Cd}$ hyperaccumulator Arabis paniculata has also been reported [247]. However, in these studies, no indication was made regarding HMinduced ROS metabolism. The biochemical mechanism of Cd tolerance in Phragmites australis (a rhizomatous plant of the Poaceae family possessing interesting characteristics useful in phytoremediation and phytostabilisation processes) was studied to decipher the role of ROS metabolism in HM tolerance. The roots of Cd-treated $\left(\mathrm{CdSO}_{4}, 50 \mu \mathrm{M}, 21 \mathrm{~d}\right)$ plants had higher APX, CAT, GR, GST, and GPX activities and AsA and GSH content. Importantly, a sharp increase in the NDAPH/NADP ${ }^{+}$ratio was observed in roots, leaves, and stolons. Increased activity of antioxidant enzymes in Cd-treated plants suggests that HM tolerance in Phragmites plants might be associated with the efficient regulation of AsA and GSH and their metabolizing enzymes [242]. Additionally, a study with Sedum alfredii, a new Zn hyperaccumulator and $\mathrm{Pb}$ accumulator, showed an increase in GSH content in response to $\mathrm{Zn}$ and $\mathrm{Pb}$ treatments [249]. The authors suggest that GSH, rather than PCs, may be involved in $\mathrm{Zn}$ and $\mathrm{Pb}$ transport, hyperaccumulation/accumulation, and tolerance. The potential of such adaptive behavior of HM-tolerant and -accumulator plants in relation to GSH and ROS metabolism was also tested in a large number studies by using exogenous chemicals in which it was found that GSH metabolism and/or their metabolizing enzymes played a vital role in HM-induced oxidative stress tolerance (detailed later on).

Although antioxidant protection is determined by large families of nonenzymatic and enzymatic antioxidants, a detailed description of the function of each component in relation to HM tolerance is largely beyond the scope of this paper. Additionally, among the different components of antioxidant defense and MG detoxifying systems, a constitutively high level of GSH metabolizing enzymes has a substantial influence on HM tolerance in plants [17, 242, 246, 247]. In this paper, we will describe a few important GSH-utilizing and regenerating enzymes such as GST, GPX, DHAR, GR, Gly I, and Gly II that largely participate in the efficient metabolism of major ROS and MG and their products, hence tightly controlling the major plant responses and $\mathrm{H}_{2} \mathrm{O}_{2}$-induced stress signaling to HMs and metalloids conferring metal-induced oxidative stress tolerance. The potential role of GSH in HM stress tolerance is described hereinafter.

8.1. Glutathione. Glutathione (GSH), a nonenzymatic antioxidant, is a low molecular weight thiol implicated in a wide range of metabolic processes and constitutes an important plant defense system against environmental stresses, including HMs $[3,10,19,40,250]$. It is one of the major antioxidant and redox buffers in plants found abundantly in all cell compartments. GSH takes part in the control of $\mathrm{H}_{2} \mathrm{O}_{2}$ levels through the AsA-GSH cycle [226]. It can also function directly as a free radical scavenger by reacting with ${ }^{1} \mathrm{O}_{2}, \mathrm{O}_{2}{ }^{--}$, and ${ }^{\bullet} \mathrm{OH}$ [251]. Upregulation of the GSH level is of pivotal importance, because it induces the signal transduction and defense against ROS and MG which is achieved through different pathways with various control points (Figures 4 and 5 ) which include orchestrated activation of genes encoding enzymes related to GSH and AsA [10, 11, 19]. GSH protects proteins against denaturation caused by the oxidation of protein thiol groups under stress. It also plays an indirect role in protecting membranes by maintaining $\alpha$-tocopherol 


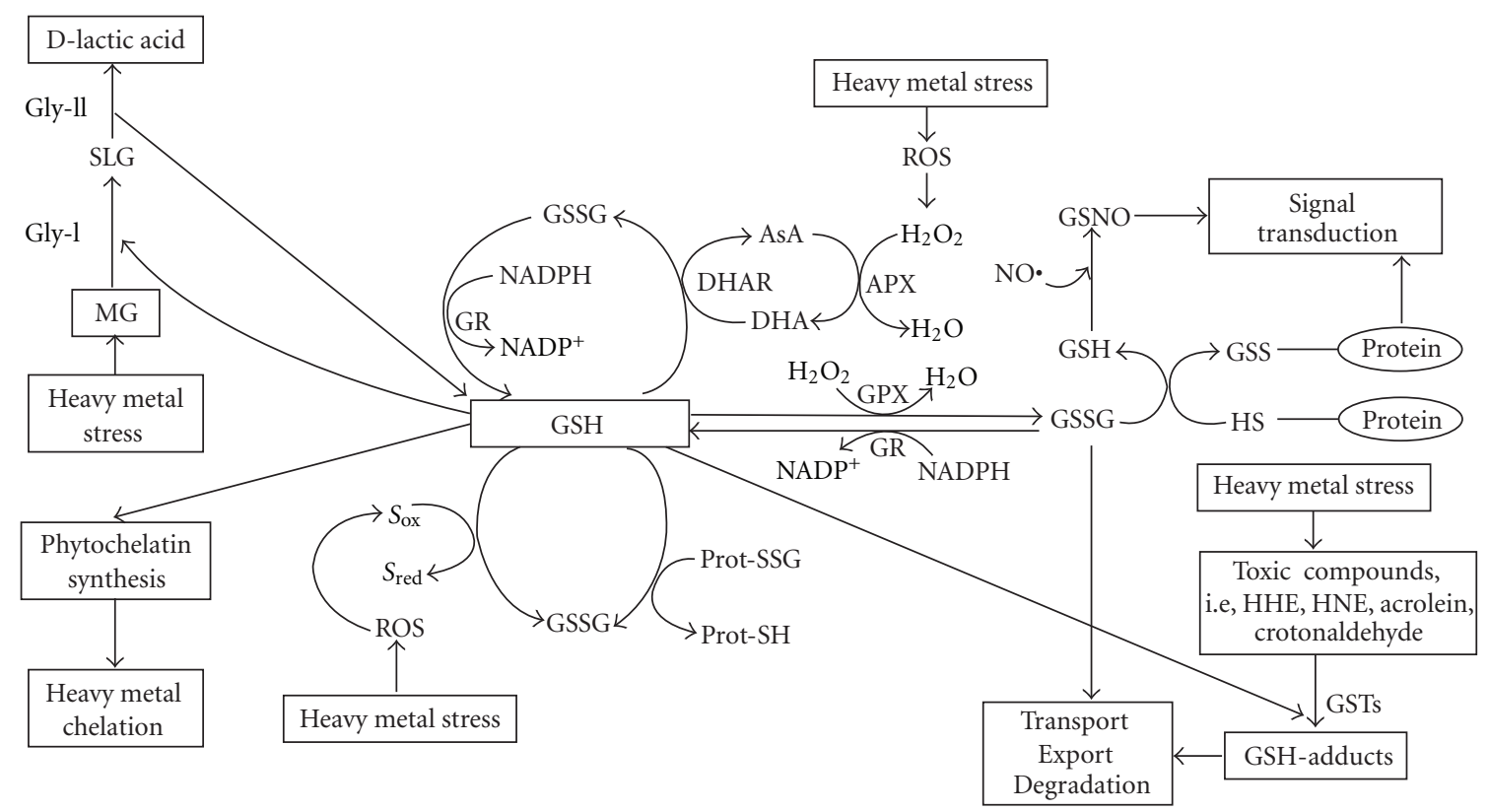

FIGURE 5: Multiple functions and regulation of GSH and its metabolizing enzyme in heavy metal-induced ROS and MG metabolism in plant cells (adapted from Hossain and Fujita [10]). For further discussion see text.

and zeaxanthin in the reduced state. GSH is a substrate for GPX and GST, which are also involved in the removal of ROS and endogenous toxic compounds [226]. It is also involved in the transfer and storage of sulfur [252] and in the detoxification of HMs where PC derived from GSH forms HM complexes [253]. It was also reported that GSH is involved in MG detoxification, a toxic metabolite produced in ample amounts under stressful conditions $[3,9,10,15$, $16,18,39]$. The property of GSH is of great biological importance since it allows fine-tuning of the cellular redox environment under normal conditions and upon the onset of stress (Figure 5). Along with its oxidized form (GSSG), it acts as a redox couple important for maintaining cellular homeostasis, playing a key role in diverse signaling systems in plants [254]. GSH accumulates in response to increased ROS, or to compensate for decreases in the defense capability of other antioxidants and GSH levels are constitutively higher in plants adapted to stress conditions [255-257]. Recent experiments indicate that GSH may function as a cellular sensor to ensure maintenance of the NADPH pool [258] further illustrating the intertwining of the metabolism of different redox compounds. However, the concentration of cellular GSH has a major effect on its antioxidant function and it varies considerably under $\mathrm{Cd}$ stress. An increase in GSH concentration has been observed with increasing Cd concentration in Brassica juncea, Brassica campestris [259, 260], and Pisum sativum [173]. The adaptive behavior of hyperaccumulating plants reflects the pivotal importance of GSH and its metabolizing enzyme in HM tolerance (described previously, Table 1). In our recent study [2] with mung bean seedlings, we found a significant increase in GSH content in response to $\mathrm{Cd}(1 \mathrm{mM} \mathrm{CdCl} 2,24 \mathrm{~h})$. Schützendübel et al. [261] showed that a low level of short-term Cd stress significantly induced the level of GSH while its level decreased when both the duration and level of $\mathrm{Cd}$ concentration increased. However, Cd-induced depletion of GSH has been mainly attributed to PC synthesis [262]. The decline in the levels of GSH might also be attributed to an increased utilization from regeneration of AsA from DHA or from the direct interaction with Cd [263]. Zhou et al. [264] reported a sharp increase in GSH accumulation in Medicago sativa roots treated with different concentrations of $\mathrm{HgCl}_{2}$. A marked increase in GSH content in the leaves, stems, and roots under multiple $\mathrm{HM}\left(\mathrm{Cd}^{+}, \mathrm{Pb}^{+}\right.$, and $\left.\mathrm{Hg}^{+}\right)$stress was reported by Huang et al. [265]. As induces a significant increase in GSH levels in As tolerant Holcus lanatus [266]. Compared to As-sensitive plant species, stimulated GSH synthesis may play a major role in maintaining a high GSH/GSSG ratio in As-tolerant plant species [267, 268]. However, the GSH level in response to various HMs depends on the plant species, the age of the plant, and duration of the treatment. GSH redox couple is an information-rich redox buffer that interacts with numerous cellular components [226]. Recent studies in plants have demonstrated that NO influenced GSH synthesis, as demonstrated in Medicago truncatula roots in which the levels of GSH, $\gamma$-EC, and glutathione synthetase (GS) gene expression were increased by NO $[199,269]$. During the interaction of GSH with NO, S-nitrosoglutathione (GSNO) is formed in a reaction that may interconnect the ROS- and reactive nitrogen-based signaling pathways [239]. The participation of GSNO in the stress response was shown in Cd-treated plants [270]. The general regulatory role of $\mathrm{NO}$ in $\mathrm{HM}$-stressed plants has been demonstrated in several studies. Xiong et al. [271] provide excellent coverage on this aspect in their review.

8.2. Glutathione S-Transferases. GSTs are a superfamily of multifunctional enzymes best known for their role in 
enzymatic detoxification of xenobiotics. GST acts by catalyzing the conjugation of GSH with electrophilic, often hydrophobic toxic compounds to form derivatives that can be secreted from the cell, sequestered in the vacuole, or catabolized [272]. In addition, plant GSTs also provide protection against oxidative stress induced by abiotic stresses and oxidants [272-277]. Functioning as GPX and DHAR, plant GSTs can catalyze the reduction of hydroperoxides to less harmful alcohols and safeguard protein function from oxidative damage and maintain redox homeostasis by regenerating AsA from DHA [272]. Among the various aldehydes, $\alpha \beta$-unsaturated aldehydes contribute more to various reactions than do other aldehydes and are more likely to form stable adducts. In plants, alkenals arise from lipid hydroperoxides after cleavage by hydroperoxide lyase $[275,278]$. Previously, we reported that alcohol (ethanol), aldehydes (acetaldehyde), and saturated chain aldehydes (formaldehyde, acetaldehyde, propionaldehyde, butyraldehyde, pentanal, 1-hexanal) induce GST activity whereas $\alpha \beta$ unsaturated aldehydes are the most effective inducer [275]. In sorghum, for example, phi GSTs (SSP-7108) actively detoxify 4-hydroxynonenal, a degradation product of oxidative membrane damage [279]. Environmental chemicals and their metabolites detoxified by GST include acrolein, atrazine, and others [280]. An increase in GST activity was observed in pumpkin (Curbita maxima Duch.) seedlings subjected to Cd, Cr, Mn, and As stress [274, 276] and in rice (Oryza sativa L. cv. N07-63) seedlings in response to Cd stress $(50 \mu \mathrm{M} \mathrm{Cd}, 7 \mathrm{~d})$ [281]. Halusková et al. [282] showed that barley (Hordeum vulgare cv. Jubilant) subjected to several $\mathrm{HMs}(\mathrm{Cd}, \mathrm{Pb}, \mathrm{Cu}, \mathrm{Hg}, \mathrm{Co}$, and $\mathrm{Zn})$ showed a significant increase in GST activity. Similarly, our results showed a significant increase in GST activity in mung bean seedlings subjected of Cd stress $\left(1 \mathrm{mM} \mathrm{CdCl}_{2}, 24 \mathrm{~h}\right)$ which was accompanied by higher oxidative damage [3]. In our another study, there was a significant increase in GST activity in response to Cd stress $\left(1 \mathrm{mM} \mathrm{CdCl}_{2}\right)$ in onion callus [11, 283]. Szollosi et al. [284] found a time- and dose-dependent increase in GST activity in Brassica juncea. Therefore, it is possible that in the case of strong stress, where basal antioxidant mechanisms are exhausted, more effective responses are activated like GST [3, 19, 40]. Zhang and Ge [285] found a close relationship between Cd level and GSH content as well as GST activity, suggesting that these two parameters of antioxidant defense system may be used as biomarkers of Cd-induced stress. A sharp increase in GST activity in both root and shoot tissues was also observed in response to Ni stress (100 and $200 \mu \mathrm{M})$ in wheat [286]. $\mathrm{Pb}$-induced GST activity was also observed in Macrotyloma uniflorum and Cicer arietinum [287]. Skórzyńska-Polit et al. [278] found a significant increase in GST activity in response to $\mathrm{Cu}$ stress $(100 \mu \mathrm{M}, 7 \mathrm{~d})$ in Arabidopsis thaliana. The activity of GST was also greater in the Al-tolerant lines, suggesting that this enzyme may be important not only for the detoxification of certain HMs [288] but also for that of Al phytotoxicity, perhaps via the elimination of the lipid peroxidation induced by Al stress, as found by Cakman and Horst [289]. In plants exposed to HMs, the role of GST may be related not only to the removal of toxic products of lipid peroxidation but also to its possible involvement in the transport of phytochelatin-metal complexes to the vacuole [290]. Dixit et al. [291] noted that tobacco plants overexpressing the GST gene (TvGST) showed better Cd tolerance, as indicated by lower $\mathrm{Cd}$ accumulation and lipid peroxidation, than WT plants. Most importantly, the transgenic plants showed significantly higher SOD, GST, GPX, APX, and CAT activities under Cd stress than WT plants, further proving that GSH metabolizing enzymes act coordinately in inducing stress tolerance, including to HM stress $[11,14,19]$.

8.3. Glutathione Peroxidase (GPX). Glutathione peroxidases (GPXs) are key enzymes of the antioxidant network in plants present in different subcellular organelles. Their principal activity is thought to catalyze the reduction of $\mathrm{H}_{2} \mathrm{O}_{2}$, organic hydroperoxides (ROOHs), and lipid hydroperoxides to $\mathrm{H}_{2} \mathrm{O}$ and alcohol using GSH and/or other reducing equivalents [292]. The most identified plant GPX genes were shown to have high homology to the mammalian phospholipid hydroperoxide glutathione peroxidases (PHGPXs), which have a higher affinity to lipid hydroperoxides than to $\mathrm{H}_{2} \mathrm{O}_{2}$. However, at least two plant PHGPXs probably represent novel isoforms of TRX peroxidase, which are generally more active against $\mathrm{H}_{2} \mathrm{O}_{2}$ than lipid peroxides [293]. Differential regulation of GPX activity was observed in response various HMs and metalloids stress treatments (see Anjum et al. [14]). Cuypers et al. [294] suggested that peroxidase activity can be used as a potential biomarker for HM toxicity. Besides disproportionation of $\mathrm{H}_{2} \mathrm{O}_{2}$, GPX also catalyses the quenching of organic peroxides. Our recent study showed that a significant increase in GPX activity was in response to $\mathrm{Cd}$ stress $(1 \mathrm{mM} \mathrm{CdCl} 2,24 \mathrm{~h})$ in mung bean seedlings [3]. Similarly, a significant increase in GPX activity was also observed in Allium cepa exposed to a variety of HMs $(\mathrm{Hg}, \mathrm{Pb}, \mathrm{Cr}, \mathrm{Cu}, \mathrm{Zn}$, or $\mathrm{Cd})$ suggesting that the elevated activity of GPX was a result of HM-induced free radical generation [295]. Arabidopsis thaliana subjected to Cd stress ( 1 and $10 \mu \mathrm{M}, 7 \mathrm{~d}$ ) showed a significant increase in GPX activity. Higher GPX activity might be an indication of protection against lipid peroxidation caused by $\mathrm{Cd}$ exposure [296]. Differential response of GPX activity was observed in Hordeum vulgare cv. Jubilant root tips subjected to $\mathrm{Cd}, \mathrm{Hg}$, $\mathrm{Cu}, \mathrm{Zn}, \mathrm{Co}$, and $\mathrm{Pb}$ stresses. Cd stress increased GPX activity in a dose-dependent manner. Additionally, $\mathrm{Ni}, \mathrm{Hg}$, and $\mathrm{Cu}$ also showed a significant increase in GPX activity whereas $\mathrm{Pb}, \mathrm{Co}$, and $\mathrm{Zn}$ treatment had no significant effect on GPX activity [282]. GPX activity also increased in As-tolerant Brassica juncea var. TPM-1 in response to both $\mathrm{As}(\mathrm{V})$ and As(III) stress [297]. The enhancement of GPX activity upon exposure to both $\mathrm{As}(\mathrm{V})$ and $\mathrm{As}(\mathrm{III})$ in TPM-1 suggested that this enzyme served as an intrinsic defense tool to resist Asinduced oxidative stress. An induction of GPX activity has also been previously reported under As stress in other plants $[298,299]$. On the other hand, TM-4 demonstrated a decline in GPX activity after 15 days in response to both $\mathrm{As}(\mathrm{V})$ and As(III), suggesting that downstream processing of $\mathrm{H}_{2} \mathrm{O}_{2}$ was not being efficiently taken care of. There are reports of a significant increase in GPX activity in leaf tissues of different 
plant species exposed to $\mathrm{Se}$ and $\mathrm{Cu}$, under both laboratory and field conditions [300, 301]. Aravind and Prasad [302] studied the influence of exogenous $\mathrm{Zn}$ on $\mathrm{Cd}$-induced antioxidant defense in Ceratophyllum demersum. Cd stress $(10 \mu \mathrm{M}, 7 \mathrm{~d})$ showed a $40 \%$ decrease in GPX activity whereas $\mathrm{Zn}$-supplementation under $\mathrm{Cd}$ stress efficiently restored as well as increased the activity of GPX accounting for increased ROS scavenging induced by $\mathrm{Zn}$.

Therefore, GPX activity in response to HM exposure is diverse and depends on the HM in question, the species, and pivotal role it plays in HM-induced ROS detoxification.

8.4. Dehydroascorbate Reductase. The univalent oxidation of AsA leads to the formation of monodehydroascorbate (MDHA) which is reduced to AsA by MDHAR. In the chloroplast, the MDHA radical can also be reduced to AsA by thylakoid-associated, reduced ferredoxin that is more effective than reduction by MDHAR [303]. If MDHA is not rapidly reduced again to AsA by MDHAR, it will spontaneously disproportionate into AsA and DHA. DHA is then reduced to AsA by Dehydroascorbate reductase (DHAR) in a reaction requiring GSH [304]. In the absence of sufficient DHAR, however, DHA undergoes irreversible hydrolysis to 2, 3-diketogulonic acid. Rapid regeneration is necessary in order to maintain the antioxidative capacity of AsA. DHAR allows the plant to recycle DHA, thereby recapturing AsA before it is lost. Because AsA is the major reductant in plants, DHAR serves to regulate its redox state. Thus, DHAR is a physiologically important reducing enzyme in the AsA-GSH recycling reaction for higher plants [304]. The following section will update readers on the modulation of DHAR activity by HM stress in different plants species based on reports over the past decade.

Schützendübel et al. [261] showed that DHAR activity decreased in Populus $x$ canescens roots subjected to $50 \mu \mathrm{M} \mathrm{Cd}$ stress within $15 \mathrm{~h}$ of treatment but later the activity increased significantly with the progression of the stress period. A consistent increase in DHAR activity was observed in two barely genotypes (Weisuobuzhi, relatively-Cd tolerant and Dong 17, relatively-Cd sensitive) exposed to $5 \mu \mathrm{M}$ Cd for 1,5 , 10,15 , and $25 \mathrm{~d}$ [305]. Similarly, DHAR activity increased in wheat roots and leaves subjected to different concentrations of $\mathrm{Cd}(10,20,40 \mu \mathrm{M})$ but the increase in AsA level was not enough to prevent protein or lipid oxidation [306]. In contrast, a decrease in DHAR activity was also observed in our study with mung bean seedlings subjected to $\mathrm{Cd}$ stress $\left(1 \mathrm{mM} \mathrm{CdCl}_{2}, 24 \mathrm{~h}\right)$ which was accompanied by lower AsA content in leaf tissues [3]. Sharma and Dubey et al. [7] reported that DHAR activity increased significantly in $\mathrm{Al}^{3+}$-treated rice seedlings compared to controls, and the increase was more pronounced in the $80 \mu \mathrm{M} \mathrm{Al}^{3+}$-treated seedlings than in the $160 \mu \mathrm{M} \mathrm{Al}^{3+}$-treated seedlings. The enhanced activity of DHAR observed in $\mathrm{Al}^{3+}$-stressed rice seedlings appears to be due to the need of maintaining a favorable redox status, by maintaining a sufficient amount of AsA and GSH and to overcome the possible problems of oxidation. As tolerant cultivar (TPM-1) showed significant increase in DHAR activity in response to $\mathrm{As}(\mathrm{V})$ and $\mathrm{As}(\mathrm{III})$; in contrast, the sensitive cultivar (TM4) showed a significant increase in response to $\mathrm{As}(\mathrm{V})$ but the activity declined upon exposure to As(III) [297]. Additionally, DHAR activity increased in rice shoots and roots subjected to Ni stress, suggesting that $\mathrm{Ni}$ activates the AsA regenerating system to maintain an elevated level of AsA [307]. Two tomato cultivars ("Kosaco" and "Josefina") subjected to B stress (0.50 and $2.00 \mathrm{mM} \mathrm{H}_{3} \mathrm{BO}_{3}$ ) showed a significant increase in DHAR activity in addition to a total and reduced AsA content although the level of $\mathrm{H}_{2} \mathrm{O}_{2}$ and MDA increased, indicating that the increase enzymatic activity was high enough to reduce the oxidative stresses [308]. Transgenic tobacco plants overexpressing the DHAR gene showed better root growth than WT plants after exposure to toxic levels of $\mathrm{Al}$ accompanied by lower $\mathrm{H}_{2} \mathrm{O}_{2}$ content, less lipid peroxidation, and a lower level of oxidative DNA damage. Furthermore, DHAR-overexpressing plants maintained a higher AsA level both with and without $\mathrm{Al}$ exposure when compared to WT plants. Based on their findings, the authors suggest that the overexpression of DHAR that maintained a higher AsA level was essential in acquiring Al tolerance [309]. Similarly, transgenic Arabidopsis plants overexpressing CAT and GST genes subjected to $\mathrm{Cd}\left(\mathrm{NO}_{3}\right)_{2}(8 \mathrm{mM})$ stress showed a significant increase (151\%) in DHAR activity, whereas the activity declined in a nontransgenic line. The higher activity of DHAR in transgenic plants was consistent with the AsA redox state under $\mathrm{Cd}$ stress suggesting an activated redox cycling of AsA [310].

8.5. Glutathione Reductase. Glutathione reductase (GR) belongs to a family of flavin-containing pyridine nucleotidedisulphide oxido-reductases which catalyzes the reduction of GSSG to GSH with the accompanying oxidation of NADPH [311]. GR plays an essential role in a cell's defense against reactive oxygen metabolites by sustaining the reduced status of glutathione and ascorbate pools which in term maintain the cellular redox state under various abiotic stresses including HM [11, 19, 39, 40, 312-314]. Biochemical and molecular studies have shown that GR is an important enzyme for scavenging ROS, which are continuously generated in different compartments during various abiotic stresses. Accumulated evidence suggests that GR plays an important role in the detoxification of Cd-induced ROS, possibly via the AsA-GSH cycle. Nouairi et al. [110] reported that GR activity in leaves of Brassica napus was strongly affected by $\mathrm{Cd}$ treatment. GR activity increased significantly up to $10 \mu \mathrm{M}$ $\mathrm{Cd}$ and then decreased at higher concentrations after $15 \mathrm{~d}$ of treatment. In contrast, GR activity levels in the leaves of Brassica juncea plants were unaffected by changing the $\mathrm{Cd}$ supply. Aravind and Prasad [302] showed a sharp decrease in GR activity in Ceratophyllum demersum in response to Cd stress $(10 \mu \mathrm{M})$. Importantly, Zn supplementation in Cdtreated plants improved the impairment of GR activity. Arabidopsis thaliana subjected to Cd stress ( 1 and $10 \mu \mathrm{M}, 7 \mathrm{~d}$ ) showed a significant increase in GR activity [296]. In our study [3], in mung bean seedlings, there was a significant decrease in GR activity in response to Cd Stress $(1 \mathrm{mM}$ $\mathrm{CdCl}_{2}, 24 \mathrm{~h}$ ) whereas there was an increase in GR activity in both Cd-tolerant (Pusa 9531) and -sensitive (PS 16) cultivars of mung bean [315], indicating that the response of GR varies 
greatly due to differences in genotype. Similar to Cd stress, a significant increase in GR activity was also observed in response to As(V) and As(III) in both tolerant (TPM-1) and sensitive cultivar (TM4) after 15 days of treatment [297]. In Hydrilla verticillata, GR activity increased in response to a low concentration of $\mathrm{Cu}$ whereas at higher concentrations (5 and $25 \mu \mathrm{M}$ ) the activity declined, manifested by higher lipid peroxidation [316]. Israr and Sahi [317] showed a significant increase $(62.8 \%)$ in GR activity in response to $\mathrm{Hg}$ stress in Sesbania drummondii whereas the activity of GR drastically declined with $50 \mu \mathrm{M}$ Hg. Similarly, Medicago sativa roots exhibited a strong inhibition of GR activity when exposed to $\mathrm{Hg}(10 \mu \mathrm{M})$ for $24 \mathrm{~h}$ [264]. Russo et al. [318] reported that GR activity in Brassica napus exposed to $\mathrm{Cu}(100 \mu \mathrm{M})$ decreased in roots, whereas in leaves, GR activity was induced during the whole stress period. In earlier reports, a reduction in cellular GSH levels as well as GR activity was observed in plants exposed to toxic levels of $\mathrm{Cu}$ [319]. Verma and Dubey [320] showed a significant increase in GR activity in shoot tissues of rice after $15 \mathrm{~d}$ of $\mathrm{Pb}$ treatment $(1000 \mu \mathrm{M})$. Increased $\mathrm{GR}$ activity in $\mathrm{Pb}$-treated rice seedlings suggested the possible involvement of GR in regenerating GSH from GSSG under $\mathrm{Pb}$ toxicity conditions to increase the GSH/GSSG ratio and the total glutathione pool. These authors concluded that GR appears to play a pivotal role in combating oxidative stress in plants. Finally, it can be concluded that increased GR activity under HM stress contributes to the maintenance of a higher GSH/GSSG ratio and increased GSH level which is used during phytochelatin synthesis and by DHAR and other GSH-dependent enzymes involved in ROS and MG metabolism $[3,11,14,19,40]$.

8.6. Glyoxalase I. Glyoxalase I (Gly I) is the first enzyme of the GSH-based glyoxalase pathway involved in detoxification of MG. Induction of Gly I activity in response to various stresses has been reported over a range of plant species under both biotic and abiotic stresses, including $\mathrm{HM}[2,3,10,11$, $15-17,19,232,233]$. In our study with pumpkin seedlings, we found a slight increase in Gly I activity in response to Cd stress $\left(1 \mathrm{mM} \mathrm{CdCl}_{2}, 24 \mathrm{~h}\right)$. Similar to our results, SinglaPareek et al. [17] also observed an increase in Gly I activity in tobacco seedlings subjected to $\mathrm{Zn}$ stress $\left(5 \mathrm{mM} \mathrm{ZnCl}_{2}\right.$, $24 \mathrm{~h}$ ). Later on, we studied the regulation of Gly I enzyme activities in response to various stresses in the callus of onion which had very high Gly I activity than other plant species [321]. We observed a significant increase in Gly I activity in response to various stresses where low-temperature stress showed the highest induction ( 2.57 -fold) followed by salinity (2.52-fold) and drought stress (1.43-fold). Importantly, we observed a decrease in Gly I activity in response to HM stress $(0.5 \mathrm{mM} \mathrm{CdCl}, 7 \mathrm{~d})$ in onion callus [9]. Therefore, it can be concluded that Gly I activity varies due to differences in genetic background, stress conditions, type of HM used, or differential regulation of different Gly I isoforms [322]. It is conceivable that an elevated level of Gly I activity is required to remove excessive MG produced in ample amounts under normal and various stressful conditions $[2,3,9,11,15,16$, 19, 40]. El-Shabrawi et al. [323] found that salt-tolerant rice cultivar (Pokkali) maintained higher Gly I activity under salt stress than a sensitive cultivar (IR64). Importantly, the other antioxidant enzymes (SOD, APX, CAT, GST, GPX, GR and POX) studied also showed a significant increase relative to Gly I, which indicates a balance among the glyoxalase pathway and antioxidant pathway enzymes to increase abiotic stress tolerance.

8.7. Glyoxalase II. Glyoxalase II (Gly II) catalyzes the second step of MG detoxification and forms D-lactate while GSH is regenerated. Two Gly II isoforms were identified from Arabidopsis and they are differentially expressed, suggesting their different roles in plant cells [324]. The cytoplasmic form of Arabidopsis Gly II contains an Fe- $\mathrm{Zn}$ binuclear metal centre that is essential for its activity. Both metals participate in substrate binding, transition site stabilization, and the hydrolysis reaction. Subtle alterations in the geometry and/or electrostatics of the binuclear center have profound effects on the activity of the enzyme $[325,326]$. In our study [9] with onion callus we found a decrease in Gly II activity in response to $\mathrm{Cd}$ stress $\left(0.5 \mathrm{mM} \mathrm{CdCl}_{2}, 7 \mathrm{~d}\right)$. Similarly, we also observed a decrease in Gly II activity in mung bean seedlings subjected to $\mathrm{Cd}$ stress $(1 \mathrm{mM} \mathrm{CdCl}, 24 \mathrm{~h})$ [3]. Based on our results, we conclude that $\mathrm{Cd}$ stress might interact with the Fe-Zn binuclear centre and decreased the catalytic activity of the enzymes. Additionally, Gly II activity increased slightly in WT tobacco seedlings and even more increased in the transgenic plants overexpressing both Gly I and II under $\mathrm{Zn}$ stress $\left(5 \mathrm{mM} \mathrm{ZnCl}_{2}, 24 \mathrm{~h}\right)$ [17] and maintained a higher GSH level. As GSH is recycled by the glyoxalase system, it is assumed that an increased level of MG is efficiently detoxified in transgenic plants overexpressing glyoxalase pathway enzymes, thus creating the probability of upregulation of GSH levels at least during stress, which would help to form PCs under HM stress, thus proving HM stress tolerance. Transgenic tobacco plants overexpressing both Gly I and Gly II genes also showed higher salinity tolerance and by additional increase of GSH metabolizing enzyme (GST, GPX, and GR) activities further denoting the close interaction between the antioxidant system and the glyoxalase system in imparting stress tolerance $[11,16,19$, $39,40,327,328]$.

\section{Exogenous Chemical Treatment and Heavy Metal Tolerance in Plants in relation to GSH and Their Metabolizing Enzymes}

Some of the adaptive biochemical responses of HM stress in plants are characterized by the synthesis of GSH, amino acids like Pro and PAs, and singling molecules like SA and NO (described previously). A wealth of studies have demonstrated that treatment of plants with such compounds influences plant HM uptake and HM-induced oxidative stress tolerance by efficient regulation of ROS and MG detoxification pathways.

We investigated the regulatory effects of exogenous Pro and glycinebetaine (betaine) in inducing $\mathrm{HM}$ tolerance of mung bean (cv. Binamoog-1) seedlings with special reference to ROS and MG metabolism [3]. Seven-day-old seedlings 
were subjected to $\mathrm{Cd}$ stress $\left(1 \mathrm{mM} \mathrm{CdCl}_{2}, 48 \mathrm{~h}\right.$ ) with or without Pro and betaine. Cd stress caused a profound increase in GSH and GSSG content, while the AsA content decreased with a sharp increase in $\mathrm{H}_{2} \mathrm{O}_{2}$ and lipid peroxidation (MDA). APX, GST, GPX, and Gly I activities increased in response to $\mathrm{Cd}$ stress while the activity of CAT, MDHAR, DHAR, GR, and Gly II decreased. Exogenous application of Pro and betaine $(5 \mathrm{mM})$ showed an increase in GSH and AsA content, maintained a high GSH/GSSG ratio, and increased the activity of APX, DHAR, MDHAR, GR, GST, GPX, CAT, Gly I, and Gly II involved in ROS and MG detoxification systems more than the control and most Cd-stressed plants, with a concomitant decrease in GSSG content, $\mathrm{H}_{2} \mathrm{O}_{2}$, and MDA levels. These findings suggest that both betaine and Pro provide protection against $\mathrm{Cd}$-induced oxidative stress by reducing $\mathrm{H}_{2} \mathrm{O}_{2}$ and $\mathrm{MDA}$ levels and by increasing the antioxidant defense and MG detoxification systems. Additionally, $\mathrm{Xu}$ et al. [201] showed that improvement of Cd-tolerance caused by Pro pretreatment was correlated with increase antioxidant enzyme activity and higher intracellular GSH content.

The influence of exogenous GSH in the antioxidant defense system against $\mathrm{Cd}$-induced oxidative stress was studied in two barley genotypes (sensitive, Dong 17, and tolerant, Weisuobuzhi) by Chen et al. [305]. Seedlings at the two-leaf stage ( $10 \mathrm{~d}$ ) were subjected to $5 \mu \mathrm{M}$ Cd with basal nutrient solution for up to $25 \mathrm{~d}$. Cd stress significantly inhibited plant height, root length, and biomass whereas accumulation of $\mathrm{O}_{2}{ }^{--}, \mathrm{H}_{2} \mathrm{O}_{2}$, and MDA increased sharply in both tolerant and sensitive genotypes. The addition of GSH $(20 \mathrm{mg} / \mathrm{L})$ in $5 \mu \mathrm{M}$ Cd culture medium significantly alleviated Cd-induced growth inhibition, especially for the sensitive genotype Dong 17 , and dramatically depressed $\mathrm{O}_{2}{ }^{--}, \mathrm{H}_{2} \mathrm{O}_{2}$, and MDA accumulation. The GSH content decreased significantly in response to $\mathrm{Cd}$ stress, whereas exogenous GSH application increased the endogenous GSH content more than in seedlings subjected to $\mathrm{Cd}$ stress alone. External GSH counteracted $\mathrm{Cd}$-induced alterations of certain antioxidant enzymes. The activities of DHAR, MDHAR, and GPX activities were downregulated and reached the control level in seedlings treated with GSH whereas depressed APX and CAT activity was elevated specially in susceptible genotype (Dong 17). Therefore, exogenous GSH not only influences the GSH metabolizing enzymes but also substantially influences other ROS-metabolizing enzymes while playing an important role in Cd-induced alleviation of oxidative stress.

The role of GSH in heat shock- (HS-) and $\mathrm{H}_{2} \mathrm{O}_{2}$ induced protection of rice (cv. Taichung 1) seedlings against Cd stress $(5 \mu \mathrm{M} \mathrm{Cd}, 7 \mathrm{~d})$ was investigated by Chao et al. [329]. HS $\left(45^{\circ} \mathrm{C}, 3 \mathrm{~h}\right)$ and $\mathrm{H}_{2} \mathrm{O}_{2}(0.5 \mathrm{mM}, 3 \mathrm{~h})$ pretreatment resulted in an increase in GSH content in the leaves of rice seedlings. Pretreatment of seedlings with exogenous GSH $(1 \mathrm{mM}, 3 \mathrm{~h})$ resulted in an increase in GSH in leaves, enhancing subsequent $\mathrm{Cd}$ tolerance. Pretreatment with buthionine sulfoximine (BSO), a specific inhibitor of GSH synthesis, effectively inhibited GSH content induced by $\mathrm{HS}$ and $\mathrm{H}_{2} \mathrm{O}_{2}$ and reduced subsequent $\mathrm{Cd}$ tolerance. Furthermore, the effect of BSO on HS- and $\mathrm{H}_{2} \mathrm{O}_{2}$-induced
GSH accumulation and toxicity by subsequent Cd stress can be reversed by the addition of GSH. Time-course analyses of $\mathrm{HS}$ in rice seedlings demonstrated that the accumulation of $\mathrm{H}_{2} \mathrm{O}_{2}$ preceded the increase in GSH. Finally, they concluded that the early accumulation of $\mathrm{H}_{2} \mathrm{O}_{2}$ during $\mathrm{HS}$ signals an increase in GSH content, which in turn protects rice seedlings from ROS-induced damage under Cd stress.

To understand the mechanism by which PAs relieve the damage of plants by HMs and improve the phytoremediation efficiency, Tang et al. [330] sprayed Spd (0.25 to $0.50 \mathrm{mM})$ on Typha latifolia L. leaves and then subjected them to Cd stress $\left(0.1\right.$ and $\left.0.2 \mathrm{mM} \mathrm{Cd}^{2+}\right) . \mathrm{Cd}^{2+}$ stress induced oxidative injury, as evidenced by an increase in the generation of $\mathrm{O}_{2}{ }^{\bullet-}$, as well as the $\mathrm{H}_{2} \mathrm{O}_{2}$ and MDA contents in both leaves and caudices. An increase in the activities of CAT, GPX, and GR was observed in both leaves and caudices, SOD activity increased in caudices, and APX activity increased in leaves following $\mathrm{Cd}^{2+}$ treatment. The GSH content in both leaves and caudices and the reductive ascorbate content in leaves increased obviously, prompted by the application of exogenous Spd. Spraying with Spd increased the activity of GR and APX in both leaves and caudices, whereas the activity of SOD, CAT, and GPX increased only in caudices following a spray with Spd. The generation of $\mathrm{O}_{2}{ }^{\bullet-}$ and the $\mathrm{H}_{2} \mathrm{O}_{2}$ and MDA content in both leaves and caudices decreased after spraying with Spd. Finally, it was assumed that exogenous Spd elevated the tolerance of T. latifolia under $\mathrm{Cd}^{2+}$ stress primarily by increasing GR activity and the GSH level.

Application of exogenous silicon ( $\mathrm{Si}$ ) was also found to increase Cd tolerance in two Brassica chinensis L. cultivars (Shanghaiqing, a Cd-sensitive cultivar; and Hangyoudong, a Cd-tolerant cultivar). Plants were grown in 0.5 and $5 \mathrm{mg} / \mathrm{L} \mathrm{Cd}$ with or without $1.5 \mathrm{mM}$ Si. The activity of antioxidant enzymes such as SOD, CAT, and APX decreased at both concentrations of $\mathrm{Cd}$, although $\mathrm{MDA}$ and $\mathrm{H}_{2} \mathrm{O}_{2}$ concentrations increased at the higher $\mathrm{Cd}$ level, which was counteracted by the addition of Si. The content of AsA, $\mathrm{GSH}$, and nonprotein thiols increased at the higher Cd level, further intensified by the addition of Si. However, the protective influence of Si was more effective in enhancing $\mathrm{Cd}$ tolerance in the Cd-tolerant cultivar than in the Cd-sensitive cultivar. It can be concluded that Si-enhanced Cd tolerance in B. chinensis was attributed mainly to Si-suppressed Cd uptake and root-to-shoot $\mathrm{Cd}$ transport and Si-enhanced antioxidant defense activity [331].

$\mathrm{H}_{2} \mathrm{O}_{2}$ is a small, diffusible molecule and is widely considered to be a signal molecule in the regulation of the defense system [239]. $\mathrm{H}_{2} \mathrm{O}_{2}$ plays a dual role in plants: at low concentration, it acts as a signal that induces the expression of numerous defense genes and activates multiple defense responses to abiotic stresses, while excessive accumulation leads to cellular oxidative damage and even programmed death $[19,331,332]$. The influence of exogenous $\mathrm{H}_{2} \mathrm{O}_{2}$ pretreatment on $\mathrm{Cd}$ tolerance and translocation was studied by $\mathrm{Hu}$ et al. [281] in rice (cv. N07-63) seedlings. Cdstress $(50 \mu \mathrm{M}, 7 \mathrm{~d})$ significantly decreased plant growth as indicated by decreased length and biomass of shoots and roots. Additionally, the level of $\mathrm{H}_{2} \mathrm{O}_{2}$ and MDA increased significantly in both shoot and root tissues of Cd-stressed 
seedlings due to impairment of antioxidant metabolism. Importantly, $\mathrm{H}_{2} \mathrm{O}_{2}$ pretreatment $(100 \mu \mathrm{M}, 24 \mathrm{~h})$ mitigated $\mathrm{Cd}$ stress by increasing the activities of SOD, CAT, GPX, APX, and GST as well as nonenzymatic antioxidant such as GSH and AsA resulting in lower $\mathrm{H}_{2} \mathrm{O}_{2}$ and MDA content and less growth inhibition. $\mathrm{H}_{2} \mathrm{O}_{2}$ pretreatment also decreased $\mathrm{Cd}$ concentration in shoots indicating that $\mathrm{H}_{2} \mathrm{O}_{2}$ affected $\mathrm{Cd}$ distribution in rice seedlings. Therefore, improved $\mathrm{Cd}$ tolerance was partly due to an enhanced antioxidative system and higher $\mathrm{Cd}$ sequestration in roots that ultimately reduced Cd translocation.

$\mathrm{Xu}$ et al. [333] showed the $\mathrm{H}_{2} \mathrm{O}_{2}$-induced upregulation of AsA and GSH metabolism showing $\mathrm{Al}$-induced oxidative stress tolerance in wheat seedlings. Al stress increased the $\mathrm{O}_{2}{ }^{\cdot-}$ and $\mathrm{H}_{2} \mathrm{O}_{2}$ levels leading to more predominant lipid peroxidation, programmed cell death, and inhibition of root elongation in both $\mathrm{Al}$-tolerant and -sensitive genotypes. $\mathrm{Al}$ stress increased the activities of SOD, POD, CAT, MDHAR, DHAR, GR, GPX and AsA and GSH content and their redox state. However, $\mathrm{H}_{2} \mathrm{O}_{2}$-pretreated Al-stressed seedlings showed higher SOD, POD, CAT, MDHAR, DHAR, GR, GPX, and AsA and GSH content and their redox state than nontreated Al-stressed seedlings. Importantly, enhancement of antioxidant capacity was greater in the $\mathrm{Al}$-sensitive genotype than in the tolerant one. Therefore, optimum $\mathrm{H}_{2} \mathrm{O}_{2}$ pretreatment makes the plant more tolerant to $\mathrm{Al}$-induced oxidative stress in a synergistic fashion.

The protective effects of $\mathrm{NO}$ against the toxicity caused by excess $\mathrm{Cu}\left(\mathrm{CuSO}_{4}, 50 \mu \mathrm{M}\right)$ in Panax ginseng were also studied by Tewari et al. [334]. The addition of an NO donor, $\mathrm{SNP}$, was effective in reducing $\mathrm{Cu}$-induced toxicity in $P$. ginseng adventitious roots. The protective effect of SNP, as indicated by the extent of lipid peroxidation, was reversed by incorporation of a NO scavenger, in the medium suggesting that the protective effect of SNP is attributable to NO released. Reduction of excess Cu-induced toxicity by SNP is most likely mediated through modulation in the activities of antioxidant enzymes involved in $\mathrm{H}_{2} \mathrm{O}_{2}$ detoxification (APX, CAT and POD) and in GSH regeneration (GR) and contents of molecular antioxidants (particularly nonprotein thiol, ascorbate and its redox status).

The role of SA in regulating $\mathrm{Hg}$-induced oxidative stress in the roots of alfalfa (Medicago sativa) was investigated by Zhou et al. [171]. Plants were pretreated with $0.2 \mathrm{mM}$ SA for $12 \mathrm{~h}$ and subsequently exposed to $10 \mu \mathrm{M} \mathrm{Hg}{ }^{2+}$ for $24 \mathrm{~h}$. The SA-promoted root growth was correlated with decreased lipid peroxidation in root cells. The ameliorating effect of SA was confirmed by histochemical staining for detecting the loss of membrane integrity in $\mathrm{Hg}$-treated roots. Additionally, treatment with $0.2 \mathrm{mM} \mathrm{SA}$ increased the activity of NADH oxidase, APX, and POD in the roots exposed to $\mathrm{Hg}$. However, slightly decreased SOD activity was observed in SA + Hg-treated roots than in roots treated with $\mathrm{Hg}$ alone. Importantly, SApretreated $\mathrm{Hg}$-stressed seedlings accumulated more AsA, GSH, and Pro in the roots than seedlings subjected to Hgstress without pre-treatment. Finally, the authors suggested that exogenous SA improved $\mathrm{Hg}$ tolerance by modulating antioxidant enzymes and also by increasing the AsA and GSH contents.

Therefore, the chemicals or compounds synthesized in plant cells in response to $\mathrm{HM}$ stress further prove their protective roles in $\mathrm{HM}$ tolerance in relation to ROS and MG metabolism.

\section{Proteomic Changes in Response to HM Stress in relation to GSH Metabolism}

Proteomic offers a new platform for studying complex biological functions involving large numbers and networks of proteins and can serve as a key tool for revealing the molecular mechanisms that are involved in the interactions between toxic HMs and plant species. Quantitative analysis of proteins and metabolites is able to provide accurate information about molecular changes allowing the establishment of a range of more or less specific mechanisms, leading to the identification of major players in the considered pathways [5]. However, the detail description of plant proteomic changes under HM stress fall beyond the scope of this paper. For a few excellent recent reviews in plant proteomic changes in response to HM stress, see $[335,336]$. In this paper, we will focus only on GSH and its related proteins which have a significant impact of HM-induced stress response and tolerance in plants.

A comparative proteomic analysis of the short-term responses of rice roots and leaves to $\mathrm{Cd}$ stress was made by Lee et al. [337]. A total of 36 proteins were up- or downregulated following Cd stress $\left(100 \mu \mathrm{M} \mathrm{CdCl}_{2}, 24 \mathrm{~h}\right)$. Importantly, the upregulated proteins in rice roots belonged to the proteins involved in the oxidative stress response and GSH metabolism (GST, GS, GR, APX1, and POD) indicating that prompt antioxidative responses might be necessary for the reduction of $\mathrm{Cd}$-induced oxidative stress. Previously, we reported a robust increase in CmGSTU1 and CmGSTU2 protein in response to As stress $(0.1 \mathrm{mM}, 24 \mathrm{~h})$ and CmGSTU1, CmGSTU2, and CmGSTF1 in response to $\mathrm{Cr}(1 \mathrm{mM}, 24 \mathrm{~h}), \mathrm{Mn}(1 \mathrm{mM}, 24 \mathrm{~h})$, and Cd stress $(100 \mu \mathrm{M}$ $\mathrm{Cd}, 24 \mathrm{~h})[274,276]$. In our more recent study with onion callus, we also observed significant accumulation of two GST protein (GSTe and AcGSTF1) under Cd stress (1 mM $\mathrm{CdCl}_{2}, 96 \mathrm{~h}$ ) condition [283] but no increase in Gly I protein was observed in response to $\mathrm{Cd}$ stress $\left(0.5 \mathrm{mM} \mathrm{CdCl}_{2}, 7 \mathrm{~d}\right)$ [9].

Zhao et al. [67] studied the Cd-induced changes of the leaf proteome by two-dimensional gel electrophoresis (2DE) in a Cd hyperaccumulator plant, Phytolacca americana L. Among the 32 differentially expressed protein spots, 14 were enhanced/induced while 11 were reduced under $\mathrm{Cd}$ stress $(400 \mu \mathrm{M}, 48 \mathrm{~h})$. However, major changes were found in the proteins involved in the photosynthetic pathway as well as the sulfur- and GSH-related metabolisms. Additionally, Wang et al. [338] made a comparative proteomic analysis of wheat (Triticum aestivum L. cv. Yangmai 15) roots to gain a comprehensive understanding of the plant's response to $\mathrm{Cd}$ stress exposed to a range of $\mathrm{Cd}$ concentrations (10, 100 and $200 \mu \mathrm{M}, 1$ week). Protein profiles analyzed by 2-DE 
revealed that 46 protein spots showed a 1.5 -fold change in protein abundance following $\mathrm{Cd}$ exposure; 31 protein spots were upregulated and 15 protein spots were downregulated; 25 of them were identified by matrix-assisted laser desorption/ionization time-of-flight mass spectrometry (MALDITOF MS). Importantly, most of the upregulated proteins were related to sulfur and GSH metabolism (such as $\gamma \mathrm{ECS}$, S-adenosyl-methionine synthase (SAMS), GST, DHAR, and Malate dehydrogenase) involved in HM detoxification and antioxidant processes indicating the role of GSH metabolism in Cd stress tolerance.

To elucidate the precise mechanisms underlying the toxicity of As (50 and $100 \mu \mathrm{M} \mathrm{Na}_{2} \mathrm{HAsO}_{4} \cdot 7 \mathrm{H}_{2} \mathrm{O}$ ) in rice (Oryza sativa L. cv. Dongjin), the metabolism and defense reactions were studied by Ahsan et al. [339] using a combination of comparative proteomic analysis in combination with physiological and biochemical analyses. Proteomic analyses identified 23 differentially expressed proteins in rice roots, including predicted ones such as S-adenosylmethionine synthetase (SAMS), CS, and novel proteins including tyrosinespecific protein phosphatase protein and GST containing an omega domain. These differentially expressed proteins are functionally involved in cell signaling, stress and detoxification, defense and development, and protein biosynthesis. Based on physiological and proteomic investigations, it is proposed that As stress in plants generates ROS, triggering signaling molecules such as JA and S-adenosyl-L-methionine (SAM), and activating the detoxification process, which mainly involves GSH/PC biosynthesis. Importantly, these pathways are coordinately regulated, where GSH plays a central role in the complex cellular network [339].

Ingle et al. [340] analyzed the root and shoot proteomes of a Ni hyperaccumulator plant (Alyssum lesbiacum) by using 2-DE coupled with LC-MS/MS to gain more information about Ni metabolism. The accumulation of several proteins involved with sulfur metabolism in response to Ni stress suggests that Cys or a downstream metabolite, such as GSH, may play a role in $\mathrm{Ni}$ tolerance. Similarly, a proteomic study identifies the metabolic pathways involved in $\mathrm{Cr}$ stress during germination of maize (Zea mays L.) seedlings exposed to high concentrations of potassium dichromate, and the proteome pattern and MT content were analyzed by Labra et al. [341]. Increases in the abundance of several antioxidant, detoxification, and glycolytic pathway-related enzymes suggested that under $\mathrm{Cr}$ stress, activation of oxidative stress mechanisms occurred together with an effect on sugar metabolism. Importantly, increases in the abundance of Gly I and MTs after exposure to $\mathrm{Cr}$ suggest that plants might use glyoxalase and MTs pathways to detoxify $\mathrm{Cr}$ or Cr-induced toxic by-products in plant cells. Involvement of Gly I during higher ATP synthesis under stress has also been reported [228].

Tuomainen et al. [342] compared the effects of $\mathrm{Zn}$ deficiency under increased concentrations of $\mathrm{Zn}$ and $\mathrm{Cd}$ on three genotypes of Thlaspi caerulescens, a tiny plant from the Brassicaceae family closely related to A. thaliana and a known hyperaccumulator of several HMs. These researchers used close homology of most protein sequences found in $T$. caerulescens to $A$. thaliana and were able to identify the vast majority of differentially expressed proteins. Under increased $\mathrm{Zn}$ or $\mathrm{Cd}$ concentrations, most upregulated proteins in shoots belonged to enzymes participating in ROS scavenging such as $\mathrm{Cu} / \mathrm{Zn}-\mathrm{SOD}, \mathrm{APX}, \mathrm{DHAR}$, and peroxiredoxin. Later on, proteomic changes in response to excess $\mathrm{Cu}$-stress were studied by Ahsan et al. [343] in rice (Oryza sativa L. cv. Hwayeong) seedlings by using $\mathrm{CuSO}_{4} \cdot 5 \mathrm{H}_{2} \mathrm{O}(0.2$ to $1.5 \mathrm{mM}$ ). Protein profiles analyzed by 2 -DE revealed that 25 protein spots were differentially expressed in $\mathrm{Cu}$-treated samples. Among them, 18 proteins were upregulated while 7 were downregulated. These differentially displayed proteins were identified by MALDI-TOF MS. The upregulation of some antioxidant, and stress-related proteins such as Gly I, peroxiredoxin, aldose reductase, and some regulatory proteins such as DnaK-type molecular chaperone, UlpI protease, and receptor-like kinase clearly indicated that excess $\mathrm{Cu}$ generates oxidative stress that might be disruptive to other important metabolic processes.

Zhen et al. [344] studied the molecular mechanism underlying $\mathrm{Al}$ stress $\left(50 \mu \mathrm{M} \mathrm{AlCl}_{3}\right.$ ) responses by comparative proteome analysis of Al-stress-responsive proteins in an $\mathrm{Al}$ resistant soybean (Glycine max (L.) Merr) cultivar (Baxi 10). A total of 39 differentially expressed spots in abundance were identified by MS, with 21 being upregulated, 13 newly induced, and 5 downregulated. Importantly, proteins related to sulfur metabolism (GST and OASTL) were upregulated and GST expression was found to be an early response to Al toxicity. They concluded that the expression of GSHrelated proteins might detoxify the ROS elicited by $\mathrm{Al}$ toxicity. Similarly, Yang et al. [345] studied the Al stress(100 and $250 \mu \mathrm{M} \mathrm{AlCl}_{3}$ ) induced proteomic changes in an Al-resistant rice cultivar (Oryza sativa L. cv Xiangnuo 1). A total of $17 \mathrm{Al}$-responsive proteins were identified, with 12 of those being upregulated and 5 downregulated. Among the upregulated proteins were $\mathrm{Cu} / \mathrm{Zn} \mathrm{SOD}$, GST, and SAMS, which are the consistently known Al-induced enzymes. Most of these proteins identified are functionally associated with signal transduction, antioxidation, and detoxification. Cysteine synthase (CS), consistently detected in both $\mathrm{Al}$ stress systems, was further validated by Western blot and CS activity assays. Moreover, the metabolic products of CS catalysis, that is, both the total glutathione pool and GSH, were also significantly increased in response to $\mathrm{Al}$ stress. Finally, they suggested that antioxidation and detoxification were ultimately related to sulfur metabolism, particularly to CS, and may play a functional role in rice's adaptation to $\mathrm{Al}$.

From the foregoing examples, it is clear that proteins involved in GSH biosynthesis or the GSH-cycle, such as CS, $\gamma$-ECS, GR, GSTs, DHAR, and Gly I, are differentially regulated under HM-stress. However, such proteomic studies lead to identification of potential protein markers whose changes in abundance can be associated with quantitative changes in some physiological parameters used for the description of genotypes and level of stress tolerance. Importantly, among the different key identified proteins, those related to GSH synthesis or GSH utilizing and regenerating enzymes have a potential role in $\mathrm{HM}$-induced stress response and tolerance. 


\section{Glutathione (GSH), Phytochelatins (PCs), Metallothioneins (MTs), Reactive Oxygen Species (ROS), and Glyoxalase System-Related Gene Expression under Heavy Metal Stress}

Plants adaptation to HM stress is controlled by a wellbalanced, genetically determined signaling system. The identification and characterization of plant genes which control responses to HM stresses is an essential step to elucidate the complex regulatory network, which determines the tolerance of plants to HMs. Although molecules related to HM transport, chelation, and sequestration such as transporters and HM chelators are good candidates for the function of tolerance and accumulation, knowledge about global gene expression remains limited. The molecular genetics of model organisms can lend much to our understanding of the basic components of essential HM metabolism in plants. The constitutive expression of genes may contribute, at least in part, to the molecular adoption of plants that might be useful for plant genetic transformation and phytoremediation.

The expression of GSH metabolic genes was studied by Ortega-Villasante et al. [346] in Cd- and Hg-treated alfalfa seedlings, including the level of GSH, homoglutathione (hGSH), and AsA. The expression of genes involved in their metabolism, that is, ECS, GS, hGS, GR1, GR2, GPX, and $P C S$, was analyzed by semiquantitative RT-PCR. Different exposure periods to $30 \mu \mathrm{M} \mathrm{Cd}$ did not alter the expression of the genes analyzed. However, $30 \mu \mathrm{M} \mathrm{Hg}$ clearly affected the accumulation of some of the transcripts. With the exception of PCS, GPX, and GS genes, which were expressed at similar levels at all periods analyzed, the genes were induced in a transient manner. $\mathrm{Hg}$ produced a clear induction of GR1 (cytosolic) and GR2 (plastidic) genes, with maximum expression being reached at $3 \mathrm{~h}$ after metal supply and decreasing thereafter. Similarly, ECS and $h G S$ genes were expressed transiently, also reaching maximum transcript accumulation after $3 \mathrm{~h}$. Notably, this pattern can be linked to GSH/hGSH depletion. Similarly, induction of the GSH metabolic gene in response to Cd stress was studied in Camellia sinensis (L.) O. Kuntze by Mohanpuria et al. [347]. The transcript levels of GSH biosynthetic and regenerating genes, namely, $\gamma$-ECS, GS, and GR increased in response to $\mathrm{Cd}$ stress. However, the transcript levels of GST did not show any change following Cd treatment. This study in which Cd exposure induced oxidative stress in C. sinensis and upregulated the transcript levels of GSH metabolic genes, except for GST, suggests the role of these enzymes in the protection of plants from a high level of $\mathrm{Cd}$ exposure. Consequently, Arabidopsis thaliana (ecotype Columbia) plants treated with $\mathrm{Cd}$ or $\mathrm{Cu}$ responded by increasing the transcription of genes for GSH synthesis, $\gamma$ ECS and GS, as well as GR. The response was specific for those HMs whose toxicity is thought to be mitigated through PCs and other toxic and nontoxic HMs, which did not alter mRNA levels. JA also activated the same suite of genes, which suggests that it might be involved in the signal transduction pathway for $\mathrm{Cu}$ and $\mathrm{Cd}$ [348].
Lee et al. [337] showed that rice roots subjected to $\mathrm{Cd}$ stress $(100 \mu \mathrm{M}, 24 \mathrm{~h})$ increased GST and APX gene expression. Three GST genes (GSTs: OsGSTU3, OsGSTU4, and OsGSTU12) that belong to the plant-specific tau class were markedly overexpressed in roots following Cd exposure. Ogawa et al. [349] also found strong induction of the OsGST gene (OsGSTU5) in response to Cd stress. GSTs have been reported to be involved in the direct quenching of $\mathrm{Cd}$ ions, forming GSH-Cd complexes [350]. Panda and Matsumoto [351] studied antioxidant gene expression in pea (Pisum sativum L.) root and shoot tissues under $\mathrm{Al}$ stress (10 and $50 \mu \mathrm{M}$ ). GST and CAT gene expression was higher in roots whereas cAPX increased in shoots. The $\mathrm{Cu} / \mathrm{Zn}$ SOD gene showed higher expression after $24 \mathrm{~h}$ whereas MnSOD and FeSOD showed higher expression after 24 and $48 \mathrm{~h}$.

Perennial ryegrass (Lolium perenne L.), widely used in temperate climates, is a turfgrass that enriches $\mathrm{Cd}$. Candidate gene expression in perennial ryegrass to $\mathrm{Cd}$ stress was studied by Luo et al. [352]. Grasses were subjected to three levels of $\mathrm{Cd}(0,0.2$, and $0.5 \mathrm{mM}, 7 \mathrm{~d})$. The Cd stress-induced upregulated expression of FeSOD, MnSOD, Chl Cu/ZnSOD, Cyt $\mathrm{Cu} / \mathrm{ZnSOD}, \mathrm{APX}, \mathrm{GPX}, \mathrm{GR}$, and POD was observed at 4-24 h after treatment. They concluded that genes involved in antioxidant enzymes could play important roles in $\mathrm{Cd}$ tolerance in perennial ryegrass.

Smeets et al. [353] studied the early antioxidative defense mechanisms by applying a range of realistic $\mathrm{Cd}$ concentrations $(5,10,20 \mu \mathrm{M} \mathrm{CdSO}, 24 \mathrm{~h})$ to the root and leaf tissues of Arabidopsis thaliana (Columbia ecotype). Highly coordinated oxidative stress-related defense gene (FeSOD, MnSOD, APX, DHAR, GR, CAT, and GPX) expression was observed at 5 and $10 \mu \mathrm{M} \mathrm{CdSO}$; however, $20 \mu \mathrm{M}$ $\mathrm{CdSO}_{4}$ stress gene expression of some antioxidant enzyme downward to control level was oberved. Importantly, GPX gene expression in leaf tissues showed a continual increase as Cd concentration increased. Transcript abundance of several genes involved in antioxidative defense in root and leaf tissues was observed. The generation of $\mathrm{O}_{2}{ }^{--}$seems to be the main cause of oxidative stress in the roots, whereas in the leaves $\mathrm{H}_{2} \mathrm{O}_{2}$ appears to be an important player. Furthermore, an increased transcript level of LOX, a potential inducer of oxidative stress, suggests a central role of this gene in causing the Cd-related redox imbalance. Their findings suggest that the antioxidative defense system is moderated by the activation of different genes in different organs and cellular compartments.

The identification of genes involved in HM tolerance was studied by Goupil et al. [354] in cultivated tomato (Lycopersicon esculentum $\mathrm{cv}$. VFN-8) plants subjected to $\mathrm{As}(\mathrm{V})$ or $\mathrm{Cr}(\mathrm{VI})$ stress by real-time PCR transcript analysis of genes using RNA isolated from tomato roots or shoots treated for $24 \mathrm{~h}$ with $\mathrm{As}(\mathrm{V})$ or $\mathrm{Cr}(\mathrm{VI})$ at concentrations ranging from 80 to $640 \mu \mathrm{M}$. An increase in Hsp90-1 transcript accumulation was observed due to both of the metallic stress treatments. MT2- and GR1-like transcripts accumulated in tomato roots treated with $\mathrm{As}(\mathrm{V})$ but were only slightly affected by $\mathrm{Cr}(\mathrm{VI})$ treatment. Tomatoes showed phenotypic symptoms of HM toxicity when plants were exposed to $\mathrm{Cr}(\mathrm{VI})$ but not to 
$\mathrm{As}(\mathrm{V})$, indicating that tomatoes are more tolerant to As than Cr.

PCs are synthesized from GSH by the action of the enzyme $\gamma$-glutamylcysteine dipeptidyl transpeptidase, trivially named phytochelatin synthase (PCS). The enzyme is constitutively expressed but may be regulated at transcriptional and translational levels by HMs and metalloids [355]. The relative contribution of PCs and MTs in HM $(\mathrm{Cd}$ or $\mathrm{Cu})$ tolerance was examined in black mangrove, Avicennia germinans. Seedlings were subjected to $\mathrm{Cd}$ and $\mathrm{Cu}$ stress hydroponic conditions and gene expression was evaluated. Importantly, a low concentration of $\mathrm{Cd}$ and $\mathrm{Cu}$ led to a significant increase in AvPCS expression within a short period of metal exposure $(4 \mathrm{~h})$ whereas a sharp increase in $A v M t 2$ expression was observed after $16 \mathrm{~h}$ of metal exposure. This strongly suggested that rapid induction of $A v M t 2$ and $A v P C S$ expression might contribute to $\mathrm{Cd}$ and $\mathrm{Cu}$ detoxification either by sequestering $\mathrm{Cd}$ and/or by directly scavenging deleterious oxygen radicals [356]. Similar results were reported by Akashi et al. [357] and Zhang et al. [358] where Mt2 and PCS genes were shown to act as potent scavengers of hydroxyl radicals in Citrullus lanatus and A. sativum exposed to HMs, respectively.

To discover the genetic factor underlying the mechanism of Al tolerance, Duressa et al. [359] conducted a comprehensive transcriptomic study by using Al-tolerant soybean line (PI 416937) and found that GST and GR transcript increased in response to $\mathrm{Al}$ stress $(10 \mu \mathrm{M} \mathrm{Al})$ indicating that among the various genes involved in transcription activation, stress response, cell metabolism, and signaling, the ROS metabolic genes had a potential role in $\mathrm{Al}$ tolerance in plants. The induction of proteins related to GSH metabolism and its potential implication in As tolerance in rice seedlings was reported by Ahsan et al. [339]. They also studied the expression of CS, GST-omega, and GR genes by Northern blot analysis. Importantly, genes exhibited very similar expression patterns at the mRNA and protein levels. Thus, their results provided additional evidence for correlative expression/accumulation of the identified proteins and gene expression in As-stressed rice roots. Similarly, in our study [276] with pumpkin (Cucurbita maxima L.) seedlings, we found a significant increase in the induction of CmGSTU1, CmGSTU2, and CmGSTU3 transcripts in response to As stress $(0.1 \mathrm{mM}, 6 \mathrm{~h})$. Additionally, in our previous study with pumpkin seedlings, we found an increase in Gly I transcript in response to Cd stress ( $1 \mathrm{mM} \mathrm{Cd}, 24 \mathrm{~h})$. Lin et al. [360] found a significant increase in Gly I transcript in response to $\mathrm{Zn}$ stress (10 and $20 \mathrm{mM} \mathrm{ZnCl}_{2}, 24 \mathrm{~h}$ ). Based on the previous evidence we, therefore, concluded that genes that utilize and regenerate GSH as well as PC- and MT-related genes play a predominant role in $\mathrm{HM}$ stress response and tolerance in plants.

\section{Plant Microbe Interaction and Heavy Metal Tolerance in relation to Glutathione}

The extraordinary genetic and physiological diversity of fungi makes them key components of almost all ecosystems, with a great potential for bioremediation purposes [3, 361, 362]. Arbuscular mycorrhizal (AM) fungi, which are ubiquitous root symbionts, are particularly attractive in this regard. It is becoming increasingly evident that the mutualistic or symbiotic association between plants and fungi significantly contributes to plant growth by improving mineral nutrition and also by protecting plants against a variety of biotic and abiotic stresses, including HM stress $[25,362,363]$. Although biophysical methods do not allow discrimination of HM distribution between fungal and plant cell structures, the fungi obviously direct HM allocation within the roots. Several mechanisms for this allocation can be envisaged [25, 33, 364, 365]: (a) HMs may be bound to the cell wall and may be deposited in the vacuoles of the fungi, (b) HMs may be attached to siderophores and sequestered either into the root apoplasm or into the soil, (c) HMs may be bound to MTs or PCs inside the fungal or plant cells, or (d) HM transporters at the plasmalemma or tonoplast of both partners may catalyse the export of HMs from the cytoplasm. AMF (Glomus intraradices) that colonized Medicago truncatula plants subjected to $\mathrm{Zn}$ stress $\left(\mathrm{ZnSO}_{4}, 100 \mu \mathrm{M}\right)$ showed a sharp transcriptional increase of a GSH-dependent GST gene [366]. Upregulation of ROS metabolic genes indicates that effective fungal HM-tolerance mechanism(s) could provide a pivotal contribution to the increased HM tolerance of mycorrhizal plants. The association of plants with mycorrhizal fungi was found to increase plant fitness under HM stress by utilizing GSH-dependent detoxification mechanisms. However, further investigations may reveal the more subtle regulatory role of AMF fungi on GSH-dependent HM tolerance of plants or other abiotic stresses. A complete understanding of the molecular bases of HM tolerance in this symbiotic system will, thus, also aid the selection of the most effective AM isolates [367] and plantfungus combinations for bioremediation and soil protection [368]. Therefore, detailed mechanisms of AMF-induced HM tolerance in relation to GSH metabolism in plants are still a matter of intensive research.

\section{Transgenic Plants and Heavy Metal Tolerance with reference to Glutathione}

Molecular biology and genetic engineering are being increasingly considered as effective tools for better understanding and improving the phytoremediation capability of plants because several key steps have been identified at the molecular level, through molecular-genetic technologies $[28,70$, 155]. Classic genetic studies demonstrated that many genes are involved in HM uptake, translocation, sequestration, chemical modification, and tolerance. Unless regulatory genes are identified that simultaneously induce many HMrelated genes, it is feasible that more than one gene will need to be upregulated in order to substantially enhance HM phytoremediation capacity. Transfer and/or overexpression of genes responsible for HM uptake, translocation, and sequestration may allow for the production of plants which, depending on the strategy, can be successfully exploited in phytoremediation $[31,70,369-371]$. The overexpression of 
any (combination) of these genes is a possible strategy for genetic engineering. Depending on which phytoremediation application is to be used, the genetic engineering strategy may strive to create plants that accumulate more HMs in harvestable plant parts (phytoextraction) or adsorb more HMs at their root surface (rhizofiltration, phytostabilization).

Cysteine is the precursor molecule for the synthesis of $\mathrm{GSH}$, the predominant nonprotein thiol, which plays an important role in plant stress responses. GSH has been implicated in plant responses to toxic levels of HMs, as it is the precursor for the synthesis of PCs, the thiolate peptides involved in the detoxification of $\mathrm{Cd}$ and other $\mathrm{HMs}$. Stimulation of the synthesis of building blocks for GSH may have been found to increase $\mathrm{Cd}$ tolerance in transgenic plants. Arabidopsis thaliana overexpressing cytosolic Oacetylserine(thiol)lyase gene (OASTL) showed Cd tolerance by increasing bothcysteine and GSH availability [372]. Few research findings showed that transgenic plants overexpressing the GSH synthesis genes, $\gamma$-ECS or GS, showed enhance HM tolerance. Two E. coli genes involved in GSH biosynthesis, GS or $\gamma$-ECS, were constitutively expressed in Brassica juncea [373, 374]. The expression of either GS or $\gamma$-ECS in plant species resulted in higher accumulation of GSH and PCs as well as enhanced tolerance to Cdinduced oxidative stress. Additionally, transgenic poplar hybrid overexpressing a cytosol targeted $\gamma$-ECS gene showed a 3- to 4-fold increase in GSH levels [375]. However, transgenic tobacco overexpressing chloroplast-targeted $\gamma$ ECS contained elevated GSH levels but exhibited lightdependent chlorosis and necrosis [376]. This was attributed to the increased levels of GSSG and a failure of the redox sensing mechanism in chloroplasts of the transgenic plants. Transgenic poplar plants that overexpress $\gamma$-ECS in the cytosol accumulated 2.5-3 times higher Cd than WT plants in young leaves when grown on soil in laboratory conditions [250]. Reisinger et al. [377] showed that B. juncea overexpressing GS or $\gamma$-ECS showed enhanced tolerance to a variety of HMs (particularly As, $\mathrm{Cd}, \mathrm{Zn}$, and $\mathrm{Pb}$ ) due to higher capacity of GSH synthesis as well as PC synthesis. Ivanova et al. [378] found that overexpression of the GSH1 gene in the cytosol led to a 2-fold increase of foliar GSH content and influenced the photosynthetic apparatus at different levels of organisation, that is, leaves, photosynthetic cells, and chloroplasts. Biomass accumulation of WT poplar hybrid (Populus tremula $\times$ Populus alba) decreased in HM-contaminated soil by more than 30 -fold, whereas transformants showed a 2 fold decrease. Thus, poplars overexpressing $\gamma$-ECS in the cytosol were more tolerant to HM stress.

However, Li et al. [379] showed that overexpression of either $\gamma$-ECS or GS in A. thaliana was not sufficient to increase accumulation of $\mathrm{As}$ or $\mathrm{Hg}$ in above-ground tissues, even though the plants were more resistant to these contaminants. Coexpression of two genes, $\gamma$-ECS and GS, showed an increase in the accumulation of $\mathrm{Hg}$ governed by enhanced concentrations of PCs as compared to single gene transformants. Based on their finding, it can be concluded that for the accumulation of some HMs, both GSH and PCs are a prerequisite for higher tolerance. Later on, Pomponi et al. [380] also showed that an increase in Cd tolerance and accumulation in tobacco plants overexpressing AtPCS1 was directly related to GSH availability. Increased tolerance to HM stress by overexpressing PCs synthetic genes has also been widely reported [381-384]. Poplar plants overexpressing the TaPCS1 gene produced more biomass and accumulated more $\mathrm{Pb}$ and $\mathrm{Zn}$ than $\mathrm{WT}$ plants when growing on mined soils [382]. Transgenic tobacco plants overexpressing the Thlaspi caerulescens phytochelatin synthetase gene (TcPCS) enhanced PC production in tobacco. Cd accumulation in the roots and shoots of TcPCS1 transgenic seedlings increased compared to the WT, while Cd translocation from roots to shoots was not affected under $\mathrm{Cd}$ treatment. The roots of the TcPCS1 transgenic tobacco seedlings were significantly longer than those of WT under Cd stress, indicating that TcPCS1 expression might increase $\mathrm{Cd}$ accumulation and tolerance in transgenic tobacco. Importantly, the MDA content in TcPCS1 plants was below that of WT.

Wojas et al. [383] further showed the fundamental role of GSH in transgenic tobacco plants overexpressing the AtPCS1 or CePCS gene. Transgenic plants under moderate stress ( $50 \mu \mathrm{M}$ As) showed increased tolerance and accumulation; however, under a high level $(200 \mu \mathrm{M})$, a reduction of $\gamma$ Glutamylcysteine and GSH was observed and PC level decreased in both leaf and root tissues indicating that HM tolerance depends on both the GSH content and the concentration of HMs. Importantly, transgenic Arabidopsis plants overexpressing the AtPCS1 gene showed high resistance to As but hypersensitivity to Cd [385], and critical analysis of different transgenic lines with various expression levels of PCS transgene expression has revealed that moderate expression of the transgene is desirable. Coexpression of the AsPCS1 and GSH1 genes in Arabidopsis thaliana (Columbia ecotype) showed better $\mathrm{Cd}$ and As tolerance as indicated by longer roots. Single-gene transgenic lines had higher tolerance to and accumulated more $\mathrm{Cd}$ and As than WT. Importantly, dual-gene transformants exhibited significantly higher tolerance and accumulated more $\mathrm{Cd}$ than single-gene transgenic lines. Simultaneous overexpression of AsPCS1 and GSH1 led to elevated total PC production in transgenic Arabidopsis. These results indicate that coordinated induction of both GSH and PCs synthesis genes represents a highly promising new tool for phytoremediation [386]. Additionally, transgenic plants overexpressing the human MT-II gene in tobacco and oilseed rape (Brassica napus) enhanced Cd tolerance and Cd accumulation or modified $\mathrm{Cd}$ distribution. Growth of these transgenic seedlings was unaffected up to $100 \mu \mathrm{mol} / \mathrm{L} \mathrm{Cd} \mathrm{[387]} \mathrm{whereas} \mathrm{control}$ seedlings showed severe inhibition of root and shoot growth and leaf chlorosis. Sekhar et al. [388] showed that transgenic Arabidopsis plants overexpressing the pigeon pea type I MT gene (CcMT1) imparted increased $\mathrm{Cu}$ and $\mathrm{Cd}$ tolerance as evidence by higher plant biomass and Chl content besides profuse root growth compared to control plants. Transgenic plants expressing CcMT1 accumulated more $\mathrm{Cu}$ and $\mathrm{Cd}$ ions in roots than in shoots. However, no differences were observed in the expression levels of $\mathrm{Cu}$ (AtZIP2) and Cd (AtNRAMP) transporter genes of CcMT1transgenics and control plants under both stressed and 
unstressed conditions. The overall results amply indicate that CcMT1 contributes to the detoxification of HM ions, thereby providing marked tolerance against metal stresses.

The involvement of the GHS-dependent glyoxalase pathway in HM tolerance was also reported by Singla-Pareek et al. [17]. Transgenic tobacco plants overexpressing both the Gly I and Gly II genes showed restricted MG accumulation and less lipid peroxidation at a high $\mathrm{Zn}$ concentration $\left(5 \mathrm{mM} \mathrm{ZnCl}_{2}\right.$ ) and were able to survive, sustain growth, and flower and set normal viable seeds without any reduction in yield. The most striking observation was that double transgenic plants performed better than either the singlegene transformants as initially observed under salt stress. The endogenous ion content reflected that roots are the major sink for excess $\mathrm{Zn}$ accumulation, with a negligible amount in the seeds of transgenic plants. The use of the GSH biosynthetic inhibitor (BSO) revealed that higher PCs synthesizing capability and maintenance of the GSH/GSSG redox ratio in transgenic plants provided tolerance to $\mathrm{Zn}$ stress $[17,30]$. They concluded that maintenance of glutathione homeostasis in transgenic plants was the possible mechanism behind tolerance to Zn toxicity.

The aforementioned results clearly indicate that use of transgenic plants overexpressing cysteine, GSH, PC, MT, or glyoxalase pathway-related genes showed substantial tolerance against HM stress. Therefore, transgenic approaches can be effectively used for the clean up of HM pollution and as a promising approach for phytoremediation.

\section{Conclusion and Future Perspective}

The numerous deleterious health effect upon exposure to toxic HMs in the environment is a matter of serious concern and a global issue. Therefore, molecular and cellular adaptation of plant cells in response to HM stress appears to be necessary to improve plant HM tolerance that ultimately reduces the chance of entering HM into the food chain. Plant HM tolerance is a multigenic traits and controlled at multiple levels. A wealth of recent studies demonstrated that plants protect themselves from HM toxicity, besides other mechanisms, through an elevated level of nonenzymatic and enzymatic components of antioxidant and glyoxalase defense systems $[2,3,8,11,13,17,19,31]$. Significant progress has been achieved in regards to HM toxicity and tolerance and different key components ensuring HM tolerance in plants have been identified; however, many key questions remain unanswered. Additionally, different HMs appear to have different mechanisms to elicit toxicity symptoms and plants employ different mechanisms as resistant reactions to particular HMs. Likewise, the reaction response and tolerance mechanisms are also different when a plant is grown under excess HMs in hydroponic or actual field conditions. Therefore, it is very difficult to hypothesize a common resistance mechanism against all HMs and metalloids. Importantly, among the various nonenzymatic antioxidant molecules that plants usually utilize against HM stress, GSH is the most vital one. Besides detoxification of ROS directly or detoxification of ROS and MG through antioxidative and glyoxalase systems, GSH also plays additional roles, including
HM uptake, transport, and sequestration and formation of specific metal-binding ligands such as PCs. The reviewed literature confirms the central role of GSH metabolism in $\mathrm{HM}$ tolerance in plants as evidenced by proteomic, genomic, and transgenic studies over a range of plant species.

Although significant progress has been made in different aspects of GSH and its related enzymes (GST, GPX, DHAR, GR, Gly I, and Gly II) in HM-induced ROS and MG metabolism and HM chelation in a large number of plant species, most of the studies were conducted under laboratory conditions. Therefore, to get more realistic information we need to move from the laboratory to actual field conditions by using commercial plant species at various phases of plant growth. Likewise, the subcellular distribution of GSH and its related enzymes in model plant species may give deeper insight into compartment-specific HMs and metalloid-accrued reactions and resistance mechanisms and ROS and MG metabolism and other fundamental plant physiological process $[13,14]$. Mutants, hyperaccumulators and naturally tolerant plant species give us important cues about a plant's response to HM stress, HM tolerance and metal-induced ROS and MG metabolism. Recently, a few genes responsible for acquired tolerance, to HM stress have already been identified. Ectopic expression of these genes related to GSH and its metabolizing enzymes in different species plant showed promising results. However, very few transgenic plants showed resistant reactions over a range of HMs [389, 390]. The increasing identification and study of the remarkable natural variation in the capacity of plants to accumulate and tolerate HMs is and will continue to provide a wealth of information. Therefore, concerted efforts by various research domains will further increase our understanding of the fundamental mechanisms involved in hyperaccumulation processes that naturally occur in metal hyperaccumulating plants. This should allow us to develop plants that are more ideally suited for phytoremediation of HM- contaminated soils [391].

\section{Acknowledgments}

The authers apologize to their colleagues whose primary work could not be cited due to space constraints. Financial grant from Japan government (Monbukagakusho) is gratefully acknowledged.

\section{References}

[1] G. DalCorso, S. Farinati, S. Maistri, and A. Furini, "How plants cope with cadmium: staking all on metabolism and gene expression," Journal of Integrative Plant Biology, vol. 50, no. 10, pp. 1268-1280, 2008.

[2] M. A. Hossain, M. Z. Hossain, and M. Fujita, "Stress-induced changes of methylglyoxal level and glyoxalase I activity in pumpkin seedlings and cDNA cloning of glyoxalase I gene," Australian Journal of Crop Science, vol. 3, no. 2, pp. 53-64, 2009.

[3] M. A. Hossain, M. Hasanuzzaman, and M. Fujita, "Up-regulation of antioxidant and glyoxalase systems by exogenous glycinebetaine and proline in mung bean confer tolerance to 
cadmium stress," Physiology and Molecular Biology of Plants, vol. 16, no. 3, pp. 259-272, 2010.

[4] N. Rascio and F. Navari-Izzo, "Heavy metal hyperaccumulating plants: how and why do they do it? And what makes them so interesting?" Plant Science, vol. 180, no. 2, pp. 169-181, 2011.

[5] F. Villiers, C. Ducruix, V. Hugouvieux et al., "Investigating the plant response to cadmium exposure by proteomic and metabolomic approaches," Proteomics, vol. 11, no. 9, pp. 1650-1663, 2011.

[6] G. Ramesh, Cloning and characterization of metallothionein genes of ectomycorrhizal fungus Hebeloma cylindrosporum, Ph.D. thesis, Thapar University, Punjab, India, 2008.

[7] P. Sharma and R. S. Dubey, "Involvement of oxidative stress and role of antioxidative defense system in growing rice seedlings exposed to toxic concentrations of aluminum," Plant Cell Reports, vol. 26, no. 11, pp. 2027-2038, 2007.

[8] S. S. Sharma and K. J. Dietz, "The relationship between metal toxicity and cellular redox imbalance," Trends in Plant Science, vol. 14, no. 1, pp. 43-50, 2009.

[9] M. A. Hossain and M. Fujita, "Purification of glyoxalase I from onion bulbs and molecular cloning of its cDNA," Bioscience, Biotechnology and Biochemistry, vol. 73, no. 9, pp. 2007-2013, 2009.

[10] M. A. Hossain and M. Fujita, "Regulatory role of components of ascorbate-glutathione (AsA-GSH) pathway in plant tolerance to oxidative stress," in Oxidative Stress in Plants: Causes, Consequences and Tolerance, N. A. Anjum, S. Umar, and A. Ahmed, Eds., IK International Publishing House Pvt. Ltd., New Delhi, India, 2011.

[11] M. A. Hossain, M. D. Hossain, M. M. Rohman, J. A. T. da Silva, and M. Fujita, "Onion major compounds (flavonoids, organosulfurs) and highly expressed glutathione-related enzymes: possible physiological interaction, gene cloning and abiotic stress response," in Onion Consumption and Health, C. B. Aguirre and L. M. Jaramillo, Eds., Nova Science Publishers, New York, NY, USA, 2012.

[12] Y. F. Tan, N. O’Toole, N. L. Taylor, and A. Harvey Millar, "Divalent metal ions in plant mitochondria and their role in interactions with proteins and oxidative stress-induced damage to respiratory function," Plant Physiology, vol. 152, no. 2, pp. 747-761, 2010.

[13] R. S. Dubey, "Metal toxicity, oxidative stress and antioxidative defense system in plants," in Reactive Oxygen Species and Antioxidants in Higher Plants, S. D. Gupta, Ed., pp. 177-203, CRC Press, Boca Raton, Fla, USA, 2011.

[14] N. A. Anjum, I. Ahmad, I. Mohmood et al., "Modulation of glutathione and its related enzymes in plants' responses to toxic metals and metalloids-A review," Environmental and Experimental Botany, vol. 75, pp. 307-324, 2012.

[15] S. K. Yadav, S. L. Singla-Pareek, M. Ray, M. K. Reddy, and S. K. Sopory, "Methylglyoxal levels in plants under salinity stress are dependent on glyoxalase I and glutathione," Biochemical and Biophysical Research Communications, vol. 337, no. 1, pp. 61-67, 2005.

[16] S. K. Yadav, S. L. Singla-Pareek, M. K. Reddy, and S. K. Sopory, "Transgenic tobacco plants overexpressing glyoxalase enzymes resist an increase in methylglyoxal and maintain higher reduced glutathione levels under salinity stress," FEBS Letters, vol. 579, no. 27, pp. 6265-6271, 2005.

[17] S. L. Singla-Pareek, S. K. Yadav, A. Pareek, M. K. Reddy, and S. K. Sopory, "Transgenic tobacco overexpressing glyoxalase pathway enzymes grow and set viable seeds in zinc-spiked soils," Plant Physiology, vol. 140, no. 2, pp. 613-623, 2006.
[18] M. A. Hoque, M. Uraji, M. N. Akhter Banu, I. C. Mori, Y. Nakamura, and Y. Murata, "The effects of methylglyoxal on glutathione S-transferase from Nicotiana tabacum," Bioscience, Biotechnology and Biochemistry, vol. 74, no. 10, pp. 2124-2126, 2010.

[19] M. A. Hossain, J. A. T. da Silva, and M. Fujita, "Glyoxalase system and reactive oxygen species detoxification system in plant abiotic stress response and tolerance: an intimate relationship," in Abiotic Stress in Plants-Mechanisms and Adaptations, A. K. Shanker and B. Venkateswarlu, Eds., pp. 235266, INTECH-Open Access Publisher, Rijeka, Croatia, 2011.

[20] R. Saito, H. Yamamoto, A. Makino, T. Sugimoto, and C. Miyake, "Methylglyoxal functions as Hill oxidant and stimulates the photoreductin of $\mathrm{O}_{2}$ at photosystem I: a symptom of plant diabetes," Plant, Cell and Environment, vol. 34, no. 9, pp. 1454-1464, 2011.

[21] F. Navari-Izzo, "Thylakoid-bound and stromal antioxidative enzymes in wheat treated with excess copper," Physiologia Plantarum, vol. 104, no. 4, pp. 630-638, 1998.

[22] M. C. Romero-Puertas, J. M. Palma, M. Gómez, L. A. Del Río, and L. M. Sandalio, "Cadmium causes the oxidative modification of proteins in pea plants," Plant, Cell and Environment, vol. 25, no. 5, pp. 677-686, 2002.

[23] D. Barconi, G. Bernardini, and A. Santucci, "Linking protein oxidation to environmental pollutants: redox proteome approaches," Journal of Proteomics, vol. 74, no. 11, pp. 23242337, 2011.

[24] G. Dalcorso, S. Farinati, and A. Furini, "Regulatory networks of cadmium stress in plants," Plant Signaling and Behavior, vol. 5 , no. 6 , pp. $1-5,2010$.

[25] C. Leyval, K. Turnau, and K. Haselwandter, "Effect of heavy metal pollution on mycorrhizal colonization and function: physiological, ecological and applied aspects," Mycorrhiza, vol. 7, no. 3, pp. 139-153, 1997.

[26] C. S. Cobbett, "Phytochelatins and their roles in heavy metal detoxification," Plant Physiology, vol. 123, no. 3, pp. 825-832, 2000.

[27] J. L. Hall, "Cellular mechanisms for heavy metal detoxification and tolerance," Journal of Experimental Botany, vol. 53, no. 366, pp. 1-11, 2002.

[28] X. E. Yang, X. F. Jin, Y. Feng, and E. Islam, "Molecular mechanisms and genetic basis of heavy metal tolerance/ hyperaccumulation in plants," Journal of Integrative Plant Biology, vol. 47, no. 9, pp. 1025-1035, 2005.

[29] S. Clemens, "Toxic metal accumulation, responses to exposure and mechanisms of tolerance in plants," Biochimie, vol. 88, no. 11, pp. 1707-1719, 2006.

[30] S. K. Yadav, "Heavy metals toxicity in plants: an overview on the role of glutathione and phytochelatins in heavy metal stress tolerance of plants," South African Journal of Botany, vol. 76, no. 2, pp. 167-179, 2010.

[31] C. S. Seth, T. Remans, E. Keunen et al., "Phytoextraction of toxic metals: a central role for glutathione," Plant, Cell and Environment, vol. 35, no. 2, pp. 334-346, 2012.

[32] K. J. Dietz, M. Bair, and U. Krämer, "Free radical and reactive oxygen species as mediators of heavy metal toxicity in plants," in Heavy Metal Stress in Plants from Molecules to Ecosystems, M. N. V. Prasad and J. Hagemeyer, Eds., pp. 73-79, SpingerVerlag, Berlin, Germany, 1999.

[33] A. Schützendübel and A. Polle, "Plant responses to abiotic stresses: heavy metal-induced oxidative stress and protection by mycorrhization," Journal of Experimental Botany, vol. 53, no. 372, pp. 1351-1365, 2002. 
[34] E. Nieboer and D. H. S. Richardson, "The replacement of the nondescript term \%heavy metals' by a biologically and chemically significant classification of metal ions," Environmental Pollution Series B: Chemical and Physical, vol. 1, no. 1, pp. 326, 1980 .

[35] G. F. Wildner and J. Henkel, "The effect of divalent metal ions on the activity of $\mathrm{Mg}^{2+}$ depleted ribulose-1,5-bisphosphate oxygenase," Planta, vol. 146, no. 2, pp. 223-228, 1979.

[36] F. Van Assche and H. Clijsters, "Inhibition of photosynthesis in Phaseolus vulgaris by treatment with toxic concentration of zinc: effect on ribulose-1,5-bisphosphate carboxylase/oxygenase," Journal of Plant Physiology, vol. 125, no. 3-4, pp. 355-360, 1986.

[37] A. Rivetta, N. Negrini, and M. Cocucci, "Involvement of $\mathrm{Ca}^{2+}$-calmodulin in $\mathrm{Cd}^{2+}$ toxicity during the early phases of radish (Raphanus sativus L.) seed germination," Plant, Cell and Environment, vol. 20, no. 5, pp. 600-608, 1997.

[38] A. A. Meharg, "The role of plasmalemma in metal tolerance in angiosperm," Physiologia Plantarum, vol. 88, no. 1, pp. 191-198, 1993.

[39] M. A. Hossain and M. Fujita, "Evidence for a role of exogenous glycinebetaine and proline in antioxidant defense and methylglyoxal detoxification systems in mung bean seedlings under salt stress," Physiology and Molecular Biology of Plants, vol. 16, no. 1, pp. 19-29, 2010.

[40] M. A. Hossain, M. Hasanuzzaman, and M. Fujita, "Coordinate induction of antioxidant defense and glyoxalase system by exogenous proline and glycinebetaine is correlated with salt tolerance in mung bean," Frontiers of Agriculture in China, vol. 5, no. 1, pp. 1-14, 2011.

[41] C. D. Foy, R. L. Chaney, and M. C. White, "Physiology of metal toxicity in plants," Annual Review of Plant Physiology and Plant Molecular Biology, vol. 29, pp. 511-566, 1978.

[42] L. M. Sandalio, H. C. Dalurzo, M. Gómez, M. C. RomeroPuertas, and L. A. Del Río, "Cadmium-induced changes in the growth and oxidative metabolism of pea plants," Journal of Experimental Botany, vol. 52, no. 364, pp. 2115-2126, 2001.

[43] P. Carrier, A. Baryla, and M. Havaux, "Cadmium distribution and microlocalization in oilseed rape (Brassica napus) after long-term growth on cadmium-contaminated soil," Planta, vol. 216, no. 6, pp. 939-950, 2003.

[44] E. Gamalero, G. Lingua, G. Berta, and B. R. Glick, "Beneficial role of plant growth promoting bacteria and arbuscular mycorrhizal fungi on plant responses to heavy metal stress," Canadian Journal of Microbiology, vol. 55, no. 5, pp. 501-514, 2009.

[45] F. Fodor, "Physiological responses of vascular plants to heavy metals," in Physiology and Biochemistry of Metal Toxicity and Tolerance in Plants, M. N. V. Prasad and K. Strzalka, Eds., pp. 149-177, Kluwer Academic, Dortrech, UK, 2002.

[46] C. Poschenrieder and J. Barceló, "Water relations in heavy metal stressed plants," in Heavy Metal Stress in Plants, M. N. V. Prasad, Ed., pp. 249-270, Springer, Berlin, Germany, 3rd edition, 2004.

[47] M. P. Benavides, S. M. Gallego, and M. L. Tomaro, "Cadmium toxicity in plants," Brazilian Journal of Plant Physiology, vol. 17 , no. 1, pp. 21-34, 2005.

[48] Y. T. Hsu and C. H. Kao, "Cadmium toxicity is reduced by nitric oxide in rice leaves," Plant Growth Regulation, vol. 42, no. 3, pp. 227-238, 2004.

[49] M. Backor, P. Vaczi, M. Bartak, J. Budova, and A. Dzubaj, "Uptake, photosynthetic characteristics and membrane lipid peroxidation levels in the lichen photobiont Trebouxia erici exposed to copper and cadmium," Bryologist, vol. 110, no. 1, pp. 100-107, 2007.

[50] B. Boddi, A. R. Oravecz, and E. Lehoczki, "Effect of cadmium on organization and photoreduction of protochlorophyllide in dark-grown leaves and etioplast inner membrane preparations of wheat," Photosynthetica, vol. 31, no. 3, pp. 411-420, 1995.

[51] K. Shakya, M. K. Chettri, and T. Sawidis, "Impact of heavy metals (copper, zinc, and lead) on the chlorophyll content of some mosses," Archives of Environmental Contamination and Toxicology, vol. 54, no. 3, pp. 412-421, 2008.

[52] L. Perfus-Barbeoch, N. Leonhardt, A. Vavasseur, and C. Forestier, "Heavy metal toxicity: cadmium permeates through calcium channels and disturbs the plant water status," Plant Journal, vol. 32, no. 4, pp. 539-548, 2002.

[53] F. Vinit-Dunand, D. Epron, B. Alaoui-Sossé, and P. M. Badot, "Effects of copper on growth and on photosynthesis of mature and expanding leaves in cucumber plants," Plant Science, vol. 163, no. 1, pp. 53-58, 2002.

[54] A. Llamas, C. I. Ullrich, and A. Sanz, " $\mathrm{Cd}^{2+}$ effects on transmembrane electrical potential difference, respiration and membrane permeability of rice (Oryza sativa L) roots," Plant and Soil, vol. 219, no. 1-2, pp. 21-28, 2000.

[55] A. Bhushan Jha and R. Shanker Dubey, "Arsenic exposure alters activity behaviour of key nitrogen assimilatory enzymes in growing rice plants," Plant Growth Regulation, vol. 43, no. 3, pp. 259-268, 2004.

[56] P. Sharma and R. S. Dubey, "Modulation of nitrate reductase activity in rice seedlings under aluminium toxicity and water stress: role of osmolytes as enzyme protectant," Journal of Plant Physiology, vol. 162, no. 8, pp. 854-864, 2005.

[57] R. Maheshwari and R. S. Dubey, "Nickel toxicity inhibits ribonuclease and protease activities in rice seedlings: protective effects of proline," Plant Growth Regulation, vol. 51, no. 3, pp. 231-243, 2007.

[58] K. S. Kasprzak, "Possible role of oxidative damage in metalinduced carcinogenesis," Cancer Investigation, vol. 13, no. 4, pp. 411-430, 1995.

[59] A. Fusconi, O. Repetto, E. Bona et al., "Effects of cadmium on meristem activity and nucleus ploidy in roots of Pisum sativum L. cv. Frisson seedlings," Environmental and Experimental Botany, vol. 58, no. 1-3, pp. 253-260, 2006.

[60] W. H. O. Ernst, G. J. Krauss, J. A. C. Verkleij, and D. Wesenberg, "Interaction of heavy metals with the sulphur metabolism in angiosperms from an ecological point of view," Plant, Cell and Environment, vol. 31, no. 1, pp. 123143, 2008.

[61] J. Deikman, "Molecular mechanisms of ethylene regulation of gene transcription," Physiologia Plantarum, vol. 100, no. 3 , pp. 561-566, 1997.

[62] W. Maksymiec, "Effect of copper on cellular processes in higher plants," Photosynthetica, vol. 34, no. 3, pp. 321-342, 1997.

[63] A. J. Enyedi, N. Yalpani, P. Silverman, and I. Raskin, "Signal molecules in systemic plant resistance to pathogens and pests," Cell, vol. 70, no. 6, pp. 879-886, 1992.

[64] U. H. Cho and N. H. Seo, "Oxidative stress in Arabidopsis thaliana exposed to cadmium is due to hydrogen peroxide accumulation," Plant Science, vol. 168, no. 1, pp. 113-120, 2005.

[65] E. Skórzyńska-Polit, B. Pawlikowska-Pawlęga, E. Szczuka, M. Drążkiewicz, and Z. Krupa, "The activity and localization of lipoxygenases in Arabidopsis thaliana under cadmium and 
copper stresses," Plant Growth Regulation, vol. 48, no. 1, pp. 29-39, 2006.

[66] Y. Zhen, J. L. Qi, S. S. Wang et al., "Comparative proteome analysis of differentially expressed proteins induced by $\mathrm{Al}$ toxicity in soybean," Physiologia Plantarum, vol. 131, no. 4, pp. 542-554, 2007.

[67] L. Zhao, Y.-L. Sun, and S.-X. Cui, "Cd-induced changes in leaf proteome of the hyperaccumulator plant Phytolacca americana," Chemosphere, vol. 85, no. 1, pp. 56-66, 2011.

[68] R. L. Sun, Q. X. Zhou, F. H. Sun, and C. X. Jin, "Antioxidative defense and proline/phytochelatin accumulation in a newly discovered Cd-hyperaccumulator, Solanum nigrum L," Environmental and Experimental Botany, vol. 60, no. 3, pp. 468476, 2007.

[69] C. Jonak, H. Nakagami, and H. Hirt, "Heavy metal stress. Activation of distinct mitogen-activated protein kinase pathways by copper and cadmium," Plant Physiology, vol. 136, no. 2, pp. 3276-3283, 2004.

[70] S. Clemens, M. G. Palmgren, and U. Krämer, "A long way ahead: understanding and engineering plant metal accumulation," Trends in Plant Science, vol. 7, no. 7, pp. 309-315, 2002.

[71] A. A. Meharg, "Integrated tolerance mechanisms: constitutive and adaptive plant responses to elevated metal concentrations in the environment," Plant, Cell and Environment, vol. 17, no. 9, pp. 989-993, 1994.

[72] L. Sanità Di Toppi and R. Gabbrielli, "Response to cadmium in higher plants," Environmental and Experimental Botany, vol. 41, no. 2, pp. 105-130, 1999.

[73] X. F. Zhu, C. Zheng, Y. T. Hu et al., "Cadmium-induced oxalate secretion from root apex is associated with cadmium exclusion and resistance in Lycopersicon esulentum," Plant, Cell and Environment, vol. 34, no. 7, pp. 1055-1064, 2011.

[74] J. M. Bubb and J. N. Lester, "The impact of heavy metals on lowland rivers and the implications for man and the environment," Science of the Total Environment, vol. 100, pp. 207-233, 1991.

[75] D. M. Pellet, D. L. Grunes, and L. V. Kochian, "Organic acid exudation as an aluminum-tolerance mechanism in maize (Zea mays L.)," Planta, vol. 196, no. 4, pp. 788-795, 1995.

[76] A. P. Pinto, I. Simões, and A. M. Mota, "Cadmium impact on root exudates of sorghum and maize plants: a speciation study," Journal of Plant Nutrition, vol. 31, no. 10, pp. 17461755, 2008.

[77] E. Delhaize, P. R. Ryan, and R. J. Randall, "Aluminum tolerance in wheat (Triticum aestivum L.). II.Aluminumstimulated excretion of malic acid from root apices," Plant Physiology, vol. 103, no. 3, pp. 695-702, 1993.

[78] J. W. Huang, D. M. Pellet, L. A. Papernik, and L. V. Kochian, "Aluminum interactions with voltage-dependent calcium transport in plasma membrane vesicles isolated from roots of aluminum-sensitive and -resistant wheat cultivars," Plant Physiology, vol. 110, no. 2, pp. 561-569, 1996.

[79] C. C. Chen, J. B. Dixon, and F. T. Turner, "Iron coatings on rice roots: morphology and models of development," Soil Science Society of America Journal, vol. 44, pp. 1113-1119, 1980.

[80] H. Liu, J. Zhang, P. Christie, and F. Zhang, "Influence of iron plaque on uptake and accumulation of $\mathrm{Cd}$ by rice (Oryza sativa L.) seedlings grown in soil," Science of the Total Environment, vol. 394, no. 2-3, pp. 361-368, 2008.

[81] N. Smirnoff and G. R. Stewart, "Nitrogen assimilation and zinc toxicity to zinc-tolerant and non-tolerant clones of
Deschampsia cespitosa (L.) beauv," New Phytologist, vol. 107, no. 4, pp. 671-680, 1987.

[82] H. Harmens, N. G. C. P. B. Gusmão, P. R. D. Hartog, J. A. C. Verkeij, and W. H. O. Ernst, "Uptake and transport of zinc in zinc-sensitive and zinc-tolerant Silene vulgaris," Journal of Plant Physiology, vol. 141, no. 3, pp. 309-315, 1993.

[83] K. R. Tice, D. R. Parker, and D. A. DeMason, "Operationally defined apoplastic and symplastic aluminum fractions in root tips of aluminum-intoxicated wheat," Plant Physiology, vol. 100, no. 1, pp. 309-318, 1992.

[84] K. Iwasaki, K. Sakurai, and E. Takahashi, "Copper binding by the root cell walls of Italian ryegrass and red clover," Soil Science and Plant Nutrition, vol. 36, no. 3, pp. 431-439, 1990.

[85] W. J. Horst and H. Marschner, "Effect of excessive manganese supply on uptake and translocation of calcium in bean plants (Phaseolus vulgaris L.)," Zeitschrift fur Planzenphysiologie, vol. 87, no. 2-3, pp. 137-148, 1978.

[86] A. Masion and P. M. Bertsch, "Aluminium speciation in the presence of wheat root cell walls: a wet chemical study," Plant, Cell and Environment, vol. 20, no. 4, pp. 504-512, 1997.

[87] J. A. Qureshi, D. A. Thurman, K. Hardwick, and H. A. Collin, "Uptake and accumulation of zinc, lead and copper in zinc and lead tolerant Anthoxanthum odoratum L", New Phytologist, vol. 100, no. 3, pp. 429-434, 1985.

[88] D. M. Wheeler and I. L. Power, "Comparison of plant uptake and plant toxicity of various ions in wheat," Plant and Soil, vol. 172, no. 2, pp. 167-173, 1995.

[89] S. J. Zheng, J. F. Ma, and H. Matsumoto, "High aluminum resistance in buckwheat: I. Al-induced specific secretion of oxalic acid from root tips," Plant Physiology, vol. 117, no. 3, pp. 745-751, 1998.

[90] W. J. Horst, "Factors responsible for genotypic manganese tolerance in cowpea (Vigna unguiculata)," Plant and Soil, vol. 72, no. 2-3, pp. 213-218, 1983.

[91] S. Clemens, "Molecular mechanisms of plant metal tolerance and homeostasis," Planta, vol. 212, no. 4, pp. 475-486, 2001.

[92] A. Brookes, J. C. Collins, and D. A. Thurman, "The mechanism of zinc tolerance in grasses," Journal of Plant Nutrition, vol. 3, no. 1-4, pp. 695-705, 1981.

[93] M. Lee, K. Lee, J. Lee, E. W. Noh, and Y. Lee, "AtPDR12 contributes to lead resistance in Arabidopsis," Plant Physiology, vol. 138, no. 2, pp. 827-836, 2005.

[94] H. C. Chiang, J. C. Lo, and K. C. Yeh, "Genes associated with heavy metal tolerance and accumulation in $\mathrm{Zn} / \mathrm{Cd}$ hyperaccumulator Arabidopsis halleri: a genomic survey with cDNA microarray," Environmental Science and Technology, vol. 40, no. 21, pp. 6792-6798, 2006.

[95] U. Krämer, I. Talke, and M. Hanikenne, "Transition metal transport," Federation of European Biochemical Societies Letters, vol. 581, no. 12, pp. 2263-2272, 2007.

[96] W. E. Rauser, "Structure and function of metal chelators produced by plants: the case for organic acids, amino acids, phytin, and metallothioneins," Cell Biochemistry and Biophysics, vol. 31, no. 1, pp. 19-48, 1999.

[97] A. Brune, W. Urbach, and K. J. Dietz, "Compartmentation and transport of zinc in barley primary leaves as basic mechanisms involved in zinc tolerance," Plant, Cell and Environment, vol. 17, no. 2, pp. 153-162, 1994.

[98] R. Vögeli-Lange and G. J. Wagner, "Subcellular localization of cadmium and cadmium-binding peptides in tobacco leaves: implication of a transport function for cadmium-binding peptides," Plant Physiology, vol. 92, no. 4, pp. 1086-1093, 1990. 
[99] J. Wang, B. P. Evangelou, M. T. Nielsen, and G. J. Wagner, "Computer, simulated evaluation of possible mechanisms for sequestering metal ion activity in plant vacuoles: II. Zinc," Plant Physiology, vol. 99, no. 2, pp. 621-626, 1992.

[100] J. Wang, B. P. Evangelou, M. T. Nielsen, and G. J. Wagner, "Computer-simulated evaluation of possible mechanisms for quenching heavy metal ion activity in plant vacuoles: I. Cadmium," Plant Physiology, vol. 97, no. 3, pp. 1154-1160, 1991.

[101] M. H. Zenk, "Heavy metal detoxification in higher plants - A review," Gene, vol. 179, no. 1, pp. 21-30, 1996.

[102] E. Grill, E. L. Winnacker, and M. H. Zenk, "Phytochelatins, a class of heavy-metal-binding peptides from plants, are functionally analogous to metallothioneins," Proceedings of the National Academy of Sciences of the United States of America, vol. 84, no. 2, pp. 439-443, 1987.

[103] E. Grill, S. Loffler, E. L. Winnacke, and M. H. Zenk, "Phytochelatins, the heavy-metal-binding peptides of plants, are synthesized from glutathione by a specific $\gamma$-glutamylcysteine dipeptidyl transpeptidase (phytochelatin synthase)," Proceeding of the National Academy of Science of the United States of America, vol. 86, no. 18, pp. 6838-6842, 1989.

[104] D. G. Mendoza-Cózatl, E. Butko, F. Springer et al., "Identification of high levels of phytochelatins, glutathione and cadmium in the phloem sap of Brassica napus. A role for thiol-peptides in the long-distance transport of cadmium and the effect of cadmium on iron translocation," Plant Journal, vol. 54, no. 2, pp. 249-259, 2008.

[105] M. Fujita, "The presence of two Cd-binding components in the roots of water hyacinth cultivated in a $\mathrm{Cd}^{2+}$-containing medium," Plant Cell Physiology, vol. 26, no. 2, pp. 295-300, 1985.

[106] M. Fujita and T. Kawanishi, "Purificatin and characterization of a Cd-binding complexes from the root tissues of various higher plants cultivated in $\mathrm{Cd}^{2+}$-containing medium," Plant and Cell Physiology, vol. 27, no. 7, pp. 1317-1325, 1986.

[107] S. Iglesia-Turiño, A. Febrero, O. Jauregui, C. Caldelas, J. L. Araus, and J. Bort, "Detection and quantification of unbound phytochelatin 2 in plant extracts of Brassica napus grown with different levels of mercury," Plant Physiology, vol. 142, no. 2, pp. 742-749, 2006.

[108] E. Grill, J. Thumann, E. L. Winnacker, and M. H. Zenk, "Induction of heavy-metal binding phytochelatins by inoculation of cell cultures in standard media," Plant Cell Reports, vol. 7, no. 6, pp. 375-378, 1988.

[109] J. Thumann, E. Grill, E. L. Winnacker, and M. H. Zenk, "Reactivation of metal-requiring apoenzymes by phytochelatin-metal complexes," FEBS Letters, vol. 284, no. 1, pp. 66-69, 1991.

[110] I. Nouairi, W. Ben Ammar, N. Ben Youssef, D. D. Ben Miled, M. H. Ghorbal, and M. Zarrouk, "Antioxidant defense system in leaves of Indian mustard (Brassica juncea) and rape (Brassica napus) under cadmium stress," Acta Physiologiae Plantarum, vol. 31, no. 2, pp. 237-247, 2009.

[111] H. Zhang, W. Xu, J. Guo, Z. He, and M. Ma, "Coordinated responses of phytochelatins and metallothioneins to heavy metals in garlic seedlings," Plant Science, vol. 169, no. 6, pp. 1059-1065, 2005.

[112] N. Tsuji, N. Hirayanagi, M. Okada et al., "Enhancement of tolerance to heavy metals and oxidative stress in Dunaliella tertiolecta by $\mathrm{Zn}$-induced phytochelatin synthesis," Biochemical and Biophysical Research Communications, vol. 293, no. 1, pp. 653-659, 2002.
[113] U. Krämer, J. D. Cotter-Howells, J. M. Charnock, A. J. M. Baker, and J. A. C. Smith, "Free histidine as a metal chelator in plants that accumulate nickel," Nature, vol. 379, no. 6566, pp. 635-638, 1996.

[114] Z. G. Shen, F. J. Zhao, and S. P. McGrath, "Uptake and transport of zinc in the hyperaccumulator Thlaspi caerulescens and the non-hyperaccumulator Thlaspi ochroleucum," Plant, Cell and Environment, vol. 20, no. 7, pp. 898-906, 1997.

[115] I. Leopold, D. Günther, J. Schmidt, and D. Neumann, "Phytochelatins and heavy metal tolerance," Phytochemistry, vol. 50, no. 8, pp. 1323-1328, 1999.

[116] D. E. Salt and W. E. Rauser, "MgATP-dependent transport of phytochelatins across the tonoplast of oat roots," Plant Physiology, vol. 107, no. 4, pp. 1293-1301, 1995.

[117] A. J. M. Baker, S. P. McGrath, R. D. Reeves, and J. A. C. Smith, "Metal hyperaccumulator plants: a review of the ecology and physiology of a biological resource for phytoremedation of metal polluted soils," in Phytoremediation of Contaminated Soil and Water, N. Terry and G. Banuelos, Eds., pp. 85-107, Michael Lewis, Boca Raton, Fla, USA, 2000.

[118] D. H. Hamer, "Metallothionein," Annual Review of Biochemistry, vol. 55, pp. 913-951, 1986.

[119] K. Gasic and S. Korban, "Heavy metal stress," in Physiology and Molecular Biology of Stress Tolerance in Plants, K. V. M. Rao, A. S. Raghavendra, and K. J. Reddy, Eds., pp. 219-254, Springer, Dordrecht, the Netherlands, 2006.

[120] G. Zhou, Y. Xu, J. Li, L. Yang, and J.-Y. Liu, "Molecular analyses of the metallothionein gene family in rice (Oryza sativa L.)," Journal of Biochemistry and Molecular Biology, vol. 39, no. 5, pp. 595-606, 2006.

[121] J. H. R. Kagi, "Overview of metallothionein," Methods in Enzymology, vol. 205, pp. 613-626, 1991.

[122] S. Castiglione, C. Franchin, T. Fossati, G. Lingua, P. Torrigiani, and S. Biondi, "High zinc concentrations reduce rooting capacity and alter metallothionein gene expression in white poplar (Populus alba L. cv. Villafranca)," Chemosphere, vol. 67, no. 6, pp. 1117-1126, 2007.

[123] Y. O. Ahn, S. H. Kim, J. Lee, H. R. Kim, H.-S. Lee, and S.-S. Kwak, "Three Brassica rapa metallothionein genes are differentially regulated under various stress conditions," Molecular Biology Reports, vol. 39, no. 3, pp. 2059-2067, 2012.

[124] R. Jabeen, A. Ahmad, and M. Iqbal, "Phytoremediation of heavy metals: physiological and molecular mechanisms," Botanical Review, vol. 75, no. 4, pp. 339-364, 2009.

[125] D. Singh and S. K. Chauhan, "Organic acids of crop plants in alumium detoxification," Current Science, vol. 100, no. 10, pp. 1509-1515, 2011.

[126] J. Lee, R. D. Reeves, R. R. Brooks, and T. Jaffré, "Isolation and identification of a citrato-complex of nickel from nickelaccumulating plants," Phytochemistry, vol. 16, no. 10, pp. 1503-1505, 1977.

[127] J. Lee, R. D. Reeves, R. R. Brooks, and T. Jaffré, “The relation between nickel and citric acid in some nickel-accumulating plants," Phytochemistry, vol. 17, no. 6, pp. 1033-1035, 1978.

[128] S. C. Miyasaka, J. George Buta, R. K. Howell, and C. D. Foy, "Mechanism of aluminum tolerance in snapbeans: root exudation of citric acid," Plant Physiology, vol. 96, no. 3, pp. 737-743, 1991.

[129] G. J. Wagner, "Accumulation of Cadmium in Crop Plants And Its Consequences to Human Health," Advances in Agronomy, vol. 51, no. C, pp. 173-212, 1993.

[130] D. L. Godbold, W. J. Horst, J. C. Collins, D. A. Thurman, and H. Marschner, "Accumulation of zinc and organic acids in roots of zinc tolerant and non-tolerant ecotypes of 
Deschampsia caespitosa," International Journal of Plant Physiology, vol. 116, no. 1, pp. 59-69, 1984.

[131] M. Oven, E. Grill, A. Golan-Goldhirsh, T. M. Kutchan, and M. H. Zenk, "Increase of free cysteine and citric acid in plant cells exposed to cobalt ions," Phytochemistry, vol. 60, no. 5, pp. 467-474, 2002.

[132] J. F. Ma, P. R. Ryan, and E. Delhaize, "Aluminium tolerance in plants and the complexing role of organic acids," Trends in Plant Science, vol. 6, no. 6, pp. 273-278, 2001.

[133] Jian Feng Ma, Shao Jian Zheng, H. Matsumoto, and S. Hiradate, "Detoxifying aluminium with buckwheat," Nature, vol. 390, no. 6660, pp. 569-570, 1997.

[134] S. Zheng, J. F. Ma, and H. Matsumoto, "High alumium resistance in buckwheat: I. Al induced specific secretion of oxalic acid from root tip tips," Plant Physiology, vol. 117, no. 3, pp. 745-751, 1997.

[135] W. Mathys, "The role of malate, oxalate, and mustard oil glucosides in the evolution of zinc-resistance in herbage plants," Physiologia Plantarum, vol. 40, no. 2, pp. 130-136, 1977.

[136] W. H. Zhang, P. R. Ryan, and S. D. Tyerman, "Malatepermeable channels and cation channels activated by aluminum in the apical cells of wheat roots," Plant Physiology, vol. 125, no. 3, pp. 1459-1472, 2001.

[137] F. S. Salazar, S. Pandey, L. Narro et al., "Diallel analysis of acid-soil tolerant and intolerant tropical maize populations," Crop Science, vol. 37, no. 5, pp. 1457-1462, 1997.

[138] X. F. Li, J. F. Ma, and H. Matsumoto, "Pattern of aluminuminduced secretion of organic acids differs between rye and wheat," Plant Physiology, vol. 123, no. 4, pp. 1537-1543, 2000.

[139] V. K. Rai, "Role of amino acids in plant responses to stresses," Biologia Plantarum, vol. 45, no. 4, pp. 481-487, 2002.

[140] D. E. Salt, R. C. Prince, A. J. M. Baker, I. Raskin, and I. J. Pickering, "Zinc legands in the metal hyperaccumulator Thalspi caerulescens as determined using X-absorption spectroscopy," Environmental Science and Technology, vol. 33, no. 5, pp. 713$717,1999$.

[141] U. Krämer, J. D. Cotter-Howells, J. M. Charnock, A. J. M. Baker, and J. A. C. Smith, "Free histidine as a metal chelator in plants that accumulate nickel," Nature, vol. 379, no. 6566, pp. 635-638, 1996.

[142] K. Wycisk, E. J. Kim, J. I. Schroeder, and U. Krämer, "Enhancing the first enzymatic step in the histidine biosynthesis pathway increases the free histidine pool and nickel tolerance in Arabidopsis thaliana," FEBS Letters, vol. 578, no. 1-2, pp. 128-134, 2004.

[143] K. Higuchi, K. Suzuki, H. Nakanishi, H. Yamaguchi, N. K. Nishizawa, and S. Mori, "Cloning of nicotianamine synthase genes, novel genes involved in the biosynthesis of phytosiderophores," Plant Physiology, vol. 119, no. 2, pp. 471479, 1999.

[144] H. Q. Ling, G. Koch, H. Bäumlein, and M. W. Ganal, "Map-based cloning of chloronerva, a gene involved in iron uptake of higher plants encoding nicotianamine synthase," Proceedings of the National Academy of Sciences of the United States of America, vol. 96, no. 12, pp. 7098-7103, 1999.

[145] A. Pich, R. Manteuffel, S. Hillmer, G. Scholz, and W. Schmidt, "Fe homeostasis in plant cells: does nicotianamine play multiple roles in the regulation of cytoplasmic $\mathrm{Fe}$ concentration?" Planta, vol. 213, no. 6, pp. 967-976, 2001.

[146] M. Takahashi, Y. Terada, I. Nakai et al., "Role of nicotianamine in the intracellular delivery of metals and plant reproductive development," Plant Cell, vol. 15, no. 6, pp. 1263-1280, 2003.
[147] M. Weber, E. Harada, C. Vess, E. V. Roepenack-Lahaye, and S. Clemens, "Comparative microarray analysis of Arabidopsis thaliana and Arabidopsis halleri roots identifies nicotianamine synthase, a ZIP transporter and other genes as potential metal hyperaccumulation factors," Plant Journal, vol. 37, no. 2, pp. 269-281, 2004.

[148] M. D. Vazquez, C. Poschenrieder, I. Corrales, and J. Barcelo, "Change in apoplastic aluminum during the initial growth response to aluminum by roots of a tolerant maize variety," Plant Physiology, vol. 119, no. 2, pp. 435-444, 1999.

[149] R. F. M. van Steveninck, M. E. van Steveninck, D. R. Fernando, W. J. Horst, and H. Marschner, "Deposition of zinc phytate in globular bodies in roots of Deschampsia caespitosa; a detoxification mechanism?" Journal of Plant Physiology, vol. 131, no. 3-4, pp. 247-257, 1987.

[150] D. E. Salt, M. Blaylock, N. P. B. A. Kumar et al., "Phytoremediation: a novel strategy for the removal of toxic metals from the environment using plants," Biotechnology, vol. 13, no. 5, pp. 468-474, 1995.

[151] D. E. Salt and U. Krämer, "Mechanisms of metal hyperaccumulation in plants," in Phytoremediation of Toxic MetalsUsing Plants to Clean Up the Environment, I. Raskin and B. D. Ensley, Eds., pp. 231-246, Wiley, New York, NY, USA, 2000.

[152] N. S. Pence, P. B. Larsen, S. D. Ebbs et al., "The molecular physiology of heavy metal transport in the $\mathrm{Zn} / \mathrm{Cd}$ hyperaccumulator Thlaspi caerulescens," Proceedings of the National Academy of Sciences of the United States of America, vol. 97, no. 9, pp. 4956-4960, 2000.

[153] E. Lombi, F. J. Zhao, S. J. Dunham, and S. P. McGrath, "Phytoremediation of heavy metal-contaminated soils: natural hyperaccumulation versus chemically enhanced phytoextraction," Journal of Environmental Quality, vol. 30, no. 6, pp. 1919-1926, 2001.

[154] M. M. Lasat, N. S. Pence, D. F. Garvin, S. D. Ebbs, and L. V. Kochian, "Molecular physiology of zinc transport in the $\mathrm{Zn}$ hyperaccumulator Thlaspi caerulescens," Journal of Experimental Botany, vol. 51, no. 342, pp. 71-79, 2000.

[155] E. Pilon-Smits and M. Pilon, "Phytoremediation of metals using transgenic plants," Critical Reviews in Plant Sciences, vol. 21, no. 5, pp. 439-456, 2002.

[156] N. von Wiren, S. Klair, S. Bansal et al., "Nicotinamide chelates both Fe III and Fe II. Implication of a transport function for cadmium-binding pepties," Plant Physiology, vol. 119, no. 3, pp. 1107-1114, 1999.

[157] D. Neumann, O. Lichtenberger, D. Gunther, K. Tschiersch, and L. Nover, "Heat-shock proteins induce heavy-metal tolerance in higher plants," Planta, vol. 194, no. 3, pp. 360-367, 1994.

[158] D. Neumann, U. Zur Nieden, O. Lichtenberger, and I. Leopold, "How does Armeria maritima tolerate high heavy metal concentrations?" Journal of Plant Physiology, vol. 146, no. 5-6, pp. 704-717, 1995.

[159] J. E. Sarry, L. Kuhn, C. Ducruix et al., "The early responses of Arabidopsis thaliana cells to cadmium exposure explored by protein and metabolite profiling analyses," Proteomics, vol. 6, no. 7, pp. 2180-2198, 2006.

[160] Y. Zhen, J. L. Qi, S. S. Wang et al., "Comparative proteome analysis of differentially expressed proteins induced by $\mathrm{Al}$ toxicity in soybean," Physiologia Plantarum, vol. 131, no. 4, pp. 542-554, 2007.

[161] H. E. Ireland, S. J. Harding, G. A. Bonwick, M. Jones, C. J. Smith, and J. H. H. Williams, "Evaluation of heat shock protein 70 as a biomarker of environmental stress in Fucus 
serratus and Lemna minor," Biomarkers, vol. 9, no. 2, pp. 139$155,2004$.

[162] M. P. de Souza, E. A. H. Pilon-Smits, and N. Terry, "The physiology and biochemistry of selenium volatilization by plants," in Phytoremediation of Toxic Metal-Using Plants to Clean up the Environment, I. Raskin and B. D. Ensley, Eds., pp. 171-190, Wiley, New York, NY, USA, 2000.

[163] C. M. Lytle, P. W. Lytle, N. Yang et al., "Reduction of Cr(VI) to $\mathrm{Cr}(\mathrm{III})$ by wetland plants: potential for in situ heavy metal detoxification," Environmental Science and Technology, vol. 32, no. 20, pp. 3087-3093, 1998.

[164] N. J. Robinson, C. M. Procter, E. L. Connolly, and M. L. Guerinot, "A ferric-chelate reductase for iron uptake from soils," Nature, vol. 397, no. 6721, pp. 694-697, 1999.

[165] N. Fusco, L. Micheletto, G. Dal Corso, L. Borgato, and A. Furini, "Identification of cadmium-regulated genes by cDNA-AFLP in the heavy metal accumulator Brassica juncea L," Journal of Experimental Botany, vol. 56, no. 421, pp. 30173027, 2005.

[166] J. E. Van De Mortel, H. Schat, P. D. Moerland et al., "Expression differences for genes involved in lignin, glutathione and sulphate metabolism in response to cadmium in Arabidopsis thaliana and the related $\mathrm{Zn} / \mathrm{Cd}$-hyperaccumulator Thlaspi caerulescens," Plant, Cell and Environment, vol. 31, no. 3, pp. 301-324, 2008.

[167] K. B. Singh, R. C. Foley, and L. Oñate-Sánchez, "Transcription factors in plant defense and stress responses," Current Opinion in Plant Biology, vol. 5, no. 5, pp. 430-436, 2002.

[168] G. Noctor and C. H. Foyer, "Ascorbate and glutathione: keeping active oxygen under control," Annual Review of Plant Biology, vol. 49, pp. 249-279, 1998.

[169] S. L. Singla-Pareek, M. K. Reddy, and S. K. Sopory, "Genetic engineering of the glyoxalase pathway in tobacco leads to enhanced salinity tolerance," Proceedings of the National Academy of Sciences of the United States of America, vol. 100, no. 25, pp. 14672-14677, 2003.

[170] Q. Shi and Z. Zhu, "Effects of exogenous salicylic acid on manganese toxicity, element contents and antioxidative system in cucumber," Environmental and Experimental Botany, vol. 63, no. 1-3, pp. 317-326, 2008.

[171] Z. S. Zhou, K. Guo, A. A. Elbaz, and Z. M. Yang, "Salicylic acid alleviates mercury toxicity by preventing oxidative stress in roots of Medicago sativa," Environmental and Experimental Botany, vol. 65, no. 1, pp. 27-34, 2009.

[172] J. L. Freeman, M. W. Persans, K. Nieman et al., "Increased glutathione biosynthesis plays a role in nickel tolerance in Thlaspi nickel hyperaccumulators $\mathrm{W}$ inside box sign," Plant Cell, vol. 16, no. 8, pp. 2176-2191, 2004.

[173] A. Metwally, I. Finkemeier, M. Georgi, and K. J. Dietz, "Salicylic acid alleviates the cadmium toxicity in barley seedlings," Plant Physiology, vol. 132, no. 1, pp. 272-281, 2003.

[174] Y. S. Wang, J. Wang, Z. M. Yang et al., "Salicylic acid modulates aluminum-induced oxidative stress in roots of Cassia tora," Acta Botanica Sinica, vol. 46, no. 7, pp. 819-828, 2004.

[175] R. Bassi and S. S. Sharma, "Changes in Proline Content Accompanying the Uptake of Zinc and Copper by Lemna minor," Annals of Botany, vol. 72, no. 2, pp. 151-154, 1993.

[176] R. Bassi and S. S. Sharma, "Proline accumulation in wheat seedlings exposed to zinc and copper," Phytochemistry, vol. 33, no. 6, pp. 1339-1342, 1993.

[177] V. V. Talanova, A. F. Titov, and N. P. Boeva, "Effect of increasing concentrations of lead and cadmium on cucumber seedlings," Biologia Plantarum, vol. 43, no. 3, pp. 441-444, 2000.

[178] S. Siripornadulsil, S. Traina, D. P. S. Verma, and R. T. Sayre, "Molecular mechanisms of proline-mediated tolerance to toxic heavy metals in transgenic microalgae," Plant Cell, vol. 14, no. 11, pp. 2837-2847, 2002.

[179] G. Y. Huang, Y. S. Wang, C. C. Sun, J. D. Dong, and Z. $\mathrm{X}$. Sun, "The effect of multiple heavy metals on ascorbate, glutathione and related enzymes in two mangrove plant seedlings (Kandelia candel and Bruguiera gymnorrhiza)," Oceanological and Hydrobiological Studies, vol. 39, no. 1, pp. 11-25, 2010.

[180] S. S. Hussain, M. Ali, M. Ahmad, and K. H. M. Siddique, "Polyamines: natural and engineered abiotic and biotic stress tolerance in plants," Biotechnology Advances, vol. 29, no. 3, pp. 300-311, 2011.

[181] T. Kusano, T. Berberich, C. Tateda, and Y. Takahashi, "Polyamines: Essential factors for growth and survival," Planta, vol. 228, no. 3, pp. 367-381, 2008.

[182] C. C. Lin and C. H. Kao, "Excess copper induces an accumulation of putrescine in rice leaves," Botanical Bulletin of Academia Sinica, vol. 40, no. 3, pp. 213-218, 1999.

[183] H. C. Ha, N. S. Sirisoma, P. Kuppusamy, J. L. Zweier, P. M. Woster, and R. A. Casero, "The natural polyamine spermine functions directly as a free radical scavenger," Proceedings of the National Academy of Sciences of the United States of America, vol. 95, no. 19, pp. 11140-11145, 1998.

[184] M. D. Groppa and M. P. Benavides, "Polyamines and abiotic stress: recent advances," Amino Acids, vol. 34, no. 1, pp. 3545, 2008.

[185] Y. Y. Leshem and P. J. C. Kuiper, "Is there a GAS (general adaptation syndrome) response to various types of environmental stress?" Biologia Plantarum, vol. 38, no. 1, pp. 1-18, 1996.

[186] M. N. V. Prasad and K. Strzalka, "Impact of heavy metals on photosynthesis," in Heavy Metal Stress in Plants, M. N. V. Prasad and J. Hagemeyer, Eds., pp. 117-138, Springer, Berlin, Germany, 1999.

[187] M. D. Groppa, M. S. Zawoznik, M. L. Tomaro, and M. P. Benavides, "Inhibition of root growth and polyamine metabolism in sunflower (Helianthus annuus) seedlings under cadmium and copper stress," Biological Trace Element Research, vol. 126, no. 1-3, pp. 246-256, 2008.

[188] M. D. Groppa, E. P. Rosales, M. F. Iannone, and M. P. Benavides, "Nitric oxide, polyamines and Cd-induced phytotoxicity in wheat roots," Phytochemistry, vol. 69, no. 14, pp. 2609-2615, 2008.

[189] V. Prabhavathi and M. V. Rajam, "Mannitol-accumulating transgenic eggplants exhibit enhanced resistance to fungal wilts," Plant Science, vol. 173, no. 1, pp. 50-54, 2007.

[190] X. P. Wen, X. M. Pang, N. Matsuda et al., "Inhibition of root growth and polyamine metabolism in sunflower (Helianthus annuus) seedlings under cadmium and copper stress over-expression of the apple spermidine synthase gene in pear confers multiple abiotic stress tolerance by altering polyamine titers," Transgenic Research, vol. 17, no. 2, pp. 251263, 2008.

[191] C. Franchin, T. Fossati, E. Pasquini et al., "High concentrations of zinc and copper induce differential polyamine responses in micropropagated white poplar (Populus alba)," Physiologia Plantarum, vol. 130, no. 1, pp. 77-90, 2007.

[192] L. Lamattina, C. García-Mata, M. Graziano, and G. Pagnussat, "Nitric oxide: the versatility of an extensive signal 
molecule," Annual Review of Plant Biology, vol. 54, pp. 109136, 2003.

[193] L. A. Del Río, F. J. Corpas, and J. B. Barroso, "Nitric oxide and nitric oxide synthase activity in plants," Phytochemistry, vol. 65, no. 7, pp. 783-792, 2004.

[194] M. C. Palmieri, S. Sell, X. Huang et al., "Nitric oxideresponsive genes and promoters in Arabidopsis thaliana: a bioinformatics approach," Journal of Experimental Botany, vol. 59, no. 2, pp. 177-186, 2008.

[195] Q. Shi, F. Ding, X. Wang, and M. Wei, "Exogenous nitric oxide protect cucumber roots against oxidative stress induced by salt stress," Plant Physiology and Biochemistry, vol. 45, no. 8, pp. 542-550, 2007.

[196] C. Zheng, D. Jiang, F. Liu et al., "Exogenous nitric oxide improves seed germination in wheat against mitochondrial oxidative damage induced by high salinity," Environmental and Experimental Botany, vol. 67, no. 1, pp. 222-227, 2009.

[197] M. H. Siddiqui, M. H. Al-Whaibi, and M. O. Basalah, "Role of nitric oxide in tolerance of plants to abiotic stress," Protoplasma, vol. 248, no. 3, pp. 447-455, 2011.

[198] P. A. Karplus, M. J. Daniels, and J. R. Herriot, "Atomic structure of ferredoxin-NADPH C reductase, prototype for a structurally novel flavoenzyme family," Science, vol. 251, no. 4989, pp. 60-66, 1999.

[199] J. Xu, W. Wang, J. Sun et al., "Involvement of auxin and nitric oxide in plant Cd-stress responses," Plant and Soil, vol. 346, no. 1, pp. 107-119, 2011.

[200] C. Xiumin, Z. Yikai, C. Xiuling, J. Hong, and W. Xiaobin, "Effects of exogenous nitric oxide protects tomato plants under copper stress," in Proceedings of the 3rd International Conference on Bioinformatics and Biomedical Engineering (ICBBE '09), pp. 1-7, Beijing, China, June 2009.

[201] J. Xu, H. Yin, and X. Li, "Protective effects of proline against cadmium toxicity in micropropagated hyperaccumulator, Solanum nigrum L," Plant Cell Reports, vol. 28, no. 2, pp. 325333, 2009.

[202] N. V. Laspina, M. D. Groppa, M. L. Tomaro, and M. P. Benavides, "Nitric oxide protects sunflower leaves against Cd-induced oxidative stress," Plant Science, vol. 169, no. 2, pp. 323-330, 2005.

[203] K. Apel and H. Hirt, "Reactive oxygen species: metabolism, oxidative stress, and signal transduction," Annual Review of Plant Biology, vol. 55, pp. 373-399, 2004.

[204] R. Mittler, S. Vanderauwera, M. Gollery, and F. Van Breusegem, "Reactive oxygen gene network of plants," Trends in Plant Science, vol. 9, no. 10, pp. 490-498, 2004.

[205] A. Mhamdi, G. Queval, S. Chaouch, S. Vanderauwera, F. Van Breusegem, and G. Noctor, "Catalase function in plants: a focus on Arabidopsis mutants as stress-mimic models," Journal of Experimental Botany, vol. 61, no. 15, pp. 41974220, 2010.

[206] S. Takahashi and N. Murata, "How do environmental stresses accelerate photoinhibition?" Trends in Plant Science, vol. 13, no. 4, pp. 178-182, 2008.

[207] T. Baszynski, L. Wajda, M. Król, D. Wolinska, Z. Krupa, and A. Tukendorf, "Photosynthetic activities of cadmium treated tomato plants," Plant Physiology, vol. 98, no. 3, pp. 365-370, 1980.

[208] N. Mohanty and P. Mohanty, "Cation effects on primary processes of photosynthesis," in Advances in Frontier Areas of Plant Biochemistry, R. Singh and S. K. Sawheny, Eds., pp. 118, Prentice-Hall, Delhi, India, 1988.

[209] N. Atal, P. P. Saradhi, and P. Mohanty, "Inhibition of the chloroplast photochemical reactions by treatment of wheat seedlings with low concentrations of cadmium: analysis of electron transport activities and changes in fluorescence yield," Plant and Cell Physiology, vol. 32, no. 7, pp. 943-951, 1991.

[210] P. Faller, K. Kienzler, and A. Krieger-Liszkay, "Mechanism of $\mathrm{Cd}^{2+}$ toxicity: $\mathrm{Cd}^{2+}$ inhibits photoactivation of Photosystem II by competitive binding to the essential $\mathrm{Ca}^{2+}$ site," Biochimica et Biophysica Acta, vol. 1706, no. 1-2, pp. 158-164, 2005.

[211] A. Krantev, R. Yordanova, T. Janda, G. Szalai, and L. Popova, "Treatment with salicylic acid decreases the effect of cadmium on photosynthesis in maize plants," Journal of Plant Physiology, vol. 165, no. 9, pp. 920-931, 2008.

[212] A. Siedlecka and T. BaszyńAski, "Inhibition of electron flow around photosystem I in chloroplasts of Cd-treated maize plants is due to Cd-induced iron deficiency," Physiologia Plantarum, vol. 87, no. 2, pp. 199-202, 1993.

[213] A. Siedlecka, G. Samuelsson, P. Gardenstrom, L. A. Kleczkowski, and Z. Krupa, "The activatory model of plant response to moderate cadmium stress-relationship between carbonic anhydrase and Rubisco," in Photosynthesis: Mechanisms and Effects, G. Garab, Ed., pp. 2677-2680, Kluwer Academic Publishers, Dordrecht, The Netherlands, 1998.

[214] F. J. Corpas, J. B. Barroso, and L. A. Del Río, "Peroxisomes as a source of reactive oxygen species and nitric oxide signal molecules in plant cells," Trends in Plant Science, vol. 6, no. 4, pp. 145-150, 2001.

[215] L. A. Del Río, L. M. Sandalio, F. J. Corpas, J. M. Palma, and J. B. Barroso, "Reactive oxygen species and reactive nitrogen species in peroxisomes. Production, scavenging, and role in cell signaling," Plant Physiology, vol. 141, no. 2, pp. 330-335, 2006.

[216] M. Rodríguez-Serrano, M. C. Romero-Puertas, I. Sparkes, C. Hawes, L. A. del Río, and L. M. Sandalio, "Peroxisome dynamics in Arabidopsis plants under oxidative stress induced by cadmium," Free Radical Biology and Medicine, vol. 47, no. 11, pp. 1632-1639, 2009.

[217] M. C. Romero-Puertas, M. Rodríguez-Serrano, F. J. Corpas, M. Gómez, L. A. Del Río, and L. M. Sandalio, "Cadmiuminduced subcellular accumulation of $\mathrm{O}_{2}$.- and $\mathrm{H}_{2} \mathrm{O}_{2}$ in pea leaves," Plant, Cell and Environment, vol. 27, no. 9, pp. 11221134, 2004.

[218] O. Blokhina and K. Fagerstedt, "Oxidative stress and antioxidant defenses in plants," in Oxidative Stress, Disease and Cancer, K. K. Singh, Ed., pp. 151-199, Imperial College Press, London, UK, 2006.

[219] E. Heyno, C. Klose, and A. Krieger-Liszkay, "Origin of cadmium-induced reactive oxygen species production: mitochondrial electron transfer versus plasma membrane NADPH oxidase," New Phytologist, vol. 179, no. 3, pp. 687-699, 2008.

[220] Y. S. Wang, J. Wang, Z. M. Yang et al., "Salicylic acid modulates aluminum-induced oxidative stress in roots of Cassia tora," Acta Botanica Sinica, vol. 46, no. 7, pp. 819-828, 2004.

[221] F. Hao, X. Wang, and J. Chen, "Involvement of plasmamembrane NADPH oxidase in nickel-induced oxidative stress in roots of wheat seedlings," Plant Science, vol. 170, no. 1, pp. 151-158, 2006.

[222] M. Rodríguez-Serrano, M. C. Romero-Puertas, A. Zabalza et al., "Cadmium effect on oxidative metabolism of pea (Pisum sativum L.) roots. Imaging of reactive oxygen species and nitric oxide accumulation in vivo," Plant, Cell and Environment, vol. 29, no. 8, pp. 1532-1544, 2006.

[223] B. Pourrut, G. Perchet, J. Silvestre, M. Cecchi, M. Guiresse, and E. Pinelli, "Potential role of NADPH-oxidase in early 
steps of lead-induced oxidative burst in Vicia faba roots," Journal of Plant Physiology, vol. 165, no. 6, pp. 571-579, 2008.

[224] T. Remans, K. Opdenakker, K. Smeets, D. Mathijsen, J. Vangronsveld, and A. Cuypers, "Metal-specific and NADPH oxidase dependent changes in lipoxygenase and NADPH oxidase gene expression in Arabidopsis thaliana exposed to cadmium or excess copper," Functional Plant Biology, vol. 37, no. 6, pp. 532-544, 2010.

[225] B. Halliwell, "Reactive species and antioxidants. Redox biology is a fundamental theme of aerobic life," Plant Physiology, vol. 141, no. 2, pp. 312-322, 2006.

[226] C. H. Foyer and G. Noctor, "Redox homeostasis and antioxidant signaling: a metabolic interface between stress perception and physiological responses," Plant Cell, vol. 17, no. 7, pp. 1866-1875, 2005.

[227] T. S. Gechev, F. Van Breusegem, J. M. Stone, I. Denev, and C. Laloi, "Reactive oxygen species as signals that modulate plant stress responses and programmed cell death," BioEssays, vol. 28, no. 11, pp. 1091-1101, 2006.

[228] J. Espartero, I. Sanchez-Aguayo, and J. M. Pardo, "Molecular characterization of glyoxalase-I from a higher plant; Upregulation by stress," Plant Molecular Biology, vol. 29, no. 6, pp. 1223-1233, 1995.

[229] J. P. Richard, "Mechanism for the formation of methylglyoxal from triosephosphates," Biochemical Society Transactions, vol. 21, no. 2, pp. 549-553, 1993.

[230] S. K. Yadav, S. L. Singla-Pareek, M. K. Reddy, and S. K. Sopory, "Methylglyoxal detoxification by glyoxalase system: a survival strategy during environmental stresses," Physiology and Molecular Biology of Plants, vol. 11, no. 1, pp. 1-11, 2005.

[231] D. L. Pompliano, A. Peyman, and J. R. Knowles, "Stabilization of a reaction intermediate as a catalytic device: definition of the functional role of the flexible loop in triosephosphate isomerase," Biochemistry, vol. 29, no. 13, pp. 3186-3194, 1990.

[232] Veena, V. S. Reddy, and S. K. Sopory, "Glyoxalase I from Brassica juncea: molecular cloning, regulation and its overexpression confer tolerance in transgenic tobacco under stress," Plant Journal, vol. 17, no. 4, pp. 385-395, 1999.

[233] Z. Y. Chen, R. L. Brown, K. E. Damann, and T. E. Cleveland, "Identification of a maize kernel stress-related protein and its effect on aflatoxin accumulation," Phytopathology, vol. 94, no. 9, pp. 938-945, 2004.

[234] M. N. Akhter Banu, M. A. Hoque, M. Watanabe-Sugimoto et al., "Proline and glycinebetaine ameliorated $\mathrm{NaCl}$ stress via scavenging of hydrogen peroxide and methylglyoxal but not superoxide or nitric oxide in tobacco cultured cells," Bioscience, Biotechnology and Biochemistry, vol. 74, no. 10, pp. 2043-2049, 2010.

[235] S. Ray, S. Dutta, J. Halder, and M. Ray, "Inhibition of electron flow through complex I of the mitochondrial respiratory chain of Ehrlich ascites carcinoma cells by methylglyoxal," Biochemical Journal, vol. 303, no. 1, pp. 69-72, 1994.

[236] L. Wu and B. H. J. Juurlink, "Increased methylglyoxal and oxidative stress in hypertensive rat vascular smooth muscle cells," Hypertension, vol. 39, no. 3, pp. 809-814, 2002.

[237] F. W. R. Chaplen, "Incidence and potential implications of the toxic metabolite methylglyoxal in cell culture: a review," Cytotechnology, vol. 26, no. 3, pp. 173-183, 1998.

[238] K. M. Desai, T. Chang, H. Wang et al., "Oxidative stress and aging: is methylglyoxal the hidden enemy?" Canadian Journal of Physiology and Pharmacology, vol. 88, no. 3, pp. 273-284, 2010.
[239] S. Neill, R. Desikan, and J. Hancock, "Hydrogen peroxide signalling," Current Opinion in Plant Biology, vol. 5, no. 5, pp. 388-395, 2002.

[240] P. J. Thornalley, “The glyoxalase system: new developments towards functional characterization of a metabolic pathway fundamental to biological life," Biochemical Journal, vol. 269, no. 1, pp. 1-11, 1990.

[241] M. Saxena, R. Bisht, S. D. Roy, S. K. Sopory, and N. BhallaSarin, "Cloning and characterization of a mitochondrial glyoxalase II from Brassica juncea that is upregulated by $\mathrm{NaCl}, \mathrm{Zn}$, and ABA," Biochemical and Biophysical Research Communications, vol. 336, no. 3, pp. 813-819, 2005.

[242] M. A. Iannelli, F. Pietrini, L. Fiore, L. Petrilli, and A. Massacci, "Antioxidant response to cadmium in Phragmites australis plants," Plant Physiology and Biochemistry, vol. 40, no. 11, pp. 977-982, 2002.

[243] R. Boominathan and P. M. Doran, "Cadmium tolerance and antioxidative defenses in hairy roots of the cadmium hyperaccumulator, Thlaspi caerulescens," Biotechnology and Bioengineering, vol. 83, no. 2, pp. 158-167, 2003.

[244] É. Darkó, H. Ambrus, É. Stefanovits-Bányai, J. Fodor, F. Bakos, and B. Barnabás, "Aluminum toxicity, aluminum tolerance and oxidative stress in an $\mathrm{Al}$-sensitive wheat genotype and in Al-tolerant lines developed by in vitro microspore selection," Plant Science, vol. 166, no. 3, pp. 583-591, 2004.

[245] N. Singh, L. Q. Ma, M. Srivastava, and B. Rathinasabapathi, "Metabolic adaptations to arsenic-induced oxidative stress in Pteris vittata L and Pteris ensiformis L," Plant Science, vol. 170, no. 2, pp. 274-282, 2006.

[246] X. Jin, X. Yang, E. Islam, D. Liu, and Q. Mahmood, "Effects of cadmium on ultrastructure and antioxidative defense system in hyperaccumulator and non-hyperaccumulator ecotypes of Sedum alfredii Hance," Journal of Hazardous Materials, vol. 156, no. 1-3, pp. 387-397, 2008.

[247] X. Zeng, L. Q. Ma, R. Qiu, and Y. Tang, "Responses of nonprotein thiols to Cd exposure in Cd hyperaccumulator Arabis paniculata Franch," Environmental and Experimental Botany, vol. 66, no. 2, pp. 242-248, 2009.

[248] D. K. Gupta, H. G. Huang, X. E. Yang, B. H. N. Razafindrabe, and M. Inouhe, "The detoxification of lead in Sedum alfredii $\mathrm{H}$. is not related to phytochelatins but the glutathione," Journal of Hazardous Materials, vol. 177, no. 1-3, pp. 437444, 2010.

[249] Q. Sun, Z. H. Ye, X. R. Wang, and M. H. Wong, "Increase of glutathione in mine population of Sedum alfredii: a $\mathrm{Zn}$ hyperaccumulator and $\mathrm{Pb}$ accumulator," Phytochemistry, vol. 66, no. 21, pp. 2549-2556, 2005.

[250] A. Koprivova, S. Kopriva, D. Jäger, B. Will, L. Jouanin, and H. Rennenberg, "Evaluation of transgenic poplars overexpressing enzymes of glutathione synthesis for phytoremediation of cadmium," Plant Biology, vol. 4, no. 6, pp. 664-670, 2002.

[251] R. A. Larson, "The antioxidants of higher plants," Phytochemistry, vol. 27, no. 4, pp. 969-978, 1988.

[252] C. Herschbach and H. Rennenberg, "Significance of phloemtranslocated organic sulfur compounds for the regulation of sulfur nutrition," Progress in Botany, vol. 62, pp. 177-193, 2001.

[253] R. Blum, A. Beck, A. Korte et al., "Function of phytochelatin synthase in catabolism of glutathione-conjugates," Plant Journal, vol. 49, no. 4, pp. 740-749, 2007.

[254] G. Noctor, "Metabolic signalling in defence and stress: the central roles of soluble redox couples," Plant, Cell and Environment, vol. 29, no. 3, pp. 409-425, 2006. 
[255] A. S. Gupta, R. G. Alscher, and D. McCune, "Response of photosynthesis and cellular antioxidants to ozone in Populus leaves," Plant Physiology, vol. 96, no. 2, pp. 650-655, 1991.

[256] M. J. May and C. J. Leaver, "Oxidative stimulation of glutathione synthesis in Arabidopsis thaliana suspension cultures," Plant Physiology, vol. 103, no. 2, pp. 621-627, 1993.

[257] K. A. Marrs, "The functions and regulation of glutathione $S$ transferases in plants," Annual Review of Plant Physiology and Plant Molecular Biology, vol. 47, no. 1, pp. 127-158, 1996.

[258] M. J. May, T. Vernoux, C. Leaver, M. Van Montagu, and D. Inzé, "Glutathione homeostasis in plants: implications for environmental sensing and plant development," Journal of Experimental Botany, vol. 49, no. 321, pp. 649-667, 1998.

[259] S. Qadir, M. I. Qureshi, S. Javed, and M. Z. Abdin, "Genotypic variation in phytoremediation potential of Brassica juncea cultivars exposed to Cd stress," Plant Science, vol. 167, no. 5, pp. 1171-1181, 2004.

[260] N. A. Anjum, S. Umar, A. Ahmad, M. Iqbal, and N. A. Khan, "Ontogenic variation in response of Brassica campestris L. to cadmium toxicity," Journal of Plant Interactions, vol. 3, no. 3, pp. 189-198, 2008.

[261] A. Schützendübel, P. Nikolova, C. Rudolf, and A. Polle, "Cadmium and $\mathrm{H}_{2} \mathrm{O}_{2}$-induced oxidative stress in Populus $\mathrm{x}$ canescens roots," Plant Physiology and Biochemistry, vol. 40, no. 6-8, pp. 577-584, 2002.

[262] E. Grill, E. L. Winnacker, and M. H. Zenk, "Phytochelatins: the principal heavy-metal complexing peptides of higher plants," Science, vol. 230, no. 4726, pp. 674-676, 1985.

[263] F. Pietrini, M. A. Iannelli, S. Pasqualini, and A. Massacci, "Interaction of cadmium with glutathione and photosynthesis in developing leaves and chloroplasts of Phragmites australis (Cav.) Trin. ex steudel," Plant Physiology, vol. 133, no. 2, pp. 829-837, 2003.

[264] Z. S. Zhou, S. J. Wang, and Z. M. Yang, "Biological detection and analysis of mercury toxicity to alfalfa (Medicago sativa) plants," Chemosphere, vol. 70, no. 8, pp. 1500-1509, 2008.

[265] G. Y. Huang, Y. S. Wang, C. C. Sun, J. D. Dong, and Z. $\mathrm{X}$. Sun, "The effect of multiple heavy metals on ascorbate, glutathione and related enzymes in two mangrove plant seedlings (Kandelia candel and Bruguiera gymnorrhiza)," Oceanological and Hydrobiological Studies, vol. 39, no. 1, pp. $11-25,2010$.

[266] J. Hartley-Whitaker, G. Ainsworth, and A. A. Meharg, "Copper- and arsenate-induced oxidative stress in Holcus lanatus L. clones with differential sensitivity," Plant, Cell and Environment, vol. 24, no. 7, pp. 713-722, 2001.

[267] N. Verbruggen, C. Hermans, and H. Schat, "Mechanisms to cope with arsenic or cadmium excess in plants," Current Opinion in Plant Biology, vol. 12, no. 3, pp. 364-372, 2009.

[268] S. Mishra, S. Srivastava, R. D. Tripathi, and P. K. Trivedi, "Thiol metabolism and antioxidant systems complement each other during arsenate detoxification in Ceratophyllum demersum L," Aquatic Toxicology, vol. 86, no. 2, pp. 205-215, 2008.

[269] G. Innocenti, C. Pucciariello, M. Le Gleuher et al., "Glutathione synthesis is regulated by nitric oxide in Medicago truncatula roots," Planta, vol. 225, no. 6, pp. 1597-1602, 2007.

[270] J. B. Barroso, F. J. Corpas, A. Carreras et al., "Localization of $S$-nitrosoglutathione and expression of $S$-nitrosoglutathione reductase in pea plants under cadmium stress," Journal of Experimental Botany, vol. 57, no. 8, pp. 1785-1793, 2006.

[271] J. Xiong, G. Fu, L. Tao, and C. Zhu, "Roles of nitric oxide in alleviating heavy metal toxicity in plants," Archives of
Biochemistry and Biophysics, vol. 497, no. 1-2, pp. 13-20, 2010.

[272] D. P. Dixon and R. Edwards, "Glutathione transferases," in The Arabidopsis Book, vol. 8, The American Society of Plant Biologists, Austin, Tex, USA, 2010.

[273] M. Z. Hossain and M. Fujita, "Purification of a phitype glutathione $S$-transferase from pumpkin flowers, and molecular cloning of its cDNA," Bioscience, Biotechnology and Biochemistry, vol. 66, no. 10, pp. 2068-2076, 2002.

[274] M. Fujita and M. Z. Hossain, "Molecular cloning of cDNAs for three tau-type glutathione $S$-transferases in pumpkin (Cucurbita maxima) and their expression properties," Physiologia Plantarum, vol. 117, no. 1, pp. 85-92, 2003.

[275] M. Fujita and M. Z. Hossain, "Modulation of pumpkin glutathione $S$-transferases by aldehydes and related compounds," Plant and Cell Physiology, vol. 44, no. 5, pp. 481490, 2003.

[276] M. Z. Hossain, M. D. Hossain, and M. Fujita, "Induction of pumpkin glutathione $S$-transferases by different stresses and its possible mechanisms," Biologia Plantarum, vol. 50, no. 2, pp. 210-218, 2006.

[277] M. Z. Hossain, J. A. T. da Silva, and M. Fujita, "Differential roles of glutathione $S$-transferase in oxidative stress modulation," in Floriculture, Ornamental and Plant Biotechnology. Advances and Topical Issues, J. A. T. da Silva, Ed., pp. 108-116, Global Science Books Ltd, London, UK, 2006.

[278] E. Skórzyńska-Polit, M. Drążkiewicz, and Z. Krupa, "The activity of the antioxidative system in cadmium-treated Arabidopsis thaliana," Biologia Plantarum, vol. 47, no. 1, pp. 71-78, 2004.

[279] J. W. Gronwald and K. L. Plaisance, "Isolation and characterization of glutathione $S$-transferase isozymes from sorghum," Plant Physiology, vol. 117, no. 3, pp. 877-892, 1998.

[280] J. D. Hayes, J. U. Flanagan, and I. R. Jowsey, "Glutathione transferases," Annual Review of Pharmacology and Toxicology, vol. 45, pp. 51-88, 2005.

[281] Y. Hu, Y. Ge, C. Zhang, T. Ju, and W. Cheng, "Cadmium toxicity and translocation in rice seedlings are reduced by hydrogen peroxide pretreatment," Plant Growth Regulation, vol. 59, no. 1, pp. 51-61, 2009.

[282] L. Halusková, K. Valentovicová, J. Huttová, I. Mistrík, and L. Tamás, "Effect of abiotic stresses on glutathione peroxidase and glutathione $S$-transferase activity in barley root tips," Plant Physiology and Biochemistry, vol. 47, no. 11-12, pp. 1069-1074, 2009.

[283] M. M. Rohman, M. S. Uddin, and M. Fujita, "Up-regulation of onion bulb glutathione $S$ (GSTs) by abiotic stresses: a comparative study between two differently sensitive GSTs to their physiological inhibitors," Plant OMICS, vol. 3, no. 1, pp. 28-34, 2010.

[284] R. Szollosi, I. S. Varga, L. Erdei, and E. Mihalik, "Cadmiuminduced oxidative stress and antioxidative mechanisms in germinating Indian mustard (Brassica juncea L.) seeds," Ecotoxicology and Environmental Safety, vol. 72, no. 5, pp. 1337-1342, 2009.

[285] C. H. ZHANG and Y. GE, "Response of glutathione and glutathione $S$-transferase in rice seedlings exposed to cadmium stress," Rice Science, vol. 15, no. 1, pp. 73-76, 2008.

[286] E. Gajewska and M. Skłodowska, "Differential biochemical responses of wheat shoots and roots to nickel stress: antioxidative reactions and proline accumulation," Plant Growth Regulation, vol. 54, no. 2, pp. 179-188, 2008. 
[287] A. M. Reddy, S. G. Kumar, G. Jyothsnakumari, S. Thimmanaik, and C. Sudhakar, "Lead induced changes in antioxidant metabolism of horse gram (Macrotyloma uniflorum (Lam.) Verdc.) and bengal gram (Cicer arietinum L.)," Chemosphere, vol. 60, no. 1, pp. 97-104, 2005.

[288] C. Gullner, M. Uotila, and T. Kömives, "Responses of glutathione and glutathione $S$-transferase to cadmium and mercury exposure in pedunculate oak (Quercus robur) leaf discs," Botanica Acta, vol. 111, no. 1, pp. 62-65, 1998.

[289] I. Cakman and W. J. Horst, "Effect of aluminum on lipid peroxidation, superoxide dismutase, catalase, and peroxidase activities in root tips of soybean (Glycine max L.)," Physiologia Plantarum, vol. 83, no. 3, pp. 463-468, 1991.

[290] K. A. Marrs and V. Walbot, "Expression and RNA splicing of the maize glutathione $S$-transferase Bronze2 gene is regulated by cadmium and other stresses," Plant Physiology, vol. 113, no. 1, pp. 93-102, 1997.

[291] P. Dixit, P. K. Mukherjee, V. Ramachandran, and S. Eapen, "Glutathione transferase from Trichoderma virens enhances cadmium tolerance without enhancing its accumulation in transgenic Nicotiana tabacum," PLoS ONE, vol. 6, no. 1, Article ID e16360, 2011.

[292] C. H. Foyer and G. Noctor, "Ascorbate and glutathione: the heart of the redox hub," Plant Physiology, vol. 155, no. 1, pp. 2-18, 2011.

[293] C. H. Foyer and G. Noctor, "Oxidant and antioxidant signalling in plants: a re-evaluation of the concept of oxidative stress in a physiological context," Plant, Cell and Environment, vol. 28, no. 8, pp. 1056-1071, 2005.

[294] A. Cuypers, J. Vangronsveld, and H. Clijsters, "Peroxidases in roots and primary leaves of Phaseolus vulgaris Copper and Zinc phytotoxicity: a comparison," Journal of Plant Physiology, vol. 159, no. 8, pp. 869-876, 2002.

[295] R. A. Fatima and M. Ahmad, "Certain antioxidant enzymes of Allium cepa as biomarkers for the detection of toxic heavy metals in wastewater," Science of the Total Environment, vol. 346, no. 1-3, pp. 256-273, 2005.

[296] B. Semane, A. Cuypers, K. Smeets et al., "Cadmium responses in Arabidopsis thaliana: glutathione metabolism and antioxidative defence system," Physiologia Plantarum, vol. 129, no. 3, pp. 519-528, 2007.

[297] S. Srivastava, A. K. Srivastava, P. Suprasanna, and S. F. D'souza, "Comparative antioxidant profiling of tolerant and sensitive varieties of Brassica juncea L. to arsenate and arsenite exposure," Bulletin of Environmental Contamination and Toxicology, vol. 84, no. 3, pp. 342-346, 2010.

[298] S. Srivastava, S. Mishra, R. D. Tripathi, S. Dwivedi, P. K. Trivedi, and P. K. Tandon, "Phytochelatins and antioxidant systems respond differentially during arsenite and arsenate stress in Hydrilla verticillata (L.f.) Royle," Environmental Science and Technology, vol. 41, no. 8, pp. 2930-2936, 2007.

[299] M. Gupta, P. Sharma, N. B. Sarin, and A. K. Sinha, "Differential response of arsenic stress in two varieties of Brassica juncea L," Chemosphere, vol. 74, no. 9, pp. 1201-1208, 2009.

[300] H. Hartikainen, T. L. Kue, and V. Piironem, "Selenium as an antioxidant and prooxidant in rye grass," Plant and Soil, vol. 225, no. 1-2, pp. 193-200, 2000.

[301] M. M. A. Boojar and F. Goodarzi, "The copper tolerance strategies and the role of antioxidative enzymes in three plant species grown on copper mine," Chemosphere, vol. 67, no. 11, pp. 2138-2147, 2007.

[302] P. Aravind and M. N. V. Prasad, "Cadmium-Zinc interactions in a hydroponic system using Ceratophyllum demersum L.: adaptive ecophysiology, biochemistry and molecular toxicology," Brazilian Journal of Plant Physiology, vol. 17, no. 1, pp. 3-20, 2005.

[303] K. Asada, "The water-water cycle in chloroplasts: scavenging of active oxygens and dissipation of excess photons," Annual Review of Plant Biology, vol. 50, pp. 601-639, 1999.

[304] Z. Chen, T. E. Young, J. Ling, S. C. Chang, and D. R. Gallie, "Increasing vitamin $\mathrm{C}$ content of plants through enhanced ascorbate recycling," Proceedings of the National Academy of Sciences of the United States of America, vol. 100, no. 6, pp. 3525-3530, 2003.

[305] F. Chen, F. Wang, F. Wu, W. Mao, G. Zhang, and M. Zhou, "Modulation of exogenous glutathione in antioxidant defense system against $\mathrm{Cd}$ stress in the two barley genotypes differing in Cd tolerance," Plant Physiology and Biochemistry, vol. 48, no. 8, pp. 663-672, 2010.

[306] A. Paradiso, R. Berardino, M. C. De Pinto et al., "Increase in ascorbate-glutathione metabolism as local and precocious systemic responses induced by cadmium in durum wheat plants," Plant and Cell Physiology, vol. 49, no. 3, pp. 362-374, 2008.

[307] R. Maheshwari and R. S. Dubey, "Nickel-induced oxidative stress and the role of antioxidant defence in rice seedlings," Plant Growth Regulation, vol. 59, no. 1, pp. 37-49, 2009.

[308] L. M. Cervilla, B. Blasco, J. J. Ríos, L. Romero, and J. M. Ruiz, "Oxidative stress and antioxidants in tomato (Solanum lycopersicum) plants subjected to boron toxicity," Annals of Botany, vol. 100, no. 4, pp. 747-756, 2007.

[309] L. Yin, S. Wang, A. E. Eltayeb et al., "Overexpression of dehydroascorbate reductase, but not monodehydroascorbate reductase, confers tolerance to Aluminum stress in transgenic Tobacco," Planta, vol. 231, no. 3, pp. 609-621, 2010.

[310] F. Y. Zhao, W. Liu, and S. Y. Zhang, "Different responses of plant growth and antioxidant system to the combination of cadmium and heat stress in transgenic and non-transgenic rice," Journal of Integrative Plant Biology, vol. 51, no. 10, pp. 942-950, 2009.

[311] C. H. Foyer and B. Halliwell, "The presence of glutathione and glutathione reductase in chloroplasts: a proposed role in ascorbic acid metabolism," Planta, vol. 133, no. 1, pp. 21-25, 1976.

[312] H. R. Lascano, L. M. Casano, M. N. Melchiorre, and V. S. Trippi, "Biochemical and molecular characterisation of wheat chloroplastic glutathione reductase," Biologia Plantarum, vol. 44, no. 4, pp. 509-516, 2001.

[313] D. Contour-Ansel, M. L. Torres-Franklin, M. H. Cruz De Carvalho, A. D'Arcy-Lameta, and Y. Zuily-Fodil, "Glutathione reductase in leaves of cowpea: cloning of two cDNAs, expression and enzymatic activity under progressive drought stress, desiccation and abscisic acid treatment," Annals of Botany, vol. 98, no. 6, pp. 1279-1287, 2006.

[314] M. C. Romero-Puertas, F. J. Corpas, L. M. Sandalio et al., "Glutathione reductase from pea leaves: response to abiotic stress and characterization of the peroxisomal isozyme," New Phytologist, vol. 170, no. 1, pp. 43-52, 2006.

[315] N. A. Anjum, S. Umar, M. Iqbal, and N. A. Khan, "Cadmium causes oxidative stress in moongbean [Vigna radiata (L.) Wilczek] by affecting antioxidant enzyme systems and ascorbate-glutathione cycle metabolism," Russian Journal of Plant Physiology, vol. 58, no. 1, pp. 92-99, 2011.

[316] S. Srivastava, S. Mishra, R. D. Tripathi, S. Dwivedi, and D. K. Gupta, "Copper-induced oxidative stress and responses of antioxidants and phytochelatins in Hydrilla verticillata (L.f.) Royle," Aquatic Toxicology, vol. 80, no. 4, pp. 405-415, 2006. 
[317] M. Israr and S. V. Sahi, "Antioxidative responses to mercury in the cell cultures of Sesbania drummondii," Plant Physiology and Biochemistry, vol. 44, no. 10, pp. 590-595, 2006.

[318] M. Russo, C. Sgherri, R. Izzo, and F. Navari-Izzo, "Brassica napus subjected to copper excess: phospholipases C and D and glutathione system in signalling," Environmental and Experimental Botany, vol. 62, no. 3, pp. 238-246, 2008.

[319] R. K. Tewari, P. Kumar, and P. N. Sharma, "Antioxidant responses to enhanced generation of superoxide anion radical and hydrogen peroxide in the copper-stressed mulberry plants," Planta, vol. 223, no. 6, pp. 1145-1153, 2006.

[320] S. Verma and R. S. Dubey, "Lead toxicity induces lipid peroxidation and alters the activities of antioxidant enzymes in growing rice plants," Plant Science, vol. 164, no. 4, pp. 645$655,2003$.

[321] M. D. Hossain, M. M. Rohman, and M. Fujita, "Comparative investigation of glutathione $S$-transferases, glyoxalase I and allinase activities in different vegetable crops," Journal of Crop Science and Biotechnology, vol. 10, no. 1, pp. 21-28, 2007.

[322] M. Tuomainen, V. Ahonen, S. O. Karenlampi et al., "Characterization of the glyoxalase 1 gene TcGLX1 in the metal hyperaccumulator plant Thlaspi caerulescens," Planta, vol. 233, no. 6, pp. 1173-1184, 2011.

[323] H. El-Shabrawi, B. Kumar, T. Kaul, M. K. Reddy, S. L. SinglaPareek, and S. K. Sopory, "Redox homeostasis, antioxidant defense, and methylglyoxal detoxification as markers for salt tolerance in Pokkali rice," Protoplasma, vol. 245, no. 1, pp. 85-96, 2010.

[324] M. K. Maiti, S. Krishnasamy, H. A. Owen, and C. A. Makaroff, "Molecular characterization of glyoxalase II from Arabidopsis thaliana," Plant Molecular Biology, vol. 35, no. 4, pp. 471-481, 1997.

[325] T. M. Zang, D. A. Hollman, P. A. Crawford, M. W. Crowder, and C. A. Makaroff, "Arabidopsis glyoxalase II contains a zinc/iron binuclear metal center that is essential for substrate binding and catalysis," Journal of Biological Chemistry, vol. 276, no. 7, pp. 4788-4795, 2001.

[326] S. K. Yadav, S. L. Singla-Pareek, and S. K. Sopory, "An overview on the role of methylglyoxal and glyoxalases in plants," Drug Metabolism and Drug Interactions, vol. 23, no. 1-2, pp. 51-68, 2008.

[327] M. A. Hoque, M. N. A. Banu, Y. Nakamura, Y. Shimoishi, and Y. Murata, "Proline and glycinebetaine enhance antioxidant defense and methylglyoxal detoxification systems and reduce $\mathrm{NaCl}$-induced damage in cultured tobacco cells," Journal of Plant Physiology, vol. 165, no. 8, pp. 813-824, 2008.

[328] M. A. Hoque, Banu M. N. A., E. Okuma et al., "Exogenous proline and glycinebetaine ingresses $\mathrm{NaCl}$-induced ascorbate-glutathione cycle enzyme activities and proline improves salt tolerance more than glycinebetaine in tobacco Bright yellow-2 suspension-cultured cells," Journal of Plant Physiology, vol. 164, no. 5, pp. 553-561, 2007.

[329] Y. Y. Chao, Y. T. Hsu, and C. H. Kao, "Involvement of glutathione in heat shock- and hydrogen peroxide-induced cadmium tolerance of rice (Oryza sativa L.) seedlings," Plant and Soil, vol. 318, no. 1-2, pp. 37-45, 2009.

[330] C. F. Tang, Y. G. Liu, G. M. Zeng et al., "Effects of exogenous spermidine on antioxidant system responses of Typha latifolia $\mathrm{L}$. under $\mathrm{Cd}^{2+}$ stress," Journal of Integrative Plant Biology, vol. 47, no. 4, pp. 428-434, 2005.

[331] A. Levine, R. Tenhaken, R. Dixon, and C. Lamb, " $\mathrm{H}_{2} \mathrm{O}_{2}$ from the oxidative burst orchestrates the plant hypersensitive disease resistance response," Cell, vol. 79, no. 4, pp. 583-593, 1994.
[332] T. K. Prasad, M. D. Anderson, B. A. Martin, and C. R. Stewart, "Evidence for chilling-induced oxidative stress in maize seedlings and a regulatory role for hydrogen peroxide," Plant Cell, vol. 6, no. 1, pp. 65-74, 1994.

[333] F. J. Xu, C. W. Jin, W. J. Liu, Y. S. Zhang, and X. Y. Lin, "Pretreatment with $\mathrm{H}_{2} \mathrm{O}_{2}$ alleviates aluminum-induced oxidative stress in wheat seedlings," Journal of Integrative Plant Biology, vol. 53, no. 1, pp. 44-53, 2011.

[334] R. K. Tewari, E. J. Hahn, and K. Y. Paek, "Modulation of copper toxicity-induced oxidative damage by nitric oxide supply in the adventitious roots of Panax ginseng," Plant Cell Reports, vol. 27, no. 1, pp. 171-181, 2008.

[335] N. Ahsan, J. Renaut, and S. Komatsu, "Recent developments in the application of proteomics to the analysis of plant responses to heavy metals," Proteomics, vol. 9, no. 10, pp. 2602-2621, 2009.

[336] K. Kosová, P. Vítámvás, I. T. Prášil, and J. Renaut, "Plant proteome changes under abiotic stress-contribution of proteomics studies to understanding plant stress response," Journal of Proteomics, vol. 74, no. 8, pp. 1301-1322, 2011.

[337] K. Lee, D. W. Bae, S. H. Kim et al., "Comparative proteomic analysis of the short-term responses of rice roots and leaves to cadmium," Journal of Plant Physiology, vol. 167, no. 3, pp. 161-168, 2010.

[338] Y. Wang, Y. Qian, H. Hu, Y. Xu, and H. Zhang, "Comparative proteomic analysis of Cd-responsive proteins in wheat roots," Acta Physiologiae Plantarum, pp. 1-9, 2010.

[339] N. Ahsan, D. G. Lee, I. Alam et al., "Comparative proteomic study of arsenic-induced differentially expressed proteins in rice roots reveals glutathione plays a central role during As stress," Proteomics, vol. 8, no. 17, pp. 3561-3576, 2008.

[340] R. A. Ingle, J. A. C. Smith, and L. J. Sweetlove, "Responses to nickel in the proteome of the hyperaccumulator plant Alyssum lesbiacum," BioMetals, vol. 18, no. 6, pp. 627-641, 2005.

[341] M. Labra, E. Gianazza, R. Waitt et al., "Zea mays L. protein changes in response to potassium dichromate treatments," Chemosphere, vol. 62, no. 8, pp. 1234-1244, 2006.

[342] M. H. Tuomainen, N. Nunan, S. J. Lehesranta et al., "Multivariate analysis of protein profiles of metal hyperaccumulator Thlaspi caerulescens accessions," Proteomics, vol. 6, no. 12, pp. 3696-3706, 2006.

[343] N. Ahsan, D. G. Lee, S. H. Lee et al., "Excess copper induced physiological and proteomic changes in germinating rice seeds," Chemosphere, vol. 67, no. 6, pp. 1182-1193, 2007.

[344] Y. Zhen, J. L. Qi, S. S. Wang et al., "Comparative proteome analysis of differentially expressed proteins induced by $\mathrm{Al}$ toxicity in soybean," Physiologia Plantarum, vol. 131, no. 4, pp. 542-554, 2007.

[345] Q. Yang, Y. Wang, J. Zhang, W. Shi, C. Qian, and X. Peng, "Identification of aluminum-responsive proteins in rice roots by a proteomic approach: cysteine synthase as a key player in Al response," Proteomics, vol. 7, no. 5, pp. 737-749, 2007.

[346] C. Ortega-Villasante, L. E. Hernández, R. Rellán-Álvarez, F. F. Del Campo, and R. O. Carpena-Ruiz, "Rapid alteration of cellular redox homeostasis upon exposure to cadmium and mercury in alfalfa seedlings," New Phytologist, vol. 176, no. 1, pp. 96-107, 2007.

[347] P. Mohanpuria, N. K. Rana, and S. K. Yadav, "Cadmium induced oxidative stress influence on glutathione metabolic genes of Camellia sinensis (L.) O. Kuntze," Environmental Toxicology, vol. 22, no. 4, pp. 368-374, 2007.

[348] C. Xiang and D. J. Oliver, "Glutathione metabolic genes coordinately respond to heavy metals and jasmonic acid in Arabidopsis," Plant Cell, vol. 10, no. 9, pp. 1539-1550, 1998. 
[349] I. Ogawa, H. Nakanishi, S. Mori, and N. K. Nishizawa, "Time course analysis of gene regulation under cadmium stress in rice," Plant and Soil, vol. 325, no. 1, pp. 97-108, 2009.

[350] P. D. B. Adamis, D. S. Gomes, M. L. C. C. Pinto, A. D. Panek, and E. C. A. Eleutherio, "The role of glutathione transferases in cadmium stress," Toxicology Letters, vol. 154, no. 1-2, pp. 81-88, 2004.

[351] S. K. Panda and H. Matsumoto, "Changes in antioxidant gene expression and induction of oxidative stress in pea (Pisum sativum L.) under $\mathrm{Al}$ stress," BioMetals, vol. 23, no. 4, pp. 753$762,2010$.

[352] H. Luo, H. Li, X. Zhang, and J. Fu, "Antioxidant responses and gene expression in perennial ryegrass (Lolium perenne $\mathrm{L}$.) under cadmium stress," Ecotoxicology, vol. 20, no. 4, pp. 770778, 2011.

[353] K. Smeets, J. Ruytinx, B. Semane et al., "Cadmium-induced transcriptional and enzymatic alterations related to oxidative stress," Environmental and Experimental Botany, vol. 63, no. $1-3$, pp. 1-8, 2008.

[354] P. Goupil, D. Souguir, E. Ferjani, O. Faure, A. Hitmi, and G. Ledoigt, "Expression of stress-related genes in tomato plants exposed to arsenic and chromium in nutrient solution," Journal of Plant Physiology, vol. 166, no. 13, pp. 1446-1452, 2009.

[355] S. Heiss, A. Wachter, J. Bogs, C. Cobbett, and T. Rausch, "Phytochelatin synthase (PCS) protein is induced in Brassica juncea leaves after prolonged Cd exposure," Journal of Experimental Botany, vol. 54, no. 389, pp. 1833-1839, 2003.

[356] D. Gonzalez-Mendoza, A. Q. Moreno, and O. Zapata-Perez, "Coordinated responses of phytochelatin synthase and metallothionein genes in black mangrove, Avicennia germinans, exposed to cadmium and copper," Aquatic Toxicology, vol. 83, no. 4, pp. 306-314, 2007.

[357] K. Akashi, N. Nishimura, Y. Ishida, and A. Yokota, "Potent hydroxyl radical-scavenging activity of drought-induced type-2 metallothionein in wild watermelon," Biochemical and Biophysical Research Communications, vol. 323, no. 1, pp. 7278, 2004.

[358] H. Zhang, W. Xu, J. Guo, Z. He, and M. Ma, "Coordinated responses of phytochelatins and metallothioneins to heavy metals in garlic seedlings," Plant Science, vol. 169, no. 6, pp. 1059-1065, 2005.

[359] D. Duressa, K. Soliman, and D. Chen, "Identification of aluminum responsive genes in Al-tolerant soybean line PI 416937," International Journal of Plant Genomics, vol. 2010, Article ID 164862, 13 pages, 2010.

[360] F. Lin, J. Xu, J. Shi, H. Li, and B. Li, "Molecular cloning and characterization of a novel glyoxalase I gene TaGly I in wheat (Triticum aestivum L.)," Molecular Biology Reports, vol. 37, no. 2, pp. 729-735, 2010.

[361] L. Lanfranco, A. Bolchi, E. C. Ros, S. Ottonello, and P. Bonfante, "Differential expression of a metallothionein gene during the presymbiotic versus the symbiotic phase of an arbuscular mycorrhizal fungus," Plant Physiology, vol. 130, no. 1, pp. 58-67, 2002.

[362] F. Ouziad, U. Hildebrandt, E. Schmelzer, and H. Bothe, "Differential gene expressions in arbuscular mycorrhizalcolonized tomato grown under heavy metal stress," Journal of Plant Physiology, vol. 162, no. 6, pp. 634-649, 2005.

[363] S. Perotto and E. Martino, "Molecular and cellular mechanisms of heavy metal tolerance in mycorrhizal fungi: what perspectives for bioremediation?" Minerva Biotecnologica, vol. 13, no. 1, pp. 55-63, 2001.
[364] U. Galli, H. Schuepp, and C. Brunold, "Heavy metal binding by mycorrhizal fungi," Physiologia Plantarum, vol. 92, no. 2, pp. 364-368, 1994.

[365] Y. Guo, E. George, and H. Marschner, "Contribution of an arbuscular mycorrhizal fungus to the uptake of cadmium and nickel in bean and maize plants," Plant and Soil, vol. 184, no. 2, pp. 195-205, 1996.

[366] U. Hildebrandt, M. Regvar, and H. Bothe, "Arbuscular mycorrhiza and heavy metal tolerance," Phytochemistry, vol. 68, no. 1, pp. 139-146, 2007.

[367] K. Turnau, P. Ryszka, V. Gianinazzi-Pearson, and D. Van Tuinen, "Identification of arbuscular mycorrhizal fungi in soils and roots of plants colonizing zinc wastes in southern Poland," Mycorrhiza, vol. 10, no. 4, pp. 169-174, 2001.

[368] N. Weyens, S. Truyens, E. Saenen et al., "Endophytes and their potential to deal with co-contamination of organic contaminants (toluene) and toxic metals (nickel) during phytoremediation," International Journal of Phytoremediation, vol. 13, no. 3, pp. 244-255, 2011.

[369] C. L. Rugh, "Genetically engineered phytoremediation: one man's trash is another man's transgene," Trends in Biotechnology, vol. 22, no. 10, pp. 496-498, 2004.

[370] Y. P. Tong, R. Kneer, and Y. G. Zhu, "Vacuolar compartmentalization: a second-generation approach to engineering plants for phytoremediation," Trends in Plant Science, vol. 9, no. 1, pp. 7-9, 2004.

[371] S. L. Doty, "Enhancing phytoremediation through the use of transgenics and endophytes," New Phytologist, vol. 179, no. 2, pp. 318-333, 2008.

[372] J. R. Domínguez-Solís, M. C. López, F. J. Ager, M. D. Ynsa, L. C. Romero, and C. Gotor, "Increased cysteine availability is essential for cadmium tolerance and accumulation in Arabidopsis thaliana," Plant Biotechnology Journal, vol. 2, no. 6, pp. 469-476, 2004.

[373] Y. L. Zhu, E. A. H. Pilon-Smits, L. Jouanin, and N. Terry, "Overexpression of glutathione synthetase in Indian mustard enhances cadmium accumulation and tolerance," Plant Physiology, vol. 119, no. 1, pp. 73-79, 1999.

[374] Y. L. Zhu, E. A. H. Pilon-Smits, A. S. Tarun, S. U. Weber, L. Jouanin, and N. Terry, "Cadmium tolerance and accumulation in Indian mustard is enhanced by overexpressing $\gamma$ glutamylcysteine synthetase," Plant Physiology, vol. 121, no. 4, pp. 1169-1177, 1999.

[375] G. Noctor, M. Strohm, L. Jouanin, K. J. Kunert, C. H. Foyer, and H. Rennenberg, "Synthesis of glutathione in leaves of transgenic poplar overexpressing $\gamma$-glutamylcysteine synthetase," Plant Physiology, vol. 112, no. 3, pp. 1071-1078, 1996.

[376] G. Creissen, P. Broadbent, R. Stevens, A. R. Wellburn, and P. Mullineaux, "Manipulation of glutathione metabolism in transgenic plants," Biochemical Society Transactions, vol. 24, no. 2, pp. 465-469, 1996.

[377] S. Reisinger, M. Schiavon, N. Terry, and E. A. H. Pilon-Smits, "Heavy metal tolerance and accumulation in Indian mustard (Brassica juncea L.) expressing bacterial $\gamma$-glutamylcysteine synthetase or glutathione synthetase," International Journal of Phytoremediation, vol. 10, no. 5, pp. 440-454, 2008.

[378] L. A. Ivanova, D. A. Ronzhina, L. A. Ivanov, L. V. Stroukova, A. D. Peuke, and H. Rennenberg, "Over-expression of gsh1 in the cytosol affects the photosynthetic apparatus and improves the performance of transgenic poplars on heavy metal-contaminated soil," Plant Biology, vol. 13, no. 4, pp. 649-659, 2011. 
[379] Y. Li, A. C. P. Heaton, L. Carreira, and R. B. Meagher, "Enhanced tolerance to and accumulation of mercury, but not arsenic, in plants overexpressing two enzymes required for thiol peptide synthesis," Physiologia Plantarum, vol. 128, no. 1, pp. 48-57, 2006.

[380] M. Pomponi, V. Censi, V. di Girolamo et al., "Overexpression of Arabidopsis phytochelatin synthase in tobacco plants enhances $\mathrm{Cd}^{2+}$ tolerance and accumulation but not translocation to the shoot," Planta, vol. 223, no. 2, pp. 180190, 2006.

[381] K. Gasic and S. S. Korban, "Expression of Arabidopsis phytochelatin synthase in Indian mustard (Brassica juncea) plants enhances tolerance for Cd and Zn," Planta, vol. 225, no. 5, pp. 1277-1285, 2007.

[382] J. L. Couselo, J. Navarro-Avino, and A. Ballester, "Expression of the phytochelatin synthase TaPCS1 in transgenic aspen, insight into the problems and qualities in phytoremediation of $\mathrm{Pb}$," International Journal of Phytoremediation, vol. 12, no. 4, pp. 358-370, 2010.

[383] S. Wojas, S. Clemens, A. Sklodowska, and D. M. Antosiewicz, "Arsenic response of AtPCS1-and CePCS-expressing plantseffects of external As(V) concentration on As-accumulation pattern and NPT metabolism," Journal of Plant Physiology, vol. 167, no. 3, pp. 169-175, 2010.

[384] G.-Y. Liu, Y.-X. Zhang, and T.-Y. Chai, "Phytochelatin synthase of Thlaspi caerulescens enhanced tolerance and accumulation of heavy metals when expressed in yeast and tobacco," Plant Cell Reports, vol. 30, no. 6, pp. 1067-1076, 2011.

[385] Y. Li, O. P. Dhankher, L. Carreira et al., "Overexpression of phytochelatin synthase in Arabidopsis leads to enhanced arsenic tolerance and cadmium hypersensitivity," Plant and Cell Physiology, vol. 45, no. 12, pp. 1787-1797, 2004.

[386] J. Guo, X. Dai, W. Xu, and M. Ma, "Overexpressing GSH1 and AsPCS1 simultaneously increases the tolerance and accumulation of cadmium and arsenic in Arabidopsis thaliana," Chemosphere, vol. 72, no. 7, pp. 1020-1026, 2008.

[387] S. Misra and L. Gedamu, "Heavy metal tolerant transgenic Brassica napus L. and Nicotiana tabacum L. plants," Theoretical and Applied Genetics, vol. 78, no. 2, pp. 161-168, 1989.

[388] K. Sekhar, B. Priyanka, V. D. Reddy, and K. V. Rao, "Metallothionein 1 (CcMT1) of pigeon pea (Cajanus cajan, L.) confers enhanced tolerance to copper and cadmium in Escherichia coli and Arabidopsis thaliana," Environmental and Experimental Botany, vol. 72, no. 2, pp. 131-139, 2011.

[389] G. S. Sanghera, P. L. Kashyap, G. Singh, and J. A. T. da Silva, "Transgenics: fast track to plant stress amelioration," Transgenic Plant Journal, vol. 5, no. 1, pp. 1-26, 2011.

[390] C.-J. Ruan and J. A. T. da Silva, "Metabolomics: creating new potentials for unraveling the mechanisms in response to salt and drought stress and for the biotechnological improvement of xero-halophytes," Critical Reviews in Biotechnology, vol. 31, no. 2, pp. 153-169, 2011.

[391] S. S. Gill, N. A. Khan, N. K. Anjum, and N. Tuteja, "Amelioration of cadmium stress in crop plants by nutrients management: morphological, physiological and biochemical aspects," Plant Stress, vol. 5, no. 1, pp. 1-23, 2011. 

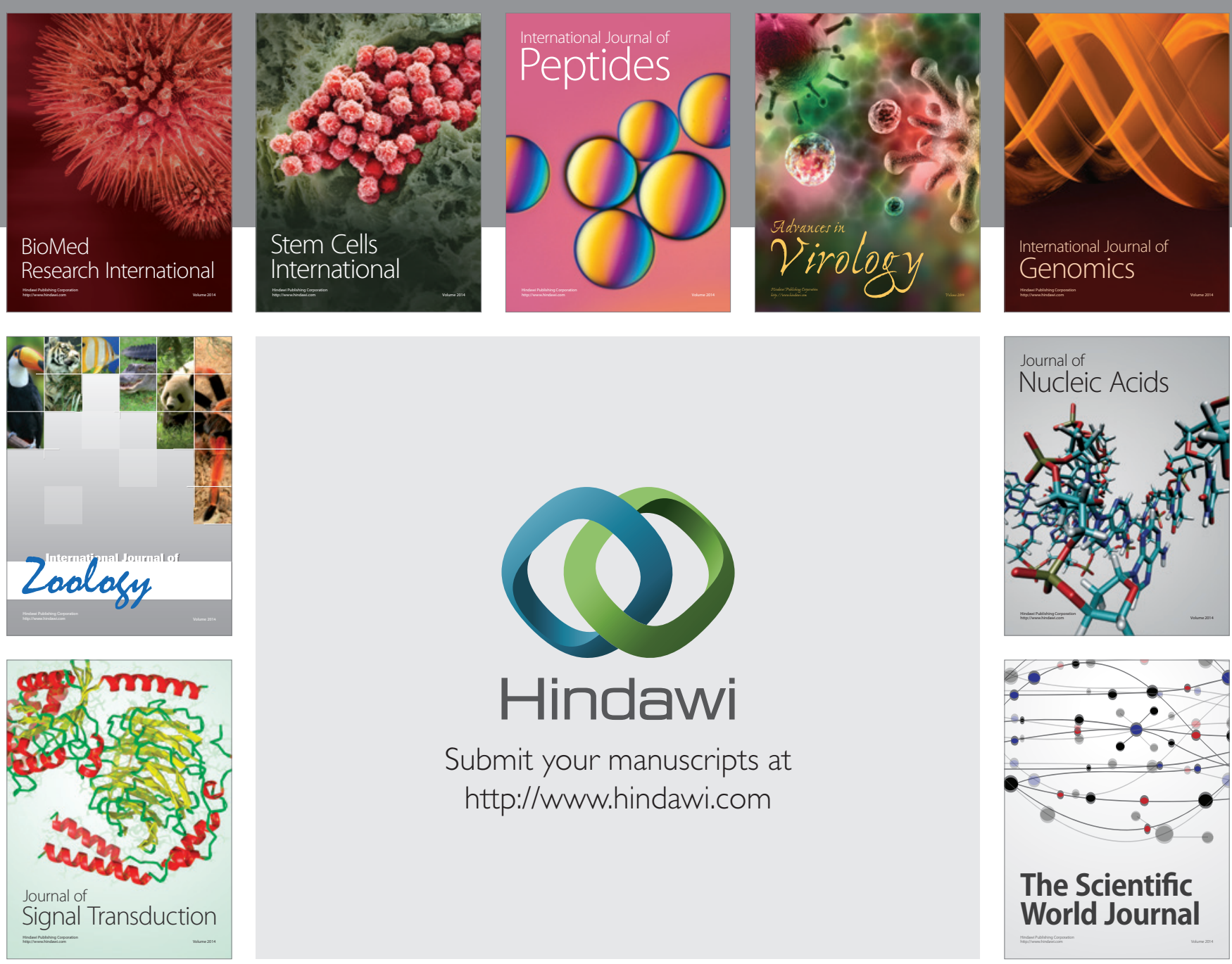

Submit your manuscripts at

http://www.hindawi.com
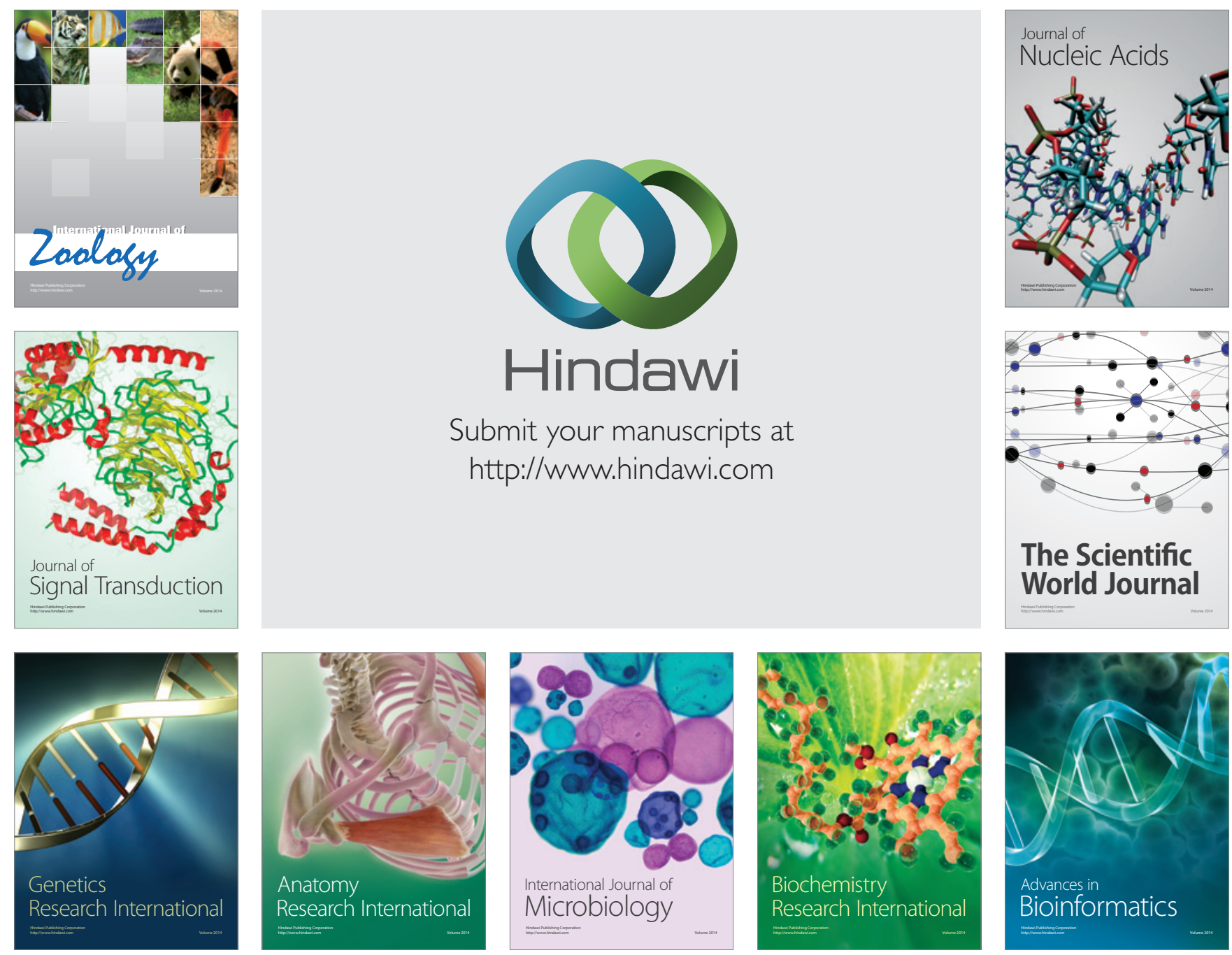

The Scientific World Journal
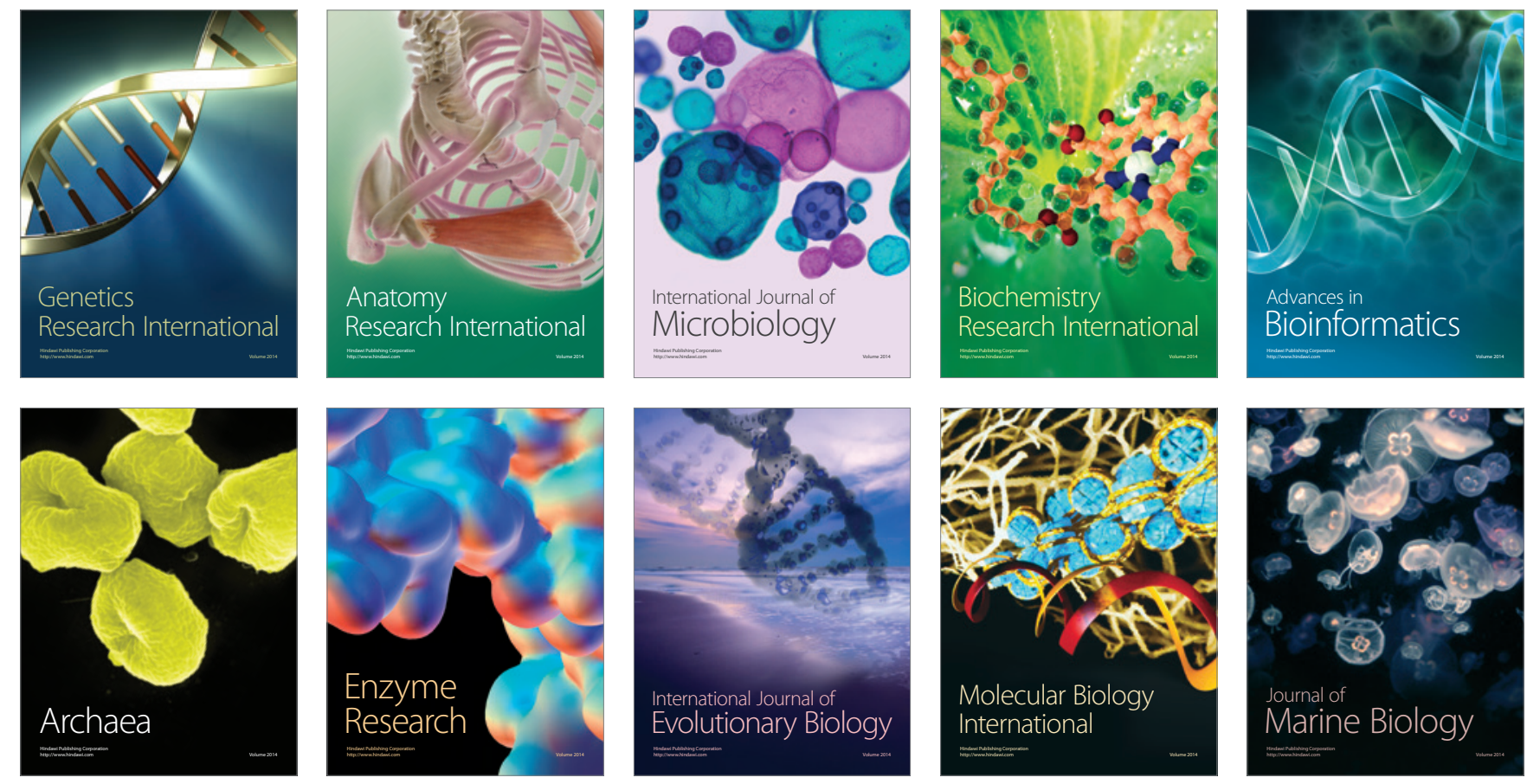